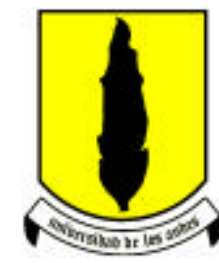

\title{
TEENAGE CHILDBEARING IN LATIN AMERICAN COUNTRIES
}

\author{
CARMEN ELISA FLOREZ \\ JAIRO NÚÑEZ
}

ENERO DE 2002
DOCUMENTO CEDE 2002-01

ISSN 1657-7191

(Edición electrónica)

\begin{abstract}
In spite of the rapid fertility transition experienced by most LAC countries, teenage fertility has not changed at the same pace or direction. Given early childbearing is deleterious for both mother and child, we describe the differentials in the levels and trends in teenage childbearing and analyze its proximate and socioeconomic determinants. We used DHS data from six LAC countries, Bolivia, Brazil, Colombia, Guatemala, Dominican Republic and Peru, for which there is available data for the second half of the 90's. Teenage fertility trends indicate different patterns of change across countries by area of residence. However, in most countries teenage fertility has increased in rural areas but has declined or remained constant in urban areas. Different contributions of marriage, proper use of family planning methods, and premarital births to teenage fertility behavior are reflected in differentials in unmarried parenthood across countries. Socioeconomic determinants are analyzed through: simple logit model, multilevel analysis, and continuous-time hazard rate models. These analyzes improve on prior research on LAC countries by: including contextual/regional factors, by isolating the effects into differentials in sexual activity and rates of childbearing, and by comparing the socioeconomic determinants of the timing of first birth and premarital birth. This research demonstrates that the effect of socioeconomic variables on the rate of childbearing can act through the timing of initial sexual intercourse (such as education, socioeconomic conditions of the households and area or residence) or through the timing of first birth (such as socialization in a female-headed family, availability/acceptability/use of family planning, and regional/country conditions cultural and inherent characteristics).
\end{abstract}

\section{INTRODUCTION}

The biological aspects of adolescence such as entry into puberty have been acknowledged as a time of transition in almost all societies. The duration and defining characteristics of adolescence vary across time, cultures and socioeconomic situations. 
As societies develop, the period of transition between childhood and adulthood tends to be prolonged.

In many Latin American countries, and particularly in the urban areas, the adolescent experience is becoming increasingly pronounced as a particular stage of the life cycle, and in this respect resembling more economically developed countries (Singh and Wulf, 1990). Adolescence for many Latin American young people is no longer an abrupt rupture from childhood to adolescence, but rather a stage of life that is being continually prolonged and includes the ages of 10 to 24 . A number of authors have reviewed the development of the biological and social definitions of adolescence in the Latin American context. Monroy de Velasco (1985) suggests that adolescence is a function of the culture of origin and that in Latin America it is still an urban phenomenon. She notes that while in rural areas of the developed world adolescence is a stage of life for young people, in Latin America rural youth experience puberty without going through adolescence. In some societies, puberty is the only distinguishing characteristic of adolescence that marks an abrupt change to adulthood. Torres-Rivas (1988) presents a complementary set of conclusions after reviewing the development of adolescence in several Latin American countries. He suggests that while adolescence has always existed in a biological sense, its socio-cultural sphere is more a function of economic development, structural transformation and modernization. In some societies, children progress directly to adulthood. This may be particularly true of families and communities where children are unable to advance beyond basic levels of education and progress directly into the labor market.

During the adolescent period there is a psychosocial change through which the individual initiates a process of development and maturation of their personality, sense of identity, capacity for abstract thought and play a role in the family and community environment (Suárez Ojeda et al., 1985; Elliott and Feldman, 1990). Adolescence may be divided into early, middle and late substages. The first stage roughly corresponds to ages 10 or 11 through 14 when profound physical and social changes coincide with puberty. The middle stage is sometimes the final stage and usually goes from age 15 to 17. It is a stage of increasing independence from parents and family. School dropout or early pregnancy may make this stage shorter. The last stage may extend as far as the late twenties for those youth who remain in the school system or who accomplish other goals that may delay their entry into the workforce and family life (Elliott and Feldman, 1991; Crockett and Petersen, 1994).

Youth and adolescents are periods of transition in which young people make a number of long and short-run choices that define their current and future health and well-being, as well as how they will devote their time as adults. The series of evolutionary experiences may include: the acceptance of their sexuality; the formation of peer alliances; the pursuit of independence from parents and adults; the search for economic security and independence; the choice of an occupation and the means to learn that occupation; the development of skills and concepts for participation in civic activities; the pursuit of responsible social conduct; preparation for marriage and family life; and, the development of values (Monroy de Velasco, 1985 citing Havighurst). The decisions adolescents make will strongly affect their educational attainment and employment opportunities. Teenage pregnancy and childbearing is a matter of special interest due to the socio-economic consequences of this behavior. As some studies 
have shown, teenage fertility have negative economic, social and health consequences for the young mothers as well as for their children (Buvinic, 1998; Burt, 1998; Gage, 1995; Alan Guttmacher Institute, 1997; Singh and Wulf, 1990; Hayes, 1987). For example, a panel established by the National Research Council (Hayes, 1987) concluded that "Women who become parents as teenagers are at greater risk of social and economic disadvantage throughout their lives than those who delay children until their twenties. They are less likely to complete their education, be employed, to earn high wages, and to be happily married." (pp. 138). And Gage (1995) concluded that "Teenage women suffer from higher rates of pregnancy complications than older women and their babies also suffer from low birth weight and heightened risks of mortality" (pp. 35). For these reasons, this paper tries to document trends in teenage fertility levels and to analyze its demographic and socioeconomic determinants for some Latin American countries.

The data derive from the Demographic and Health Surveys (DHS), an international research effort coordinated by Macro International in cooperation with national governments and organizations, and funded by the United States Agency for International Development. DHS are large nationally representative household surveys whose main purpose is to inquire about family planning and child and maternal health. The surveys are ideal for comparison since they have been carried out using a nearly identical questionnaire in all countries. The questionnaire contains a birth history of all household women aged $15-49$ as well as questions on age at first marriage and first intercourse. We use the DHS from six Latin American and Caribbean (LAC) countries: Bolivia, Brazil, Colombia, Guatemala, Peru and Dominican Republic, for which there is available data for the second half of the 90's. The omission of some LAC countries naturally limits the global generalizations that can be drawn. In a similar vein, this report is limited in scope by the population covered in the available surveys. While the experience and needs of all adolescents are important, DHS concentrate primarily on women aged 15 and older; this report necessarily share those limitations: adolescents younger than 15 are not included. Thus, given the data set we use, we broadly define adolescents as young women aged 15-19.

Among the selected LAC countries there exists great diversity of economic, social and demographic indicators such as per capita income, poverty conditions, stage of the demographic transition, secondary school enrollment, and degree of urbanization (Table 1). Thus, whereas Brazil has almost completed the fertility transition (low fertility level), Guatemala and Bolivia still are in an intermediate stage (high fertility levels). The other countries, Peru, Colombia and Dominican Republic, can be classified in an stage of advanced transition (medium low fertility levels). The selected countries also show different degrees of development. By 1997, the inequalities across countries are significant: the per capita Gross National Product (GNP) of Brazil (\$3214, the richest among the selected countries) is 3.6 times the GNP of the poorest country, Bolivia (\$892), and 3.3 times the GNP of the next poorest country, Guatemala (\$964) (Table 1). In general, countries with the lowest income levels show the lowest percentage of people living in urban areas, the highest infant mortality rate, the lowest indexes of secondary school enrollment and the highest total fertility rate. Regardless of where people live, the economic resources available to them may determine what level of 
education young people receive and what health and social services they have access to.

\section{LEVELS AND TRENDS IN TEENAGE FERTILITY}

\subsection{Teenage fertility and the fertility transition}

In most LAC countries, fertility rates remained relatively high and stable throughout the first half of XX century, with Total Fertility Rates ${ }^{1}$ (TFR) reaching an average of 6 children per woman. Then, around the late 60 's, total fertility began to decline sharply. By that time, "most countries in the region have begun to show unequivocal signs of having entered into a stage of fertility transition" (Chackiel and Schkolnik, 1996. Pp 5). By 1985/90, the average TFR for the region was around 3.6 children per woman. Although the pace and timing of the fertility decline differed among countries, there is an association between the level and the structure of fertility rates. "A decline in fertility levels is accompanied by a rejuvenation of its age structure" (Chackiel and Schkolnik, 1996. Pp 9). That means that fertility decline have occurred fundamentally among women over 25/30 years old, whereas the decline among younger women has been significantly less than that experienced by older women, shifting the fertility structure from a dilated or late to an early peak. In general, by the end of the 1990's, the age specific fertility pattern show a typical pattern: early peak with a maximum between 20-24 years old (Figure 1).

Although declines in TFR's have been significant in most LAC countries, adolescent fertility has not changed at he same pace: in some countries it has stayed practically constant, in others it has declined but the change has been less than that experienced by older women, and in others it may have increased. Thus, age specific fertility rates indicate that the contribution to total fertility by women 15-19 year-old agegroup has risen in almost all countries.

\subsection{Adolescent fertility levels}

The levels of teenage fertility in the late 90's are diverse among the selected LAC countries $^{2}$. Peru shows the lowest adolescent fertility indicators: a fertility rate ${ }^{3}$ of 75 per thousand, $10.9 \%$ of women $15-19$ years old and $1.7 \%$ of those 15 years old are mothers, and the mean number of children ever born (CEB) among 15-19 years of age is 0.13. On the other hand, Guatemala and Dominican Republic, two Caribbean countries, show the highest teenage fertility levels: fertility rates above 110 per thousand, around $18 \%$ of adolescents are mothers and the mean number of CEB of 0.24. The other countries, Bolivia, Brazil and Colombia are in the middle: a total fertility rate of $84-89$ per thousand, $11-14 \%$ of adolescents are mothers and a mean number of CEB of 0.16-0.18 (Table 2 ). The socioeconomic circumstances surrounding adolescent fertility levels are diverse that they defy generalization. For example, Bolivia being one of the poorest countries, with the highest total fertility rate and infant mortality rate, one

\footnotetext{
${ }^{1}$ Total Fertility Rate is the average number of children a women would have during her reproductive period if she behaves according to the age prevailing specific fertility pattern.

${ }^{2}$ The charts and tables are organized according to the proportion of adolescent mothers. Thus, Peru, the focus country with the smallest proportion of adolescent mothers is always represented at the top of the chart or table. Dominican Republic and Guatemala, the focus countries with the largest proportion of adolescent mothers are always at the bottom.

${ }^{3}$ Teenage fertility rate is measured as the number of births per 1,000 women aged 15-19 years.
} 
of the lowest index of secondary school enrollment among women, is not the country with the highest teenage fertility indicators. Brazil, the richest country with the lowest total fertility rate, the highest proportion of urban population, is not the country with the lowest adolescent fertility level. Peru is not the country with the highest female secondary school enrollment but it has the lowest adolescent fertility. On the contrary, Guatemala, one of the poorest countries with the lowest female secondary school enrollment, is one of the countries with the highest adolescent fertility.

Throughout much of the countries, having a child before age 15 is rare, typically fewer than $2 \%$ of women give birth by this age. In rural Bolivia, however, a little more than $5 \%$ of women aged 15 are already mothers (Figure $2 b$ ). Bearing a child at 17,18 or 19 years of age, however, is a more common experience, especially for rural women. While childbearing before age 18 is uncommon in urban areas, $25 \%$ to $30 \%$ of rural women 18 years old and almost half of rural women 19 years old are mothers in all countries (Figures 2a-b).

The social context of adolescent fertility not only varies across countries but also within countries. Teenage fertility is generally higher in rural than in urban areas. Urban women may delay the birth of their first child because they have better access than rural women do to education and jobs, and thus more reason to wait before starting a family. However, the rural/urban differences varies across countries: it ranges from 2.5 in Peru to 1.5 in Guatemala and Brazil (Figure 3). These differentials led Peru to be the country with the lowest urban adolescent fertility but Brazil be the one with the lowest teenage fertility in rural areas. Guatemala and Dominican Republic show the highest levels in urban as well as in rural areas. Urban adolescent fertility shows a higher variation across countries than rural fertility does. In urban areas, teenage fertility rate ranges from 55 in Peru to 99 per thousand in Guatemala. The range of variation in rural areas is from 122 in Brazil to 160 in Dominican Republic. In all selected countries, rural adolescent fertility seems to be the norm: $40 \%$ to $50 \%$ of 19 years old women have already had their first birth and nearly $20 \%$ of them have had at least 2 children (Figure $2 b)$.

Region of residence is also an important factor in teenage fertility differentials in all countries (Figure 4). However, the regional differences vary across countries: they are stronger in Peru, Bolivia and Colombia, while they are lower in Guatemala, Dominican Republic and Brazil. It seems that the higher the teenage fertility level, the lower the regional differences. Regional differentials are higher in Peru and Bolivia where the lowest teenage fertility was observed. In contrast, Guatemala and Dominican Republic have lower regional differences but a higher adolescent fertility level.

In all countries, education is another variable that clearly differentiates teenage fertility: high levels of education are universally associated with low early childbearing (Figure 5). As woman's level of education increases, she becomes more likely to obtain accurate information about health care and contraception, and thus better prepared to plan her pregnancies. Indeed, in every country, the proportion of adolescent mothers is 5 to 6 times higher among no educated adolescents than among adolescents with at least some secondary education. 


\subsection{Trends in teenage fertility}

Fertility of women aged $15-19$ is a censored information since this cohort has not lived through the complete years of this age interval (for example, women aged 15 still have to go through the ages of 16 to 19; and women aged 19 still have to go through the rest of the age 19). Thus, to get a more accurate information to measure trends in adolescent fertility is better to use the previous experience up to a given age (17 or 20 years) of women aged 20 years or more, by 5-years age groups. Instead of looking just at cumulated indicators by that specific age (17 or 20 ), we look at the pattern at each age up to that particular age (17 or 20).

Trends in teenage fertility can not be generalized. Figures $6 a-b$ to 9 show that early childbearing has different patterns of change across countries by area of residence. In general, we can identify three different patterns. First, Brazil and Colombia, where the proportion of women who bear their first child at each age has increased in both rural and urban areas but the change has been lower in urban areas (Figures 6a-b and 7a-b). For example, Brazilian urban women aged 20-24 have a higher probability (30\%) than women 25 years ago (women currently aged $45-49$ years) $(25 \%)$ of bearing a first child before age 20 (Figure 9). Among Brazilian rural women, the same probability increased from $28 \%$ to $41 \%$. Second, Bolivia and Peru, where urban adolescent fertility by age has recently declined and rural adolescent ertility has increased. The case of Bolivia is outstanding since rural teenage fertility shows the largest increase among all countries: the proportion of women with a child born by age 20 increases from $32 \%$ to $54 \%$. Third, Guatemala and Dominican Republic, where adolescent fertility by age shows an erratic trend with little change in urban and rural areas. The three different patterns of change have a common characteristic: teenage fertility has increased or remained constant in rural areas but has declined or remained constant in urban areas, leading to an increase in rural/urban differences.

Beyond the general pattern of teenage fertility change, is the change observed at the very early ages, 16 to 17 years, where adolescent fertility has the most negative impact. Guatemala and Dominican Republic, with the highest levels of fertility at these ages, do not show a clear pattern of change: it seems fertility stays at high levels with no tendency to decline (Figures 7a-b and 8). Brazil and Colombia, on the contrary, show important increases in early rural teenage fertility from older to younger age cohorts (Figure 8). In Peru, urban early childbearing has decline whereas it has remain almost constant in rural areas. In Bolivia, rural early childbearing has increased but it shows some decline in urban areas. In any case, as it is the case for the whole adolescent period, rural urban differentials in early teenage fertility have increased from older to younger age cohorts (Figure 8).

\section{THE PROXIMATE DETERMINANTS OF TEENAGE FERTILITY}

With the aim to identify all factors that intervened between the norms and social structure of a society and its level of fertility (hence the term proximate variables), Davis and Blake (1956) identify three groups of factors: those related to exposure to the risk of pregnancy, to conception an to gestation. Later developments included post-partum infecundity and focused only on those factors which were both major determinants of the level of fertility and, at the same time, varied across population groups: marriage, contraception, abortion and post-partum infecundity (Moreno and Singh, 1996). 
Although the last two are important variables, they are not considered here because of the lack of information. As in the case of teenage fertility, we look at level and pattern of change of the two proximate determinants: marriage and contraception.

\subsection{Marriage and pre-marital sexual activity}

The exposure to the risk of pregnancy (exposure to intercourse) is determined by marriage ${ }^{4}$ patterns as well as by sexual activity among those not married. We will look first at marriage patterns and then at sexual activity.

Early marriage is one factor contributing to high levels of teenage fertility. The proportion of ever married adolescents varies across countries in the same direction as adolescent fertility does: it ranges from a low of $12 \%$ in Peru and Bolivia to a high $29 \%$ in Dominican Republic and $23 \%$ in Guatemala (Figure 10). As well as early childbearing, marriage is more common in rural than in urban areas (Table 3 ). The timing of a first union or marriage is strongly associated with a woman's educational attainment: women who have reached secondary education marry later than women without a basic education (Figure 11). The lowest proportion of urban ever married adolescents is observed in Peru (8.4\%) where the lowest urban teenage fertility was observed. Dominican Republic, the country with the highest teenage fertility, also shows the highest proportion of ever married adolescents in urban $(24 \%)$ as well as in rural areas (38\%). It seems then that the exposure effect on teenage fertility is not negligible as one would expect in very advanced stages of the fertility transition when fertility control is widespread.

In most of the selected countries, as in other Latin American countries, adolescents do not legalize the first union. The importance of consensual unions among couples ranges from a high of $87 \%$ in Dominican Republic and $81 \%$ in Peru and Colombia to a low of $50 \%$ in Brazil (Figure 10). Goldman and Pebley (1981) has shown that almost half of couples in consensual unions in several Latin American countries eventually legalize their union, suggesting that de facto unions might be serving a function as trial marriages. This behavior is also suggested in all the selected countries: consensual unions are more common among the youngest than among the older adolescents (Figures 12a-b). The high instability in many consensual unions, specially in early months of the union (Rosero-Bixby, 1996; Guzmán, Hakkert and Contreras, 2000) results in a higher proportion of divorced/separated adolescents in Dominican Republic than in the other countries (Figure 10).

Contrary to teenage fertility or to marriage patterns, the importance of consensual unions do not show a consistent urban/rural differential across countries. In Bolivia, Guatemala and Dominican Republic, consensual unions are more common in rural than in urban areas, while in Peru consensual unions are more common in urban than in rural areas (Figures 12a-b). In Brazil and Colombia, rural and urban are equally important. It does not seem to exist a relation between the legality of the union and teenage fertility: urban Peru and Dominican Republic show similar proportion of couples in consensual unions but urban Dominican Republic teenage childbearing is 1.8 times the one observed in Peru. Even more, although consensual unions are more common in urban (82\%) than in rural (78\%) Peru, rural teenage fertility is 2.5 times the urban one.

\footnotetext{
${ }^{4}$ The term "marriage" here includes legal (legally or religiously sanctioned), consensual and cohabiting unions.
} 
Looking at marriage experience by age up to age 20 by 5 -years age groups we can identify marriage trends across countries by area of residence (Figures 13a-b). Marriage trends are in agreement with early childbearing trends. They show the same three patterns of change. First, Brazil and Colombia, where the proportion of ever married rural adolescents has increased by age but it shows however little and erratic trend in urban areas. Second, Bolivia and Peru, where the proportion of ever married by age has declined in urban areas but has increased in rural areas. In urban areas, in both countries, the proportion ever married by age 20 declines from $40 \%$ to $30-33 \%$. In rural Bolivia, this proportion increases from 39\% to 53\% (Figure 16). Third, Guatemala and Dominican Republic, where the proportion ever married by age changes widely but in erratic way, both in urban and rural areas. The three different patterns of change have a common characteristic: the proportion ever married by age 20 has increased or remained constant in rural areas but has declined or remained constant in urban areas, leading, in almost all countries, to an increase in rural/urban differences. Although fertility and marriage show the same patterns of change, marriage has changed at a slower pace in Peru, Bolivia, Brazil and Colombia, suggesting that marriage is not the dominant proximate determinant regulating teenage fertility in those countries (Figures 14a-b). In Guatemala and Dominican Republic teenage marriage and fertility have change at a similar pace indicating that in hose two countries marriage may be the dominant proximate determinant of adolescent fertility.

Marriage at very early ages (up to age 17) is more common in Guatemala and Dominican Republic: marriage rates are twice as higher in these two countries than in the others (Figure 15). However, marriage pattern shows some declining trend from the middle aged to the younger cohorts, both in urban and rural areas. Peru and Bolivia share this marriage pattern of change although they have lower marriage rates. In Brazil and Colombia, marriage at early ages does not change much in urban areas but it increases in rural areas (Figure 15). Once again, early marriage is positively related with early childbearing but the slower pace of change (at least in four out of the six selected countries) suggests that very early marriage is not the dominant proximate determinant of very early childbearing.

While most sexual activity among adolescents women occurs within marriage, sexual experimentation before marriage is tolerated in some countries. However, although never married women may be exposed to the risk of pregnancy as soon as they enter sexual relations, the risk depends on the intercourse frequency. Figures 17a$b$ show that in Brazil and Colombia, both in urban and rural areas, there is a significant proportion of never married women with a regular sex partner. In Dominican Republic and Guatemala, on the contrary, premarital sexual activity is insignificant. In Peru, only urban adolescents show a low percentage of regular premarital sexual activity whereas it is negligible in rural areas. The higher acceptance of premarital coital relationship among adolescents in Brazil and Colombia may be linked to their advanced stage in the fertility transition, specifically to the widespread availability of contraceptives in these two countries, as we will see later in this paper.

Given the higher premarital sexual activity in Brazil and Colombia, these two countries are the ones with the higher proportion of adolescents who have had first intercourse (Figure 18a-b) while they are not the ones with the higher proportion of ever married adolescents. Exposure to pregnancy is affected not only by marriage but also 
by premarital intercourse. Sexual behavior is more common in rural than in urban areas in all countries. Differences across countries in sexual activities are more pronounced in urban than in rural areas. Thus, the proportion of rural adolescents who have had first intercourse ranges from $26 \%$ in Bolivia to $33 \%$ in Colombia, but in urban areas it goes from $16 \%$ in Bolivia to $31 \%$ in Brazil. This important differences across countries led us to analyze not only first marriage but first intercourse patterns as a fertility determinant.

The age pattern of entry into sexual activities has changed, both in urban and rural areas, in the same direction as marriage patterns (Figures 19a-b to 22). However, in Brazil and Colombia, the changes in sexual activity have been more pronounced (Figures 19a-b) than the ones observed in marriage and than the ones observed in childbearing, particularly in urban areas, indicating that in these two countries, sexual activity is one dominant proximate determinant regulating teenage fertility. For example, the proportion of women who have had first intercourse by age 20 increased from $26 \%$ to $55 \%$ in urban Brazil and from $36 \%$ to $55 \%$ in urban Colombia (Figure 22). This may be highly related with the higher pre-marital sexual activity among never married adolescents observed in these two countries.

Figure 23 show the entry into sexual activity, marriage and childbearing among adolescents. Although women aged 15-19 is a censored cohort, it is still important to analyze the early entry into these three activities since they may produce differences in cumulated fertility at older ages. Two facts emerge. First, there is a relationship between early marriage and early childbearing: the higher the proportion of adolescent married by age 15, the higher the proportion of adolescents who bear their first child by the same age. However, there is not a clear relationship between early sexual activity and early childbearing: early intercourse is not associated with a higher proportion of teenage mothers. This would imply that most of early adolescent childbearing occurs within marriage. Second, the difference between the entry into sexual activity and into marriage is lower in the countries where fertility is higher: Dominican Republic and Guatemala. Two things may be happening. One, in those two countries sexual activity occurs mostly within marriage. That is, the effect of exposure to pregnancy (sexual activity) acts mainly through marriage. This make sense since Dominican Republic and Guatemala are in an intermediate stage of the fertility transition where contraception is not widespread and then sexual activity is restricted to occurs within the marital union. Second, pregnancy and marriage are closely related but the timing of these two events are not clear: it may be that marriage occurs because of pregnancy or that pregnancy occurs just after marriage. We will see later in this paper that the first explanation applies for both Guatemala and Dominican Republic.

\subsection{Knowledge and use of family planning}

Many factors influence whether an adolescent women uses birth control. Her marital status and her desire to have a child are important determinants, although in some settings, the norm in he community may have an important influence. Whether or not a young women hoping to avoid pregnancy practices birth control will depend upon both her awareness that contraceptive methods exist and the degree to which these methods are available to her. Access to birth control methods and to health care are 
critical; a young women may wish to practice contraception, yet not be able to obtain information, supplies and services she needs (The Alan Guttmacher Institute, 1998).

In general, knowledge of family planning methods is almost universal among adolescents, with the exception of Guatemala, a country with a high teenage fertility, where almost one third did not know any method (Figure 24). In the other countries, at least $85 \%$ of adolescent know a modern method. The knowledge is practically universal (above 98\%) in Dominican Republic, Colombia and Brazil. By educational level, however, the knowledge of family planning methods differs, especially in Bolivia and Guatemala, where almost 2/3 of not educated adolescents do not know any method. In contrast, in Brazil, Colombia and Dominican Republic, knowledge of family planning is almost universal independently of the level of education (Figure 25). However, knowing that a particular method exists does not mean that a young person knows how to use the method properly. Lack of knowledge or skill in using contraceptives is a prime cause of method failure among young people. Consequently, adolescents are more likely than adults to experience accidental pregnancies during their first year of contraceptive use (The Alan Guttmacher Institute, 1998).

Use of birth control among adolescents differs widely across countries. Among currently married, the proportion currently using a family planning method ranges from a low of $12 \%$ in Guatemala to a high of $55 \%$ in Brazil (Figure 26). In Dominican Republic and Bolivia about one third of married adolescents use contraceptives, while that percentage is as high as $46-49 \%$ in Peru and Colombia. Contraception is linked to premarital sexual activity. Indicating their desire to avoid pregnancy, sexually active unmarried adolescents are more likely than married adolescents to practice birth control throughout all countries: use of family planning methods is higher among not married but sexually active than among currently married adolescents (Figure 26). The differences are lower in those countries where contraceptives are widespread, as Brazil, Peru and Colombia. In contrast, they are specially high in Dominican Republic, Bolivia and Guatemala where contraception is less common. For example, in Dominican Republic $65 \%$ of currently married do not use any method but only $28 \%$ of those not married but sexually active are in such situation.

The type of method used also varies across countries. In most of the countries, with the exception of Bolivia, modern methods are more used than traditional methods. The increasing use of modern methods of birth control among adolescent women results in part form strong nationwide efforts to increase access to family planning services carried out in most LA countries since the end of the 60's. The level of contraceptive use and the type of method used are related not only to the existence and strength of public and private programme supplies but also to the existence of other actors in the supply-side of contraception such as pharmacies. Bolivia and Guatemala are countries with "very week family planning programme effort" and with pharmacies playing a lesser role than organized programmes (Mundigo, 1996). Colombia has not only a strong programme effort but pharmacies also appear as strong providers of modern methods. Although in Brazil and Peru the programme effort has been weak, the pharmacies have play an important role in supplying over-the-counter methods (Mundigo, 1996). 
With the exception of Guatemala, family planning need ${ }^{5}$ among currently married adolescents is similar across countries: it is around $65 \%-75 \%$. Although Bolivia is in an intermediate stage of the fertility transition, the family planning demand among married adolescents is as high as the one observed in Dominican Republic or Colombia, countries in a more advanced stage of the fertility transition (Figure 27). In contrast, in Guatemala only two out of every five married adolescents want to use contraceptive methods (40\%). The low level of family planning demand and contraceptive use in Guatemala may be associated with its stage of the demographic transition, an intermediate stage in which contraception is less accepted and less practiced by couples. It seems that in this country fertility among adolescent women is highly valued and sexual activity among unmarried is strongly discouraged, such that young women seeking to obtain birth control may be denied access to available methods.

The proportion of unmet need ${ }^{6}$ varies across countries: it ranges from a high $70 \%$ in Guatemala to a low 22\% in Colombia, $25 \%$ in Brazil and $28 \%$ in Peru. In Bolivia and Dominican Republic unmet need is in between: $52 \%$ and $41 \%$, respectively (Figure 28 ). Guatemala, one of the countries with the highest teenage fertility is the country with the lowest family planning demand and highest unmet need. The high level of unmet need is related to a low supply of contraception (a weak family planning programme effort and a low supply over-the counter methods). The moderate levels of unmet need of family planning in Bolivia and Dominican Republic may be related to different factors on he supply side. In Bolivia, very weak family planning programme efforts may explain the short of supply. In Dominican Republic, where programme effort has been moderate, the short of supply may come out from the lesser role played by pharmacies.

With the exception of Dominican Republic, family planning demand is higher in urban than in rural areas among both currently married and unmarried adolescents (Figure 29a-b). Among unmarried adolescents, family planning demand as well as contraception use is higher in Brazil and Colombia, the two countries that showed the highest proportion of premarital sexual activities. On the contrary, Guatemala, a country where sexual activity is mostly restricted to occur within the marital union, shows a negligible demand of amily planning among unmarried adolescents. Thus, the higher occurrence and acceptability of premarital sexuality during adolescence seems to be linked to the widespread availability of contraceptives.

Contraceptive use is higher in urban than in rural areas but unmet need is similar, leading to a higher percentage of satisfied demand in urban than in rural areas both among currently married and unmarried adolescents (Figure 30). The urban rural differences in the percentage of satisfied demand are striking in Guatemala which again can be explained by the weak family planning programme effort (family planning programmes usually reach first urban than rural areas).

\footnotetext{
${ }^{5}$ Total family planning demand includes: 1) women with unmet need for family planning, 2) women currently using any family planning method, 3) pregnant women while using a method. The last two constitute the satisfied demand. Unmet family planning includes: 1) pregnant women whose pregnancy is unwanted because they did not want more children or because they wanted the child later, 2) fecund women not using any method and who do not want more children or want more children but at least two years ahead (Profamilia, 1995).

${ }^{6}$ (Unmet need )/(total demand).
} 
Family planning use, and in particular the use of modern methods, is higher at higher levels of education (Figure 31), which can be related to a greater knowledge and acceptability among high educated adolescents.

\subsection{Early motherhood: the issue}

The data presented thus far suggest that both marriage/intercourse and contraceptive use play an important role in teenage fertility level and trends. The scatterplots in Figure 32 show a positive correlation among exposure-time and teenage fertility level, stronger with marriage than with intercourse which can be explained by the higher proportion of satisfied demand of family planning among not-married than among currently married adolescents. One would expect that the effect of exposure-time becomes less important as fertility control is widely accepted and used. One way of fertility control is abortion. However, as Guzmán, Hakkert and Contreras (2000) state, in most LAC countries, a premarital pregnancy is more likely to end into a marriage than into an abortion, leading to an increase in adolescent fertility ${ }^{7}$.

In most of the countries, teenage fertility has ncreased in rural areas but has declined or remain almost constant in urban areas. In order to estimate the impact of exposure-time on teenage fertility, we use the method of decomposition of fertility changes into marriage pattern and marital fertility components (Rosero-Bixby, 1996). The following equation was used then to estimate the amount of the change in the proportion of adolescent mothers by age 20, between women aged 40-44 and women aged 20-24, attributable to changes in the proportion of women ever married by age 20 , $\mathrm{C}_{\mathrm{m}}$ :

$$
C_{m}=\frac{\left[\left(f_{0} / m_{0}\right)+\left(f_{1} / m_{1}\right)\right]^{*}\left(m_{1}-m_{0}\right)}{2\left(f_{1}-f_{0}\right)}
$$

where the subscripts $(0,1)$ refer to the age groups $(0=20-24,1=40-44), f$ is the proportion of adolescent mothers and $\mathrm{m}$ is the proportion ever married. The relation between marriage and fertility assumes that births occur within the marriage exclusively. Since we have seen that premarital sexual activity is also important in some countries, the same equation was used to estimate the impact of the proportion of women who have had first intercourse by age $20, \mathrm{C}_{\mathrm{i}}$, on teenage fertility. Table 4 show the results. In urban areas, marriage has made meaningful contributions to somewhat important teenage fertility reductions in Peru and Dominican Republic, and the impact of intercourse patterns is particular important in Brazil. In Peru, in particular, the proportion of adolescent mothers declined from $32 \%$ to $25 \%$ and marriage patterns contributed to this decline by an estimated $43 \%$ whereas intercourse patterns contributed in $30 \%$. Thus, both marriage and intercourse patterns contributed in the same direction to teenage fertility decline in Peru. The proportion of urban adolescent mothers increased in Brazil from $27 \%$ to $30 \%$ and intercourse patterns contributed to this increase by an estimated $36 \%$ whereas marriage did not contributed. It seems then that the increase in teenage fertility in Brazil occurred mainly out of unions. In Dominican Republic on the

\footnotetext{
${ }^{7}$ In general, abortion has a higher incidence among adults than among adolescents in LAC countries. Colombia and Cuba are the only two LAC countries where the incidence of abortion is higher among adolescents than among adults women (Guzmán, Hekker and Contreras, 2000).
} 
contrary, marriage patterns contributed to adolescent fertility decline by $25 \%$ whereas intercourse patterns counterbalanced larger changes in fertility among sexually active adolescents (note the negative sign in $\mathrm{C}_{\mathrm{i}}$ ). In the other countries, marriage and intercourse contributions to early childbearing change have been modest (less than $10 \%)$.

In rural areas, neither marriage nor intercourse contributed to the small changes in adolescent fertility observed in Guatemala and Dominican Republic. In Bolivia and Colombia, intercourse patterns as well as marriage made meaningful contributions to the increase in rural teenage fertility. The important increase in rural teenage fertility observed in Bolivia appear to have been caused mainly by a marriage and a sexual activity boom among adolescents. The similar levels of $\mathrm{C}_{m}$ and $\mathrm{C}_{\mathrm{i}}$ suggests that marriage and sexual activity are closely tied but it does not say anything about the timing of those two events: it may be that marriage occurred soon after pregnancy, or pregnancy occurred soon after marriage. The first situation seems to be the case in Bolivia as we will see later in this paper. In contrast, one third of the increase in teenage fertility in rural Colombia is explained by marriage but almost all is explained by change in intercourse patterns. It seems then that part of the increase in rural adolescent fertility in Colombia has occurred outside marriage with its negative consequences.

The role of marriage and intercourse patterns in teenage fertility change shows that both of them have been important factors, especially in rural areas. However, not always they contributed in the same direction or with the same intensity in fertility change. In some countries, both marriage and intercourse contributed to teenage fertility reductions, as in the case of urban Peru. In others, they both contributed to teenage fertility increases, such as rural Bolivia. There are also countries, where the contribution to teenage fertility change mainly came from intercourse patterns whereas marriage patterns made modest, if any, contributions, such as in Brazil and in Colombia. The differential contributions of marriage and intercourse patterns to teenage fertility change in each country led us to expect changes in unmarried parenthood. Figures $33 a-b$ show the distribution of mothers by the interval between marriage to first birth by 5 -year age group ${ }^{8}$, in urban and rural areas. Although the proportion of never married mothers declines with age, it is important to see the trend in the proportion of mothers with their first dhild born out of wedlock (never married plus negative interval ${ }^{9}$ ). Clearly, urban and rural Brazil and Colombia show a steadily increase in this proportion, meaning that unmarried motherhood among teenagers has increased, which is in agreement with the important role played by intercourse in fertility increase. In urban and rural areas of Guatemala and Dominican Republic, this proportion is small and has almost remained unchanged, implying that non-marital childbearing has never been common. In Bolivia and Peru, premarital fertility has increased only in recent cohorts and only in urban areas but it has always been at relative high levels both in urban and rural areas (where around $20 \%-30 \%$ of mothers had their first child out of wedlock).

Data thus far suggest that levels and trends of teenage premarital fertility vary widely among countries, ranging from low and constant levels in Guatemala and Dominican Republic to high and increasing levels in Brazil and Colombia. However, how

\footnotetext{
${ }^{8}$ Since, as we have seen, first marriage and first birth mainly occur at early ages, first marriage to first birth interval are concentrated in adolescent period.

${ }^{9}$ First marriage to first birth interval is negative if birth occurs before marriage.
} 
does it vary within the adolescent group? Is premarital fertility as important among the 18-19 years old than among the youngest 15-17 years of age? The consequences of early childbearing are more negative the early the age of childbearing. Figure 34 show the distribution of adolescent mothers by first marriage to first birth interval by age. Once again, Brazil and Colombia show an increasing importance of premarital fertility among teenagers: about $25 \%-35 \%$ of $15-17$ years old and $20 \%$ of 19 years old had their first child out of wedlock. Guatemala and Dominican Republic have the lowest and almost constant levels of premarital fertility: less than $10 \%$ of adolescents had their first child out of wedlock, implying that in these two countries most of teenage fertility occurs within marriage.

Premarital births are determined by the differential pattern between first marriage and first live birth conception ${ }^{10}$. Figure 35 shows those patterns for adolescents aged 18-19 years, and they indicate that in only two out of the six considered countries Guatemala and Dominican Republic, there is a positive interval between first marriage and conception of first birth, higher in Dominican Republic than in Guatemala. This implies that in these two countries, with the highest teenage fertility, births occur within marriage. In Colombia, Brazil and Peru, countries with lower teenage fertility, first marriage and first birth conception occur almost at the same time which implies that adolescents formalize the union as soon as they know they are pregnant or they get pregnant as soon as they get married. In Bolivia, one of the countries with moderate teenage fertility, there is a negative interval between first marriage and first birth conception, evidencing a high incidence of premarital births.

Single adolescent mothers may formalize an union once the first child is born. Figure 36 shows the distribution of adolescent mothers by current marital status. Guatemala and Dominican Republic, where the common pattern is that births occur within marriage, show the lowest proportion of single adolescent mothers: $4 \%-8 \%$ of adolescent mothers are never married, both in urban and rural areas. In Brazil and Peru, the proportion of never married adolescent mothers is higher in urban than in rural areas: $20 \%$ of urban and $13 \%$ of rural adolescent mothers are never married. In Bolivia and Colombia, the proportion of single mothers is somewhat higher among rural than urban adolescent mothers: $18 \%$ in urban and $20-24 \%$ in rural areas.

There is empirical evidence on the negative relationship between age at first marriage and marital disruption, being intensified when first unions are consensual (Singh and Wulf, 1990). There is also evidence on the negative relationship between marital separation or divorce and either a premarital birth or premarital pregnancy (Gage, 1995). Dominican Republic, where consensual union are more common, shows the higher incidence of marital disruption among adolescent mothers, both in urban and rural areas: almost $30 \%$ of urban adolescent mothers were formerly married (Figure 36). Peru, on the contrary, presents the lower incidence of marital disruption among adolescent mothers: less than $5 \%$ of mothers were formerly married.

Thus, although Dominican Republic show the lowest proportion of never married adolescent mothers, the common norm of consensual unions leads to have a high proportion of formerly married adolescent mothers, resulting in a high incidence of adolescent mothers rearing alone their children.

\footnotetext{
${ }^{10}$ First live birth conception pattern by age was estimated by subtracting 9 months from the age at first birth.
} 


\section{THE SOCIOECONOMIC DETERMINANTS OF TEENAGE FERTILITY}

Data thus far evidenced a variation of teenage fertility levels across countries and different patterns of teenage fertility change. Adolescent fertility levels do not show a consistent relationship with the socioeconomic conditions of the countries. Exposuretime to pregnancy (marriage and sexual activity) and contraceptive use, two proximate determinants, have had important, but not equal, effects in teenage fertility levels and trends by country. Although there are common patterns across countries in youth fertility differentials, and its proximate determinants, by urban / rural area, region and by level of education, teenage fertility varies across countries even when these factors are controlled for. Thus, in this section we will analyze the socioeconomic and demographic factors that determines teenage fertility behavior.

\subsection{A conceptual framework}

Most theoretical models of adolescent behavior relate individual variables, family statuses and other factors to the likelihood of pregnancy or to the likelihood of a live birth, based on theories of social behavior such us socialization theory, social control theory, problem behavior theory and rational choice/opportunity cost theory. Gage (1995, pp. 7-8) summarizes these perspectives as follows:

- Models that derive from problem behavior theory state that adolescent behaviors, including premarital childbearing, are a function of individuals personality system and their perceived environment. Thus, sexual activity, childbearing and unmarried motherhood among adolescents are perceived to be a reflection of low self-esteem and internal locus of control, and low aspirations and expectations regarding the attainment of salient goals.

- The socialization and social control perspectives view adolescence as a troubleprone period during which children need to be constrained by parents. These perspectives relate adolescent behavior to family statuses and events. The socialization perspective hypothesizes that women who grow up in a mother-only family during childhood are socialized in ways that produce a high risk premarital birth while the social control perspective hypothesizes that the number and types of adults present during adolescent years are important predictors of the likelihood of premarital birth.

- Rational choice/opportunity cost theory maintain that teenage childbearing may not be deviant or mistimed in certain populations, but is rather a response to underlying socio-structural constraints and opportunities. Early childbearing is viewed as a strategically planned life-cycle event that enables socially-disadvantaged women to take care of their infants under the protection of their families of origin. Thus, in some communities, those teenagers who are believed to have the academic potential to overcome the social and economic barriers to upward mobility are actively discouraged from bearing children during their teenage years.

According to these theoretical models, youths decide whether to have a childbirth or not, depending upon their family status (economic condition), the environment in which they were raised, economic and school opportunities, personal characteristics, and supply of family planning methods. 
Several explanatory variables have been identified in the literature to represent those conditions. The level of woman's education has shown an strong correlation with fertility regulation, among adult and adolescent women. As it was shown in previous sections, more educated adolescents have lower teenage fertility. However, although higher levels of education are associated with lower teenage childbearing, the direction of the causality is less clear among adolescents than among adult women. Adolescents women may delay childbearing in order to complete their formal education, but teenage mothers may also be forced to leave school early upon having a child. In our analysis, education is measured as a categorical variable in order to capture non-linear effects of schooling on fertility. Five categories were used: 0/3 , 4/7, 8/10, 11/13 and 14/16 years of education.

Marriage has demonstrated to be an important proximate determinant of teenage fertility in the selected LAC countries. Since we know the age at first marriage for each woman, marital status is included as a time-varying variable as a proxy of high exposure-time to childbearing. Use of contraception is also an important proximate determinant of fertility. Although knowledge and use of contraception in DHS refer to the current situation (at the moment of the interview) and they are only a crude measure of contraceptive efficacy, it is meaningful to measure contraceptive use. Therefore, unmet need of family planning was used as a variable reflecting the combined effect of supply and demand factors: desired of using contraception vs. the access to the methods.

Place of residence has been, in the literature as well as in previous sections, of important influence on teenage fertility behavior: levels are lower in urban than in rural areas.

Woman's household income and poverty condition has shown to affect fertility regulation. The literature indicate that a teenager growing up in a poor family is more likely than a girl growing up in a middle/high-class family to initiate sexual activity at an early age and to become a single parent at an early age (Hogan, 1985). Unfortunately, DHS surveys do not include information on income of all household members. Total income has been measured through proxy variables such as household appliance possession (radio, television, refrigerator) and access to public services (water, electricity, toilet availability).

Sex of the household head is used to consider the effect of socialization factors (family status) on teenage fertility. Some studies (Hogan, 1985) present evidence that teenagers growing in female-headed households initiate sexual intercourse at an earlier age and are more likely to become adults by single motherhood than teenagers from other family situations. Although this variable refers to the actual household, the recent history of teenagers allow us to use this variable.

The regional context where the woman lives also influences fertility behavior. For example, it is expected that a woman living in a region of high fertility, has a higher probability of becoming mother at an early age than a women living in a region of low fertility. We considered three regional variables: the level of teenage fertility (proportion of adolescent mothers), proportion of adolescent women using family planning methods (demand side), and the proportion of adolescent women with unsatisfied demand of family planning methods (supply side). 


\subsection{A simple logit model}

A simple logit model ${ }^{11}$ was used as a first approximation to the analysis of the socioeconomic determinants of teenage fertility. Two logit models were estimated grouping women per age groups: 15 to 17 years old and 18 to 19 years old. Those groups were constructed given their different childbearing behaviors: bearing a child at 18 or 19 years of age is a common experience whereas childbearing before age 18 is uncommon.

The results of simple logit models indicate that the effect of the variables are not always the same across countries, and the effects are significant in some countries but not in others (Table 5). However, in most of the countries, as it was expected, the probability of being a mother increases with age, decreases with years of education, and significantly increases with marriage. Improving household conditions, in general, decreases the probability of childbearing at early ages. The regional context of fertility, the supply and demand conditions of family planning also affect the probability of being a mother in the expected direction: the higher the level of regional fertility, the lower the regional use of family planning and the higher the unmeet need of family planning, the higher the probability of early childbearing (Table 5$)^{12}$.

In the simple logit models we are assuming that the effect of a variable is the same across regions (and also across countries in the first column). The usual way to overcome this assumption is to add, as independent variables, a set of dummy variables for each region and/or country. If we expect the effect of the variables to vary between regions, such dummies should interact with each independent variable. A great advantage of DHS surveys is that, because of their size, samples are representative at the level of small regions: among the six countries we can find significance levels in 92 regions!. It would be inefficient to use 92 regional dummy variables in our model and multiply them with the ten independent variables. However, we cannot ignore the regional/country context. Ignoring such regional structure is to assume, as many previous statistical analysis have done, that the individual observations are independent. Samples selected in two stages, such as the DHS, tends to generate some correlation between observations related with regions: individuals from the same region are expected to be more alike in terms of characteristics and behaviors than those selected from different regions. There can be a higher correlation between women with different characteristics living in the same region, than the existing correlation between women with similar characteristics living in different regions. If these regional effects were ignored, the estimations of standard errors would be biased (underestimated). The use of multilevel or hierarchical models, which include group or regional effects, solve these problems.

\subsection{Multilevel Analysis (MA)}

Because individuals interact with the social context to which they belong, and because individuals who make up the group in turn influence the properties of those groups, we need to take into account those effects. Since we assume that some regional (country, region, group, etc.) variables affect teenage fertility behavior, we use

\footnotetext{
${ }^{11}$ The independent variable takes the value of one if the woman has at least one child born and zero if she has not.

12 Logit models were also estimated using urban as a dummy variable. However, the results were not statistically significant.
} 
$M A^{13}$. For instance, we expect that a woman who lives in a region with a high fertility rate has a higher probability of childbearing than a woman who lives in a region with a low fertility rate. Fertility level, use of family planning (demand side) and unmet need of family planning (supply side) are used as contextual variables. As before, we estimated two MA Logit models grouping women per age groups: 15 to 17 years old and 18 to 19 years old. Given that a high proportion of women of the oldest age group has more than one child, we also estimate the model for this group using a Poisson function. Nevertheless the predicted values were more robust with the Logit than with the Poisson function (Table 6).

The effect of the considered variables on the probability of childbearing is the same across region/countries with the exception of the intercept, age among the youngest group, and education among the oldest age group (Table 6).

As one would expect, being married significantly increases the probability of having a first child. The effect of household conditions indicates that improving household conditions decrease the probability of childbearing. Regional fertility, regional family planning demand and supply indicators have the expected effects: a regional context of high fertility, low use of contraception and high unmeet need of family planning positively influence the probability of early childbearing (Tables 6 and 7).

The probability of having a childbirth increases with age. However, for women 1517 years old, age has a different effect on childbearing across regions/countries (it has a random component, $u_{3 j}$ ). This would imply that, ceteris paribus, women of the same age in two different regions/countries have different probabilities of childbearing. On the other hand, although education has a negative effect on the probability of childbearing in both age groups, the effect is different across regions/countries among women 18-19 years old (it has a random component, $u_{2 j}$ ) (Table 6). The intercept estimation is also random at the regional/country level, $u_{1 j}$, producing variation on the unconditional probability. This suggest that women with the same characteristics in two different regions have different teenage fertility: that is, there is a clear region/country effect.

The most relevant result of our MA results is that the negative correlation between $u_{1 j}$. and $u_{2 j}$ - the random components of the intercept and education-, explains much of the regional differences in teenage fertility (Figure 37). For example, a women that lives in region $A$ has a high unconditional probability and a very large negative effect of education, whereas a women living in region B presents a very small autonomous probability and a small but positive effect of education. However, the positive effect of education on teenage childbearing was observed only in few regions. This result implies that the effect of education is much more important among women living in regions with high regional fertility.

\subsection{Continuous-time hazard rate models}

The simple and MA logit models estimated in previous sections use the crosssectional information obtained in the DHS pregnancy history data to predict the occurrence of having a first child - our event of interest- by the survey date. However, given that our data is subject to right censoring (some adolescent women have not had yet their first child by the survey interview), those techniques produce biased estimates (Hogan, 1985). To avoid this statistical problem, and because the normal assumption in

\footnotetext{
${ }^{13}$ See Goldstein H (1995) for a complete explanation of MA. Parameters were estimated using the software package MLn.
} 
a variable measuring time is not reasonable, we next use a continuous-time hazard rate model to estimate the probability of an adolescent having a first birth. Additionally, we also want to analyze the effect of demographic, socioeconomic and contextual variables on the hazard rate of first childbearing. This model estimates the instantaneous rate of transition from the origin state $j$ (e.g., childless) to the destination state $k$ (with a child born) at time $t$ as a function of the independent variables of interest, using all the information obtained in the birth history of each woman.

It is obvious that we need to know when women are at risk for having a first birth in order to analyze the hazard rate for that event. The real risk period of having a first birth never start prior to the occurrence of puberty or the first sexual intercourse. First sexual intercourse is a logically preceding event to our event of interest - having a first birth. Since we know the timing of the first sexual intercourse and given that the risk of having a birth is zero before the first sexual intercourse, the analysis in this case was divided into two steps. We first estimate a model that looks at the rate of first childbearing and then isolate these effects into components due to differentials in initial sexual activity and to differentials in the rate of childbearing among the sexually active. Thus, we estimated models of the net effect of the independent variables on the rate of first childbearing, on the rate of initial sexual intercourse and on the rate of first childbearing among the sexually active. The isolation procedure allow us to identify the main source of the effects of the independent variables on the rate of first childbearing: does the effect of an specific variable act mainly through initiation of sexual intercourse or through first childbearing among those sexually active?

In the general model for the rate of childbearing, the risk period start at the occurrence of puberty. Since we do not know the exact age of the occurrence of puberty, we assume that all women entered the risk period at the same age, 10. However, since the timing of puberty may vary considerable among women, especially across countries, we estimated several models using different ages of puberty occurrence. We used age 10,11 and 12, getting very similar results. This implies that the probability of having a first birth is not very sensitive to the exact beginning of puberty, maybe due to the fact that childbearing is very rare at this very low ages. The results presented here refer to age 10 as the starting age of the risk period. Although age 10 may seem a very low age, it was used since we observed women who already have had a child born by that age.

Isolating the effects implies, in turn, two steps. In the first step, we model the hazard rate of having the first sexual intercourse by assuming that all women enter the risk period at the same age, 10. In the second step, we model the hazard rate of having a first birth assuming that the risk period begins with the woman-specific date of the first sexual intercourse. This two-step analysis elaborates the specification for each risk period and therefore provides richer information about the occurrence of each dependent event. Certain covariates may affect the first event (first sexual intercourse) but not the second (having a first birth among the sexually active). In the same way, certain other covariates, such as knowledge or use of contraceptives, may affect only the second event ${ }^{14}$.

Because there are theoretical and empirical reasons to expect positive time dependence in the first sexual intercourse and first childbearing transitions, we decided

\footnotetext{
${ }^{14}$ Hogan and Kitagawa, 1985, used this two-step approach on the analysis of premarital pregnancy.
} 
to use a parametric model ${ }^{15}$. As Hogan and Kitagawa (1985) state: "Theoretically, the literature on maturation and development suggest that the process of physical maturation (including onset of menstruation) is age graded, with a positive association between age and maturational transitions, up to the age at which the transition has been experienced by most of the relevant population. The association of initial coitus with the level of physical maturity and psychosocial development leads to an expectation of positive duration dependence" (pp. 842). In order to search for a better specification of the continuous-time hazard rate models, three alternative parametric characterization of time dependence were used: Weibull, Exponential and Gompertz. The model selection was based on the Akaike Information Criteria (AIC) test, which permits comparisons among parametric non-nested models. The result of the test demonstrated that the Weibull distribution best fitted the data (Table 8).

The results of our analysis are reported in Table 9. Each of the independent variables displays the hypothesized association with the rate of first birth (first column). Education shows a strong negative effect on teenage childbearing, specially up to 11-13 years of education (Figure 38). Thus, the risk of having a first birth among women with $11-13$ years of education is $58 \%$ lower that the risk observed among those women with 0-3 years of education. This result, which is in agreement with the literature on the determinants of fertility (Lam and Duryea, 1999; Schultz, 1993), may indicate not only an increased ability to control fertility among more educated adolescents, but a negative effect of women's education on desired early childbearing. Adolescent women living in a urban place of residence have a lower rate of childbearing, although the effect did not appear to be large nor statistically significant either ${ }^{16}$. Net of other effects, adolescents with unmet need of family planning have rates of childbearing $12.7 \%$ higher that girls with satisfied need of family planning. Thus, increasing the ability of adolescents to realize their childbearing aspirations (decrease of unwanted births) would permit a decline in teenage childbearing rate.

Family structure indicate that teenagers from households with a male as household head experience a rate of first birth that is $11 \%$ lower (.894) than those from households headed by a woman. Thus, socialization in a female-headed family, with lax parental supervision, may enhance the acceptability of early and premarital sexual activity, and early and single parenthood. Girls living in low class households (measured by the lack of households assets: radio and refrigerator) experience a lower rate of childbearing than adolescents living in high class households. The possession of radio decreases the childbearing rate in $10 \%$. This negative effect may reflect not only the economic class of the household but their cultural level. Radio as a mass media may be playing a role in promoting social change with respect to attitudes about reproductive behavior and life aspirations.

The effects of the regional context indicate positive effects of the level of fertility and the level of unmet need of family planning on the rate of childbearing. Each percentage increase in the level of teenage fertility or in the proportion of unmet need of family planning increases the childbearing rate in $1.7 \%$ and $1.4 \%$, respectively. Thus,

\footnotetext{
${ }^{15}$ Since we know the form of the hazard function, it is preferable to use a maximum likelihood estimation (parametric model) instead of using a partial likelihood estimation procedure (semi-parametric model).

${ }^{16} \mathrm{~A}$ chi-square test that the variable was zero was accepted with a .5501 probability.
} 
the regional environment in which adolescents live (fertility and availability of family planning methods) strongly affect their fertility behavior. This is also indicated by the effect of dummy country variables on the rate of childbearing. For example, net of other effects, adolescents from Peru experience a childbearing rate $33.5 \%$ lower (hazard ratio $=0.665$ ) than those living in Bolivia.

Previous sections indicated not only that marriage plays an important role in adolescent fertility but that marriage patterns differs across countries. In order to consider both effects in our model, we included an interaction variable marriage ${ }^{17}$. country. Results indicated that, as soon as Bolivian adolescents get married, their rate of childbearing becomes 48.8 times higher. This result may be read carefully since it may suggest that marriage is an important proximate determinant of Bolivian teenage fertility but it may also represent the fact that a teenage pregnancy sometimes prompts a marriage to legitimate the child. Since Bolivian adolescents show a negative interval between first marriage and first birth conception, the high increase in fertility risk with marriage may be understood within the second explanation: an action to legitimate a birth conception. Being married in Dominican Republic or Guatemala increases even more the risk of having a first child in relation to Bolivia: it is twice as higher!. However, adolescents in these two countries have a positive interval between first marriage and first birth conception, indicating that marriage is the determinant event.

To what extent are these overall differentials in the rate of adolescent childbearing due to differing rates of initial sexual intercourse and to differing rates of childbearing among those sexually active? Table 9 also present the results of the models for the rate of initial sexual intercourse (column 2) and the rate of first birth among those sexually active (column 3). The net effects of most of the independent variables are stronger and more significant in the model of initial sexual intercourse. All the coefficients of schooling are negative, stronger and statistically significant implying that education plays an important role on the rate of initial sexual intercourse. For example, women with 11-13 years of education have a risk of initial sexual intercourse $82 \%$ lower than the risk among adolescents with $0-3$ years of education. Teenagers living in urban areas have an rate of initial sexual intercourse $16.7 \%$ higher than the rates observed among rural adolescents. Better socioeconomic conditions of the household (possession of radio and refrigerator) strongly reduce the rate of initial sexual intercourse by about one fourth. Sex of the household head did not showed the expected result: living in a household headed by a male increases the risk of initial sexual intercourse in $7.5 \%$. Adolescents living in a regional context of high teenage fertility have higher rate of initial sexual intercourse: each additional percentage increase in teenage fertility increases the rate of initial sexual intercourse in $4.8 \%$ !! The country context strongly affect the rate of sexual activity: girls from Brazil, Colombia and Dominican Republic have an initial rate of sexual intercourse that is $100-84 \%$ higher than the rates observed among those living in Bolivia!! Adolescents living in Guatemala, on the contrary, have rates of sexual activity $17 \%$ lower than the rates of those living in Bolivia. Thus, Bolivia and Guatemala are contexts that discourage the timing of initial sexual intercourse relative to the other countries.

\footnotetext{
${ }^{17}$ Marriage was used as a time-varying variable (single/married) since we have the date at first marriage. Being married and living in Bolivia is the reference category.
} 
When the model is restricted to sexually active adolescents (Table 9 , column 3 ), only country context and marriage-country interactions variables have persistent effects on the rate of first childbearing. Bolivia has a cultural context that leads to higher risk of having a first birth among sexually active adolescents. On the contrary, Dominican Republic and Guatemala's cultural contexts favor lower rates of childbearing among sexually active adolescents. However, being married in Dominican Republic and Guatemala increases the risk of first childbearing among sexually active adolescents in relation to Bolivia, indicating the important role played by marriage in adolescent fertility in the cultural context of those two countries. Age at first intercourse was introduced as a control variable: it suggests that the older a girl initiates sexual activity, the higher the rate of first childbearing (at the same analysis time).

The estimated coefficients in the three models suggest that the large impact of education and socioeconomic conditions of the household on the overall rate of first childbearing is because of the effects of these variables on the age at which adolescents become sexually active. Their effect on the rate of first childbearing among those sexually active is smaller and it is not significant. In the same way, the positive regional effect of high fertility on the overall rate of first birth acts mainly through initial sexual intercourse. On the contrary, the effects of regional contexts - such as living in a specific country - are larger and more statistically significant for the rate of initial intercourse than for the rate of childbearing among sexually active girls. Even more, they have counterbalancing effects: they positively affect the rate at initial sexual intercourse but have a negative effect on the overall rate of childbearing. In the same way, the environment effect, such as living in urban/rural area, has a positive and significant effect only on the risk of initial sexual intercourse: living in a urban area increases that risk. These results may be understood at the light of the regional/environmental effect of the availability and acceptability/use of family planning methods: a higher regional/local unmet need of family planning strongly increases the overall rate of first birth. Thus, the accelerated timing in the rate of initial sexual intercourse is discouraged by a higher practicing contraception.

Teenage parenthood is generally deleterious for both mother and child. But unmarried teenage parenthood is even worse becoming a critical social issue because of its negative potential impacts on both mother's and child's short-term and long-term health and socioeconomic success. For that reason we considered important to restrict our analysis of the socioeconomic determinants of early childbearing to premarital births only. Table 10 presents the results.

The estimated coefficients ndicate larger and stronger effects of almost all the independent variables on the timing of premarital birth than on the overall timing of childbearing. For example, the effect of education is quite strong: adolescents with 1113 years of education have a risk of premarital birth $88 \%$ lower than those girls with only 0-3 years of education!! In general, increasing schooling and improving the socioeconomic conditions of the households decreases the rate of premarital birth. The large impact of these variables is because of the effects of them on the age at which girls become sexually active. Their effects on the rate of premarital birth among those sexually active are much smaller and less significant. On the contrary, the family context acts mainly through its effect on the timing of premarital birth among those sexually active girls. Girls living in male-headed households have premarital birth rates that are 
$38 \%$ lower than those observed among girls in female-headed households. This effect mainly comes from its effect on the rate of premarital births among those sexually active. This large effect of sex of the household on the rate of premarital childbearing supports the literature that socialization in a female-headed family may enhance the acceptability of single parenthood.

Being able to satisfy the need of family planning is the independent variable that present the largest (negative) effect on the overall rate of premarital childbearing. However, this variable has the contrary effect on the rate of premarital birth among sexually active women: having unmet need of family planning decreases the rate of premarital birth by $43 \%$. This result may be due to the fact that unmet need is measured at the moment of the interview (the ideal would be at time of first intercourse or first pregnancy) or/and to the fact that it does not reflect contraceptive efficacy. An adolescent may use a contraceptive method but may not use it in a proper way.

Regional contexts indicators have large and strong effects on the rate of premarital birth. Living in a urban area positively affect the timing of initial sexual intercourse but its effect on the rate of premarital birth is not statistically significant. The conditions of the urban areas - in relation to rural areas - allow girls to realize their fertility aspirations: sexually active girls have a lower rate of premarital birth although they have an accelerated timing of initial sexual intercourse. The impact of country conditions (cultural and inherent characteristics) on the rate of premarital birth is because of the effects of these country conditions on the rate of premarital birth among sexually active girls, which counterbalance the opposite effect of country conditions on the rate of initial sexual intercourse. Thus, although girls living in Bolivia have one of the lowest rate of initial sexual intercourse, they have the highest rate of premarital birth among sexually active women and then they have the highest overall rate of premarital birth. Girls living in Guatemala and Dominican Republic present the lowest rate of overall premarital birth and the lowest rate of premarital birth among sexually active girls although they present a very different timing of initial sexual intercourse.

\section{SUMMARY AND CONCLUSIONS}

Most of LAC countries have been experiencing a fertility transition since the middle of last century. However, adolescent fertility has not changed at the same pace with fertility in the other age groups: in some countries it has stayed practically constant, in others it has declined but the change has been less than that experienced by older women, and in others it may have increased. Changes in the age fertility pattern indicate that the contribution to total fertility by women 15-19 year-old age-group has risen in almost all countries. Given that teenage is generally deleterious for both mother and child, this research has attempted to describe the differentials in levels and trends in early childbearing across LAC countries and to analyze its proximate and socioeconomic determinants.

In the late 90's, teenage fertility levels varies across LAC countries: the proportion of adolescent mothers ranges from a high level of $18 \%$ in Guatemala and Dominican Republic to a low level of $10 \%$ in Peru. Teenage fertility differentials by area of residence (rural/urban), by region and by level of education are important but especially striking by education and region. Early childbearing is the norm in rural areas and among not educated adolescents. Initial sexual activity and marriage are not so 
closely related in all countries, as in Colombia and Brazil, and in these, young women may have sexual relationships that do not lead to formal unions. Early marriage and premarital sexual activity are important factors contributing to high levels of teenage fertility. In Guatemala and Dominican Republic, births occur mainly within marriage and the exposure-time effect on fertility acts mainly through marriage whereas in the other countries, especially in Brazil and Colombia, premarital sexual activity is an important component of the exposure-time effect. Most adolescents do not legalize their first union: at least $50 \%$ of couples are in consensual unions. Although there are differences across countries, it does not seem to exist a relationship between the legality of the union and teenage fertility.

Family planning use is one factor that inhibits fertility to be high. Guatemala has the higher teenage fertility and the lower proportion of adolescents using a family planning method. Peru is in the opposite situation. Contraceptive practice depends upon supporting attitudes, policy, and service provision. Guatemala has adverse conditions on these three factors: family planning is less accepted and used among adolescent couples -and then it has the lowest demand for family planning methods-, family planning programme efforts have been weak, and it has a low supply over-the counter methods. It seems that in this country fertility among adolescent women is highly valued and sexual activity among unmarried is strongly discouraged, such that young women seeking to obtain birth control may be denied access to available methods.

Teenage fertility trends indicate different patterns of change across countries by area of residence. However, in most countries teenage fertility has increased in rural areas but has declined or remained constant in urban areas leading to an increase in rural/urban differentials. Guatemala and Dominican Republic show little change in both urban and rural areas, remaining as the two countries with the highest teenage fertility levels. In those two countries, most of teenage births occurs within marriage, and the high and constant adolescent fertility is associated with high and constant marriage patterns and high unmet need of family planning. In urban Peru, teenage fertility has declined as a result of decreases in both marriage and intercourse patterns and a high acceptability and use of family planning methods. In Brazil and Colombia, although contraception has high acceptability and sse among adolescents, teenage fertility has increased as a consequence of increasing intercourse patterns whereas marriage has have modest, if any, effects.

The different contributions of marriage, proper use of family planning methods, and premarital births to teenage fertility behavior are reflected in unmarried motherhood. The disadvantages inherent in early childbearing are compounded for young unmarried mothers and their children by a lack of economic and social support. In Guatemala and Dominican Republic, unmarried motherhood is low and has remained unchanged since the norm is that teenage fertility occurs within marriage. In Bolivia and Peru, although premarital fertility has increased only in recent cohorts it has always been at relative high levels evidencing a high incidence of premarital births on teenage fertility. In spite of high levels of satisfied demand of family planning among adolescents in Brazil and Colombia, sexual activity before marriage has increased with serious consequences on unmarried motherhood among teenagers. It seems that young unmarried, as well married, women are likely to lack accurate knowledge about the different contraceptive methods and about their proper use. 
Urban/rural area of residence, region of residence and level of education are variables that differentiate teenage fertility as well as its determinants, marriage and contraceptive use. Descriptive analysis indicated that early childbearing, early marriage, and low contraceptive use is particularly common among young women who live in rural areas and who have comparatively little education.

To analyze the socioeconomic determinants of early childbearing, three econometric approaches were used: simple logit model, complex multilevel analysis, and continuous-time hazard rate models. The results between the three econometric approaches were very consistent. This research has improved on prior demographic research on teenage fertility determinants on LAC countries by: 1) including contextual/regional factors in examining the total associations and effects of independent variables on teenage fertility, 2) isolating the effects into differentials in sexual activity and rates of childbearing, and 3) comparing the socioeconomic determinants of the timing of first birth and premarital birth.

This research confirms that education and socioeconomic conditions of the households (possession of assets) have negative effects on the timing of teenage fertility, being larger and stronger the effects on the rate of premarital birth. However, the large impact of education and socioeconomic conditions of the household on the overall rate of first childbearing and premarital birth is because of the effects of these variables on the age at which adolescents become sexually active. Their effect on the rate of childbearing among those sexually active is smaller and less significant. In the same way, a regional context of high fertility has a positive effect on the overall rate of first birth and premarital birth, which acts mainly through initial sexual intercourse. The effects of education and the regional context of fertility is also captured in MA analysis, where the results indicated that the impact of education on teenage fertility of adolescent women between 18 and 19 years old varies depending on the region. In a region where teenage fertility is high, education can reduce the probability of childbearing. On the contrary, if teenage fertility is low, education will have a very small effect on the probability of having a child.

Family planning factors, at the individual or regional level, have important effects on the overall timing of childbearing as well as on the rate of premarital birth. Higher availability and acceptability/use (unmet need) of family planning methods largely affects the overall timing of first birth and premarital birth. However, the effect of this variable was not always as expected. This result may be due to the fact that unmet need is measured at the moment of the interview (the ideal would be at time of first intercourse or first pregnancy) or/and to the fact that it does not reflect contraceptive efficacy. An adolescent may use a contraceptive method but may not use it in a proper way. Schooling will certainly affect desired fertility but the access and proper knowledge of family planning methods will ensure the ability to realize the fertility aspirations.

Marriage plays an important and positive role in adolescent fertility but its pattern differs across countries. Whereas in Bolivia the positive effect of marriage on the risk of first birth represents the fact that a teenage pregnancy sometimes prompts a marriage to legitimate the child, in Dominican Republic and Guatemala it indicates that marriage is an important proximate determinant of teenage fertility.

Regional contexts indicators have large and strong effects on the overall timing of childbearing and of premarital birth. Living in a urban area positively affect the timing of 
initial sexual intercourse but its effect on the rate of premarital birth is not statistically significant. The conditions of the urban areas - in relation to rural areas - allow girls to realize their fertility aspirations: sexually active girls have a lower rate of premarital birth although they have an accelerated timing of initial sexual intercourse. Country conditions (cultural and inherent characteristics) have differential effects on the timing of overall childbearing and premarital birth. However, contrary to urban/rural area, the impact of country on the overall rate premarital birth is (mainly) because of the effects of these country conditions on the rate of premarital birth among sexually active girls, which counterbalance the opposite effect of country conditions on the rate of initial sexual intercourse. Thus, an accelerating timing of initial sexual intercourse does not implies an accelerating timing of overall premarital birth. Availability, acceptability, accurate knowledge, and proper use of family planning methods largely affects the overall timing of first birth and premarital birth.

This research has demonstrated that the effect of independent variables on the rate of childbearing (the rate of premarital birth) can act through the timing of initial sexual intercourse or through the timing of first birth (premarital birth) among sexually active women. In the first group, having an impact through initial sexual activity, are variables such as: schooling, socioeconomic conditions of the household, and area of residence. In the second group, acting through the timing of childbearing among sexually active girls, are variables such as: socialization in a female-headed household, availability /acceptability/use of family planning (unmet need), and regional country conditions (cultural and inherent characteristics).

\section{BIBLIOGRAPHICAL REFERENCES}

Alan Guttmacher Institute. 1998. Into a New World: Young Women's Sexual and Reproductive Lives. New York: The Alan Guttmacher Institute.

---, 1999. "Risks and Realities of Early Childbearing Worlwide”. Issues in Brief:1-14.

Buvinic, Mayra. 1998. "Costos de la Maternidad Adolescente en Barbados, Chile, Guatemala and México". Reprint from Studies in Family Planning, 29 (2): 201-209.

Burt, Marta. 1998. "Porqué debemos invertir en el Adolescente". Paper presented at the Conferencia Salud Integral de los Adolescentes y Jóvenes de América Latina y el Caribe. OPS. Washington: USA.

Chackiel Juan and Susana Schkolnik. 1996. "Latin America: Overview of the Fertility Transition, 1950-1990". In Guzmán, Singh, Rodríguez and Pantelides, editors. The Fertility Transition in Latin America. New York: Claredon Press - Oxford.

Crockett, Lisa and Anne Petersen. 1994. "Adolescent Development: Health Risks and Opportunities for Health Promotion". In Susan Millstein and Anne Petersen, editors. Promoting the Health of Adolescents: New Directions for the 21st Century. 
Elliott, Glen and S. Shirley Feldman. 1990. "Capturing the Adolescent Experience". In S. Shirley Feldman and Glen Elliott, editors. At the Threshold: The Developing Adolescent. Cambridge, MA: Harvard U. Press.

Gage, Anastacia. 1995. "The Social Implications of Adolescent Fertility". Paper presented at the Seminar on Demography and Poverty. IUSSP-UNICEF-University of Florence: Italy.

Goldmand, Noreen and Pebley, Anne. 1981. "Legalization of Consensual Unions in Latin America". Social Biology. 28: 49-61.

Goldstein Harvey. 1995. Multilevel Statistical Models. John Willey \& Sons: New York.

Gupta Neeru and lúri da Costa Leite. 1999. "Adolescent Fertility Behavior: Trends and Determinants in Northeastern Brazil". International Family Planning Perspectives. 25 (3): 125-130.

Guzmán Jose Miguel, Hakkert Ralph and Contreras Juan Manuel. 2000. "Diagnóstico sobre Salud Reproductiva de Jóvenes y Adolescentes en América Latina y el Caribe". Paper presented at the Reunión de Planeación Regional en Población. UNFPA: México.

Hayes, Cheryl. 1987. Risking the Future: Adolescent Sexuality, Pregnancy and Childbearing. Washington: National Academic Press. Cited in Gage Anastacia (1995).

Hogan Dennis and E. Kitagawa. 1985. "The impact of social status, family structure, and neighborhood on the fertility of black adolescents". American Journal of Sociology. 90 (4): 825-855.

Lam David and S. Duryea. 1999. "Effects of schooling on fertility, labor supply, and investments in children, with evidence from Brazil". The Journal of Human Resources. XXXIV-I: 160-192.

Michael Robert and N. Brandon Tuma. 1985. "Entry into marriage and parenthood by young men and women: the influence of family background". Demography. 22 (4): 515544.

Monroy de Velasco, Anameli. 1985. "Pubertad, adolescencia y cultura". In OPS-OMS. La salud del adolescente y del jóven. Washington D.C.: Organización Panamericana de la Salud y Organización Mundial de la Salud. Publicación Scientífica 489.

Moreno Lorenzo and Singh Susheela. 1996. "Fertility Decline and Changes in Proximate Determinants in the Latin American and the Caribbean Region". In Guzmán, Singh, Rodríguez and Pantelides, editors. The Fertility Transition in Latin America. New York: Claredon Press - Oxford. 
Mundigo, Axel. 1996. "The Role of Family Planning Programmes in the Fertility Transition in Latin America". In Guzmán, Singh, Rodríguez and Pantelides, editors. The Fertility Transition in Latin America. New York: Claredon Press - Oxford.

Rosero-Bixby, Luis. 1996. "Nuptiality Trends and Fertility Transition in Latin America". In Guzmán, Singh, Rodríguez and Pantelides, editors. The Fertility Transition in Latin America. New York: Claredon Press - Oxford.

Singh Susheela and Deirdre Wulf. 1990. Adolescentes de Hoy, Padres del Mañana: Un Perfil de las Américas. New York: The Alan Guttmacher Institute.

Suarez Ojeda, Elbio et al. 1985. "Adolescencia y juventud: Aspectos demográficos y epidemiológicos". In OPS-OMS. La salud del adolescente y del jóven. Washington D.C.: Organización Panamericana de la Salud y Organización Mundial de la Salud. Publicación Scientífica 489.

Torres-Rivas, Edelberto. 1988. "Introducción al análisis comparativo de la juventud". In Edelberto Torres-Rivas et al editors. Escépticos, narcisos, rebeldes: 6 estudios sobre la juventud. San José: FLACSO.

Wartenberg Lucy, 1999. Embarazo Precoz y Aborto Adolescente en Colombia. Bogotá: Centro de Investigaciones sobre Dinámica Social-CIDS-Universidad Externado de Colombia and Fondo de Población de Naciones Unidas-UNFPA.

Yamaguchi Kazuo. Event history analysis. Applied Social Research Methods Series. Vol. 28. Newbury Park (California): SAGE Publications. 
Table 1: Some economic, demographic and social indicators. Selected Latin American countries

\begin{tabular}{|c|c|c|c|c|c|c|c|c|c|}
\hline \multirow[b]{2}{*}{ Country } & \multirow{2}{*}{\begin{tabular}{|c|} 
Economica \\
GNPUS\$90 \\
1997 \\
\end{tabular}} & \multicolumn{4}{|c|}{ Demograohicb } & \multicolumn{4}{|c|}{ Social } \\
\hline & & $\begin{array}{c}\mathrm{TRR} \\
199095\end{array}$ & $\begin{array}{c}\text { MR } \\
199095 \\
\end{array}$ & $\begin{array}{c}e 0 \\
199095 \\
\end{array}$ & $\begin{array}{c}\text { \% Addles } \\
1995 \\
\end{array}$ & $\begin{array}{c}\text { \% Uiban } \\
1995 \mathrm{~b}\end{array}$ & $\begin{array}{c}\text { ISESwomer } \\
1995 \mathrm{c}\end{array}$ & $\begin{array}{c}\% \mathrm{HHbelPL} \\
1997 \mathrm{a}\end{array}$ & $\begin{array}{c}\text { DH } \\
1995 \mathrm{~d}\end{array}$ \\
\hline Brazil & 3,214 & 2.5 & 472 & 66.4 & 21.4 & 78 & na & 29 & 15 \\
\hline Penu & 2,139 & 3.4 & 55.5 & 66.7 & 225 & 71 & 67 & 37 & 13 \\
\hline Colombia & 1,442 & 3.0 & 352 & 68.6 & 21.1 & 72 & 72 & 45 & 14 \\
\hline Dominican Rep. & 1,104 & 3.1 & 42.0 & 69.6 & 212 & 57 & 47 & 32 & 22 \\
\hline Guatemala & 964 & 5.4 & 51.1 & 62.6 & 24.5 & 39 & 23 & na & 26 \\
\hline Bolivia & 892 & 4.8 & 75.1 & 59.3 & 224 & 60 & 34 & na & 14 \\
\hline
\end{tabular}

Sourœ: a-CEPAL, 1999, Panorama Social 1998; b-CEADE, 1999, Boletín Demográíio №. 63; c-Population Acion Intemational, 1998; d- PNUD, 1998, Desarnollo Humano.

TFR= Total Fertility Rate $\quad$ IMR = Infant Mortally Rate (per thousand)

ISES= Index of secondary school enrollment $\quad$ IDH = indice de Desandlo Humano $\quad \% H H$ bel $\mathrm{PL}=\%$ households below Poverly Line

$\%$ Addlesc $=\% 10-19$ años

Table 2: Teenage fertility indicators by country

\begin{tabular}{|c|c|c|c|c|c|c|}
\hline \multirow[b]{2}{*}{ Country } & \multirow[b]{2}{*}{ Year } & \multirow[b]{2}{*}{ Fertiliv rate $^{\star}$} & \multicolumn{2}{|c|}{ Women Aged 15} & \multicolumn{2}{|c|}{ Women Aged 15-19 } \\
\hline & & & $\%$ Mothers & Mean \# CEB & $\%$ Mothers & Mean \# CEB \\
\hline Peru & 1996 & 75 & 1.7 & 0.016 & 10.9 & 0.131 \\
\hline Bolivia & 1998 & 84 & 2.5 & 0.031 & 11.5 & 0.152 \\
\hline Brazil & 1996 & 86 & 3.1 & 0.033 & 14.3 & 0.176 \\
\hline Colombia & 1995 & 89 & 3.1 & 0.033 & 13.5 & 0.164 \\
\hline Guatemala & 1995 & 126 & 2.7 & 0.027 & 17.5 & 0.228 \\
\hline Dominican Rep. & 1996 & 112 & 3.3 & 0.031 & 18.3 & 0.239 \\
\hline
\end{tabular}

${ }^{*}$ Per thousand. Refers to 3 years before the survey

Table 3: Distribution of adolescents by marital status, by area of residence Selected LAC countries

(Percentage)

\begin{tabular}{|c|c|c|c|c|c|c|}
\hline Country & Area & $\begin{array}{l}\text { Never } \\
\text { married }\end{array}$ & Married & $\begin{array}{l}\text { Living- } \\
\text { together }\end{array}$ & $\begin{array}{c}\text { Separated } \\
\text { Divorced }\end{array}$ & Total \\
\hline \multirow[t]{2}{*}{ Peru } & Urban & 91.6 & 1.4 & 6.5 & 0.5 & 100.0 \\
\hline & Rural & 75.3 & 5.1 & 18.8 & 0.8 & 100.0 \\
\hline \multirow[t]{2}{*}{ Bolivia } & Urban & 90.4 & 2.4 & 5.5 & 1.7 & 100.0 \\
\hline & Rural & 79.8 & 3.8 & 15.1 & 1.3 & 100.0 \\
\hline \multirow[t]{2}{*}{ Brazil } & Urban & 85.0 & 6.1 & 6.0 & 2.9 & 100.0 \\
\hline & Rural & 75.8 & 10.5 & 10.1 & 3.6 & 100.0 \\
\hline \multirow[t]{2}{*}{ Colombia } & Urban & 85.3 & 2.2 & 9.4 & 3.1 & 100.0 \\
\hline & Rural & 77.5 & 3.3 & 16.3 & 2.9 & 100.0 \\
\hline \multirow[t]{2}{*}{ Guatemala } & Urban & 84.4 & 6.4 & 7.1 & 2.1 & 100.0 \\
\hline & Rural & 70.9 & 10.9 & 16.4 & 1.8 & 100.0 \\
\hline \multirow[t]{2}{*}{ Domin.Rep. } & Urban & 76.1 & 3.0 & 15.0 & 5.9 & 100.0 \\
\hline & Bural & 62.1 & 2.7 & 27.6 & 7.6 & 100.0 \\
\hline
\end{tabular}


Table 4. Teenage fertilitv and the chanqe explained bv changes in exposure-time by area of residence and country

\begin{tabular}{|c|c|c|c|c|c|c|c|c|}
\hline \multirow{2}{*}{$\begin{array}{l}\text { Country } \\
\text { Area } \\
\end{array}$} & \multicolumn{2}{|c|}{$\begin{array}{c}\% \text { child born by } \\
\text { age } 20\end{array}$} & \multicolumn{2}{|c|}{$\begin{array}{c}\% \text { Ever-married by } \\
\text { age } 20\end{array}$} & \multicolumn{2}{|c|}{$\begin{array}{c}\% \text { Intercourse by } \\
\text { age } 20\end{array}$} & \multicolumn{2}{|c|}{$\begin{array}{c}\text { Exposure-time } \\
\text { contribution }\end{array}$} \\
\hline & $f(40-44)$ & $f(20-24)$ & $m(40-44)$ & $\mathrm{m}(20-24)$ & $\mathrm{i}(40-44)$ & $i(20-24)$ & $\mathrm{Cm}$ & $\mathrm{Ci}$ \\
\hline \multicolumn{9}{|l|}{ URBAN } \\
\hline Peru & 0.321 & 0.250 & 0.378 & 0.305 & 0.538 & 0.464 & 0.432 & 0.298 \\
\hline Bolivia & 0.308 & 0.304 & 0.413 & 0.335 & 0.534 & 0.472 & 0.026 & 0.015 \\
\hline Brazil & 0.273 & 0.302 & 0.376 & 0.374 & 0.364 & 0.555 & $-0,004$ & 0.358 \\
\hline Colombia & 0.314 & 0.315 & 0.386 & 0.372 & 0.396 & 0.549 & $-0,001$ & 0.010 \\
\hline Guatemala & 0.378 & 0.356 & 0.477 & 0.471 & 0.486 & 0.439 & 0.010 & 0.082 \\
\hline Domin.Rep. & 0.391 & 0.330 & 0.524 & 0.467 & 0.417 & 0.431 & 0.253 & $-0,073$ \\
\hline \multicolumn{9}{|l|}{ RURAL } \\
\hline Peru & 0.475 & 0.541 & 0.545 & 0.597 & 0.697 & 0.704 & 0.305 & 0.033 \\
\hline Bolivia & 0.341 & 0.544 & 0.459 & 0.534 & 0.544 & 0.635 & 1.341 & 1.370 \\
\hline Brazil & 0.348 & 0.408 & 0.460 & 0.449 & 0.357 & 0.442 & $-0,055$ & 0.484 \\
\hline Colombia & 0.417 & 0.493 & 0.495 & 0.543 & 0.493 & 0.655 & 0.319 & 0.984 \\
\hline Guatemala & 0.521 & 0.550 & 0.671 & 0.628 & 0.553 & 0.519 & $-0,103$ & $-0,099$ \\
\hline Doming.Rep. & 0.544 & 0.528 & 0.698 & 0.677 & 0.506 & 0.504 & 0.026 & 0.003 \\
\hline
\end{tabular}

Table 5. Estimated coefficients from a Loait Model for teenaae fertilitv

\begin{tabular}{|c|c|c|c|c|c|c|c|}
\hline Variable & Total & Bolivia & Brasil & Colombia & Domin.Rep & Guatemala & Perú \\
\hline Age & $0.3102^{* * *}$ & 0.2819 & 0.2356 & 0.1593 & $0.6357^{* * *}$ & $0.4491^{* *}$ & $0.3580^{* *}$ \\
\hline Education & $-0.0615^{* * *}$ & .0118 & $-0.1548 * *$ & .0008 & & $0.0731^{* \star *}$ & $-0.2340^{* * \star}$ \\
\hline Married & $2.6178^{* \star *}$ & $2.2330^{* * *}$ & $2.5733^{* \star *}$ & $2.6364^{* * *}$ & $2.1861^{* \star *}$ & $2.1928^{* * *}$ & $3.2001^{* * *}$ \\
\hline Exposure time & $1.2374^{* * *}$ & 1.6455 *** & $1.0005^{* * *}$ & $0.9235^{* * *}$ & $1.2643^{* * *}$ & $2.1643^{* * *}$ & $1.2394^{* * *}$ \\
\hline Unmet Need of F.P. & 0.0243 & $0.2958^{* * *}$ & -0.0193 & $0.3432^{* * *}$ & $0.5229 * * *$ & -0.0429 & $-0.5164 *$ \\
\hline ailability & $-0.1951 * *$ & $-0.2051^{* * *}$ & $-0.5792 * *$ & $-0.6148 * * *$ & -0.0428 & 60 ** & -0.0746 \\
\hline Hh Appliances (refrigerator) & $-0.3245 * *$ & $-0.7049^{* * *}$ & 0.1489 & $-0.8031 * *$ & $-0.7197 *$ & $-0.6569^{* * *}$ & 0.3252 \\
\hline Regional Fertility Rate & 0.0520 ** & $0.1738^{* * *}$ & 0.2449 ** & -0.0018 & 0.2226 *** & 0.0177 & $0.0791 *$ \\
\hline Regional Use of any Method & $-0.0039 * * *$ & -0.0595 ** & 0.0105 & 0.0160 & $-0.0300^{* * *}$ & $-0.0867^{* * *}$ & $-0.0293^{* * \star}$ \\
\hline Regional Unmeet Need F.P. & $-0.0739 * * *$ & $-0.1447^{\star * *}$ & $-0.1351 * * \star$ & -0.0097 & $-0.1144^{* * *}$ & $-0.0590 * *$ & $-0.1021^{\star \star \star *}$ \\
\hline Constant & $-9.1208 * * *$ & $-9,4415 * *$ & $-8.6572 * *$ & $-6.1695 * *$ & $-16.1065 * * *$ & $-12.7682 * * *$ & $-9.0242^{* * *}$ \\
\hline
\end{tabular}

\begin{tabular}{|c|c|c|c|c|c|c|c|}
\hline Variable & Total & Bolivia & Brasil & Colombia & Domin.Rep & Guatemala & Perú \\
\hline Age & 0.2180 ** & -0.1053 & -0.1031 & -0.1737 & $0.7533^{* *}$ & $0.3159^{* \star \star}$ & 0.3904 ** \\
\hline Education & -0 & 01 * & $-0.1483^{* * *}$ & $-0.0653^{* * *}$ & & & $-0.0328^{* * *}$ \\
\hline Married & $2.6884^{* * *}$ & $2.7378^{* * *}$ & $2.5606^{* * *}$ & $2.1835^{* * *}$ & $2.6685^{* * *}$ & $2.6042^{* * *}$ & $3.1859^{* * *}$ \\
\hline Exposure time & $0.8697^{\star * *}$ & $0.9079 * * *$ & $0.7346^{\star \star *}$ & $0.9530^{* \star *}$ & 0.7224 *** & $1.4928^{* \star \star}$ & $0.8040^{* * *}$ \\
\hline Unmet Need of F.P. & $0.2153 *$ & $0.6791 * *$ & $0.1086 *$ & $0.4125^{* \star *}$ & $0.2762 * *$ & $0.4345^{\star * *}$ & -0.3551 \\
\hline Water Availability & 0.0529 & 0.0728 & 0.5128 * & $-0.4040^{* * *}$ & 0.1618 & -0.0837 * & 0.1075 \\
\hline Hh Appliances (refrigerator) & $-0.5366^{* * *}$ & 0.1265 & $-0.6898 * *$ & $-0.6254 * *$ & $-0.7418 * *$ & $-0.3537^{* * *}$ & $-0.3958 *$ \\
\hline Regional Fertility Rate & 0.0279 *** & $0.0662 * * *$ & 0.0858 & 0.0496 ** & -0.0032 & -0.0419 & $0.0576^{* * *}$ \\
\hline Regional Use of any Method & $-0.0041 *$ & $-0.0321^{* * *}$ & $-0.0028 *$ & $-0.0079 *$ & 0.0651 & 0.0748 & $-0.0265 * *$ \\
\hline Regional Unmeet Need F.P. & $-0.0332 * *$ & -0.0672 ** & $-0.1082^{* * *}$ & -0.0917 * & 0.0271 & $0.1387^{* *}$ & $-0.0626 *$ \\
\hline Constant & $-7.8218^{* * *}$ & -1.5572 & -2.2274 & 0.1333 & $-19.7249 * * *$ & $-11.0593 * *$ & $-11.1065^{* * *}$ \\
\hline
\end{tabular}

Source: DHS, Author's Calculation 
Table 6. Estimated coefficients from multilevel models for teenage fertility

\begin{tabular}{|c|c|c|c|c|c|c|c|}
\hline \multirow{2}{*}{$\frac{\text { Variable }}{\text { Constant }}$} & \multicolumn{2}{|c|}{$\begin{array}{l}\text { Loqit } \\
15-17 \\
\end{array}$} & \multicolumn{2}{|c|}{$\begin{array}{l}\text { Loqit } \\
18-19 \\
\end{array}$} & \multirow{2}{*}{$\begin{array}{l}\text { Loqit }^{a} \\
18-19 \\
\begin{array}{c}-7.504 \\
-4.18\end{array}\end{array}$} & \multicolumn{2}{|c|}{$\begin{array}{c}\text { Poisson } \\
18-19 \\
\end{array}$} \\
\hline & $\begin{array}{c}-8.967 \\
-7.59\end{array}$ & $+u_{1 i}$ & $\begin{array}{c}-7.359 \\
-4.14\end{array}$ & $+u_{1 i}$ & & $\begin{array}{c}-4.218 \\
-7.40\end{array}$ & $+\mathrm{u}_{1 \mathrm{i}}$ \\
\hline Education & $\begin{array}{c}-0.057 \\
-2.71\end{array}$ & & $\begin{array}{c}-0.054 \\
-2.70\end{array}$ & $+\mathrm{u}_{2 \mathrm{i}}$ & $\begin{array}{l}-0.052+u_{2 i} \\
-2.74\end{array}$ & $\begin{array}{c}-0.024 \\
-4.00\end{array}$ & $+\mathrm{u}_{2 \mathrm{i}}$ \\
\hline Age & $\begin{array}{c}0.299 \\
4.10\end{array}$ & $+\mathrm{u}_{3 \mathrm{i}}$ & $\begin{array}{c}0.199 \\
2.07\end{array}$ & & $\begin{array}{r}0.205 \\
2.11\end{array}$ & $\begin{array}{c}0.067 \\
2.16\end{array}$ & \\
\hline Married & $\begin{array}{l}2.646 \\
21.17\end{array}$ & & $\begin{array}{l}2.672 \\
25.69\end{array}$ & & $\begin{array}{r}2.702 \\
25.25\end{array}$ & $\begin{array}{l}2.080 \\
36.49\end{array}$ & \\
\hline Exposure Time & $\begin{array}{l}1.228 \\
22.33\end{array}$ & & $\begin{array}{l}0.857 \\
23.81\end{array}$ & & $\begin{array}{r}0.874 \\
24.28\end{array}$ & $\begin{array}{l}0.272 \\
30.22\end{array}$ & \\
\hline Unmet Need of Family planning & $\begin{array}{c}0.057 \\
3.75\end{array}$ & & $\begin{array}{c}0.196 \\
4.56\end{array}$ & & $\begin{array}{r}0.207 \\
1.45\end{array}$ & $\begin{array}{c}0.074 \\
2.00\end{array}$ & \\
\hline Water Availability & $\begin{array}{c}-0.190 \\
-1.64\end{array}$ & & $\begin{array}{c}\mathbf{0 . 0 9 4} \\
0.90\end{array}$ & & $\begin{array}{r}\mathbf{0 . 1 0 7} \\
1.03\end{array}$ & $\begin{array}{c}\mathbf{0 . 0 2 6} \\
0.81\end{array}$ & \\
\hline Household Appliances (refrigerator) & $\begin{array}{c}-0.347 \\
-2.53\end{array}$ & & $\begin{array}{c}-0.572 \\
-5.15\end{array}$ & & $\begin{array}{r}-0.592 \\
-5.29\end{array}$ & $\begin{array}{c}-0.189 \\
-4.73\end{array}$ & \\
\hline Regional Fertility Rate & $\begin{array}{c}0.060 \\
2.67\end{array}$ & & $\begin{array}{c}0.040 \\
6.29\end{array}$ & & $\begin{array}{r}0.038 \\
5.52\end{array}$ & $\begin{array}{c}0.010 \\
4.11\end{array}$ & \\
\hline Regional Use of any Method of F.P. & $\begin{array}{l}-0.010 \\
-1.82\end{array}$ & & $\begin{array}{c}-0.011 \\
-2.47\end{array}$ & & $\begin{array}{r}-0.010 \\
-2.33\end{array}$ & $\begin{array}{c}-0.002 \\
-4.74\end{array}$ & \\
\hline Regional Unmeet Need of F.P. & $\begin{array}{c}0.074 \\
2.74\end{array}$ & & $\begin{array}{c}0.042 \\
2.82\end{array}$ & & $\begin{array}{r}0.041 \\
2.69 \\
\end{array}$ & $\begin{array}{c}0.007 \\
1.89 \\
\end{array}$ & \\
\hline Observations & 11,386 & & 6,64 & & 6.642 & 6,64 & \\
\hline
\end{tabular}

Source: DHS. Author's Calculation

a Using 32 regions

Table 7: $\operatorname{Exp}(B)$ from multilevel models for teenaqe fertilitv

\begin{tabular}{|c|c|c|c|}
\hline & $\begin{array}{l}\text { Logit } \\
15-17\end{array}$ & $\begin{array}{l}\text { Logit } \\
18-19\end{array}$ & $\begin{array}{c}\text { Loait }^{a} \\
18-19\end{array}$ \\
\hline Constant & $1.28 \%$ & $0.06 \%$ & $0.06 \%$ \\
\hline Education & $94.46 \%$ & $94.74 \%$ & $94.93 \%$ \\
\hline Age & $134.85 \%$ & $122.02 \%$ & $122.75 \%$ \\
\hline Married ${ }^{\mathrm{b}}$ & $0.18 \%$ & $0.92 \%$ & $0.82 \%$ \\
\hline Exposure Time & $341.44 \%$ & $235.61 \%$ & $239.65 \%$ \\
\hline Unmet Need of familv plannina ${ }^{b}$ & $0.01 \%$ & $0.08 \%$ & $0.07 \%$ \\
\hline Water Availability & $82.70 \%$ & $109.86 \%$ & $111.29 \%$ \\
\hline Household Appliances (refrigerator ) & $70.68 \%$ & $56.44 \%$ & $55.32 \%$ \\
\hline Regional Fertility Rate & $106.16 \%$ & $104.06 \%$ & $103.89 \%$ \\
\hline Regional Use of any Method of F.P. & $99.00 \%$ & $98.95 \%$ & $99.02 \%$ \\
\hline Regional Unmeet Need of F.P. & $107.72 \%$ & $104.34 \%$ & $104.21 \%$ \\
\hline Observations & 11,386 & 6,642 & 6,642 \\
\hline
\end{tabular}

Source: DHS. Author's Calculation

a Using 32 reqions

${ }^{\mathrm{b}}$ Dummy variable: $\exp ($ constant+B) 
Table 8: Comparison of Models Goodness-of-fit

First birth
\begin{tabular}{|l|r|r|r|l|}
\hline Distribution & \multicolumn{1}{|c|}{ LogLik } & $\mathbf{p}$ & $\boldsymbol{c}$ & AlC \\
\hline Weibull & -540.52 & 2 & 16 & $\mathbf{1 , 1 1 7 . 0 5}$ \\
Exponential & $-1,481.33$ & 1 & 16 & $2,996.66$ \\
Gompertz & -558.89 & 2 & 16 & 1.153 .77 \\
\hline
\end{tabular}

Initial sexual intercourse

\begin{tabular}{|l|l|l|l|l|}
\hline Distribution & LogLik & $\mathbf{p}$ & $\mathbf{c}$ & AlC \\
\hline Weibull & 2 & & \\
Exponential & 1 & & \\
Gompertz & 2 & & \\
\hline
\end{tabular}

First birth among sexually active
\begin{tabular}{|l|c|c|c|c|}
\hline Distribution & LogLik & $\mathbf{p}$ & $\mathbf{c}$ & AlC \\
\hline Weibull & $-1,614.37$ & 2 & 17 & $\mathbf{3}, \mathbf{2 6 6 . 7 4}$ \\
Exponential & $-1,843.28$ & 1 & 17 & $3,722.57$ \\
Gompertz & -1.694 .40 & 2 & 17 & 3.426 .79 \\
\hline
\end{tabular}

Note: $p=$ number of model parameters

$\mathrm{C}=$ number of model covariates 
Table 9: Estimated hazard ratios from continuous-time hazard models for the risk of havina a first birth and initial sexual intercourse. Adolescent women

\begin{tabular}{|c|c|c|c|}
\hline \multirow[b]{2}{*}{ Variables } & \multicolumn{3}{|c|}{ Model (Weibull distribution) } \\
\hline & First birth & $\begin{array}{l}\text { Initial sexual } \\
\text { intercourse }\end{array}$ & $\begin{array}{c}\text { First birth among } \\
\text { sexually active }\end{array}$ \\
\hline Years of education & & & \\
\hline $0-3$ (ref) & 1.00000 & 1.00000 & 1.00000 \\
\hline $4-7$ & 0.88523 * & $0.66191^{* * *}$ & 1.09911 \\
\hline $8-10$ & $0.62338^{* \star *}$ & $0.33955^{* * *}$ & 1.05987 \\
\hline $11-13$ & $0.41801^{\star \star *}$ & $0.18009^{* * *}$ & 1.01012 \\
\hline $14-16$ & 0.40215 & $0.24811^{* * *}$ & 1.23371 \\
\hline Women's characteristics & & & \\
\hline $\begin{array}{l}\text { Urban (ref=no) } \\
\text { Age at first intercourse }\end{array}$ & 0.97284 & 1.16793 *** & $\begin{array}{l}0.99334 \\
1.00633\end{array}$ *** \\
\hline $\begin{array}{l}\text { Unmet need of family planning (ref=no) } \\
\text { Household }\end{array}$ & $1.12713 * *$ & & 0.92582 \\
\hline Has radio $(r e f=n o)$ & $0.89769 * *$ & $0.74140^{* * *}$ & 0.99741 \\
\hline Has refrigerator $(\mathrm{ref}=\mathrm{no})$ & 0.93835 & $0.68921^{* * *}$ & 0.90483 \\
\hline Sex of household head (ref=female) & $0.89389 *$ & $1.07545^{*}$ & 0.90590 \\
\hline Regional & & & \\
\hline \% women with children & $1.01731^{* * *}$ & $1.04860^{* * *}$ & 0.99289 \\
\hline$\%$ using family planning & 0.99542 & & 1.02024 \\
\hline$\%$ unmet need of family planning & 1.01404 * & & 0.98981 \\
\hline Country & & & \\
\hline Bolivia (ref) & 1.00000 & 1.00000 & 1.00000 \\
\hline Brazil & 0.96429 & $2.01854 * * *$ & $0.57940^{* \star *}$ \\
\hline Colombia & 0.78385 & $1.87716^{* * *}$ & $0.61618^{* *}$ \\
\hline Dominican Republic & $0.34284^{* * *}$ & $1.83816^{* * *}$ & $0.16356^{* \star *}$ \\
\hline Guatemala & $0.30857^{* * *}$ & $0.83490^{* * *}$ & $0.21783^{* * *}$ \\
\hline Peru & $0.66558 * *$ & 1.23680 *** & $0.69700 *$ \\
\hline Married and country interactions & & & \\
\hline Married-Bolivia (ref) (time dependent) & $48.81061^{* * *}$ & & $8.47618^{* * *}$ \\
\hline Married-Brazil & 0.63871 & & 1.842876 *** \\
\hline Married-Colombia & 0.95545 & & $2.232751^{\star * \star}$ \\
\hline Married-Dominican Republic & 2.06120 ** & & $8.865427^{\star \star *}$ \\
\hline Married-Guatemala & $2.23380^{* * *}$ & & 7.060362 *** \\
\hline Married-Peru & 1.04560 & & $1.682408^{* * *}$ \\
\hline $\operatorname{LR} x^{2}$ & $10059.16^{* * *}$ & $2291.36^{* * *}$ & $5184.43^{\star * \star}$ \\
\hline d.f. & 23 & 14 & 24 \\
\hline $\mathrm{N}$ & 18,028 & 18,013 & 4,920 \\
\hline
\end{tabular}

${ }^{*} \mathrm{p}<.05 \quad{ }^{* *} \mathrm{p}<.01{ }^{* * *} \mathrm{p}<.001$ 
Table 10: Estimated hazard ratios from continuous-time hazard models for the risk of havina a premartial birth and initial sexual intercourse. Adolescent women

\begin{tabular}{|c|c|c|c|}
\hline \multirow[b]{2}{*}{ Variables } & \multicolumn{3}{|c|}{ Model (Weibull distribution) } \\
\hline & $\begin{array}{c}\text { Premarital } \\
\text { birth }\end{array}$ & $\begin{array}{l}\text { Initial sexual } \\
\text { intercourse }\end{array}$ & $\begin{array}{l}\text { Prem. birth amona } \\
\text { sexually active }\end{array}$ \\
\hline Years of education & & & \\
\hline $0-3$ (ref) & 1.00000 & 1.00000 & 1.00000 \\
\hline $4-7$ & $0.61204^{* * \star}$ & $0.66191^{* \star *}$ & 0.94000 \\
\hline $8-10$ & 0.23256 *** & $0.33955 * * *$ & 0.71142 \\
\hline $11-13$ & 0.12259 *** & $0.18009 * * *$ & 0.64541 \\
\hline $14-16$ & 0.12336 * & $0.24811^{* * *}$ & 0.57945 \\
\hline Women's characteristics & & & \\
\hline Urban (ref=no) & 1.09528 & $1.16793^{* * *}$ & 0.87067 \\
\hline Age at first intercourse & & & $0.97230 * * *$ \\
\hline Unmet need of family planning (ref=no) & $2.53866^{\star * *}$ & & $0.57327^{* \star *}$ \\
\hline Household & & & \\
\hline Has radio (ref=no) & 0.70764 ** & $0.74140^{* * *}$ & 0.84049 \\
\hline Has refrigerator $(r e f=n o)$ & $0.65873^{* * *}$ & $0.68921^{\star * *}$ & 0.89061 \\
\hline Sex of household head (ref=female) & $0.62596^{* * *}$ & $1.07545 *$ & 0.62020 *** \\
\hline Regional & & & \\
\hline$\%$ women with children & 1.06296 *** & $1.04860^{* * *}$ & 0.98453 \\
\hline$\%$ using family planning & 0.95425 & & 1.06983 \\
\hline$\%$ unmet need of family planning & $1.04157^{\star *}$ & & 0.98280 \\
\hline Country & & & \\
\hline Bolivia (ref) & 1.00000 & 1.00000 & \\
\hline Brazil & 0.75620 & 2.01854 *** & 0.65300 * \\
\hline Colombia & 0.59581 * & $1.87716^{* * *}$ & 0.65796 \\
\hline Dominican Republic & $0.23258^{* * \star}$ & $1.83816^{* * *}$ & $0.22342^{* * *}$ \\
\hline Guatemala & $0.20527^{\star * \star}$ & $0.83490^{* * *}$ & $0.20109 * * *$ \\
\hline Peru & $0.51469^{* * *}$ & $1.23680 * * *$ & 0.71492 \\
\hline $\operatorname{LR} x^{2}$ & $410.97^{\star \star \star}$ & $2291.36^{* * *}$ & $196.49 * * *$ \\
\hline d.f. & 17 & 14 & 18 \\
\hline $\mathrm{N}$ & 18,023 & 18,013 & 4,669 \\
\hline
\end{tabular}

${ }^{*} p<.05^{* \star} p<.01{ }^{* \star *} p<.001$ 
Figure 1: Trends in age specific fertility rates. Selected LAC countries
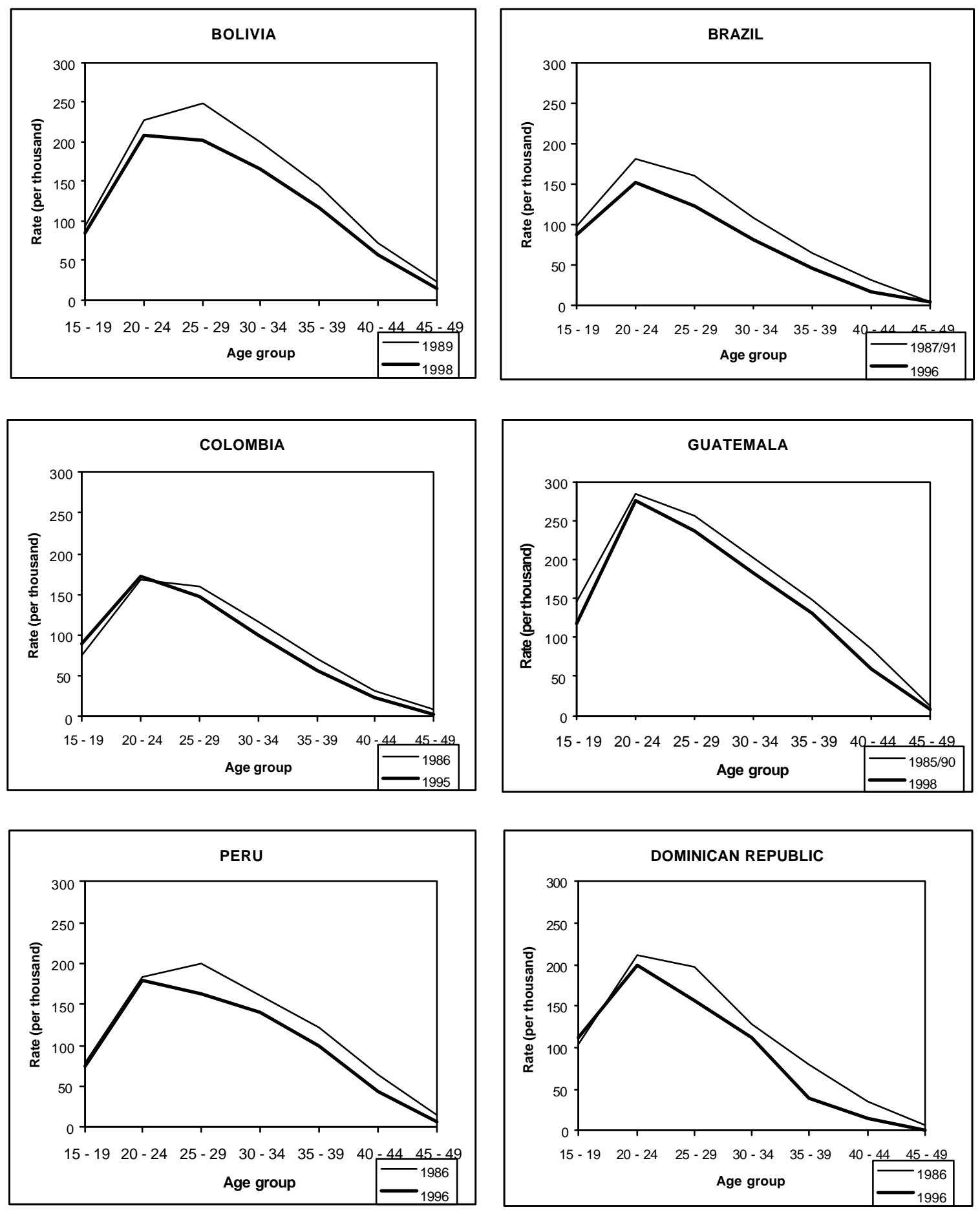
Figure 2a: Distribution of adolescents by number of children ever born at each age.

Selected LAC countries. Urban area
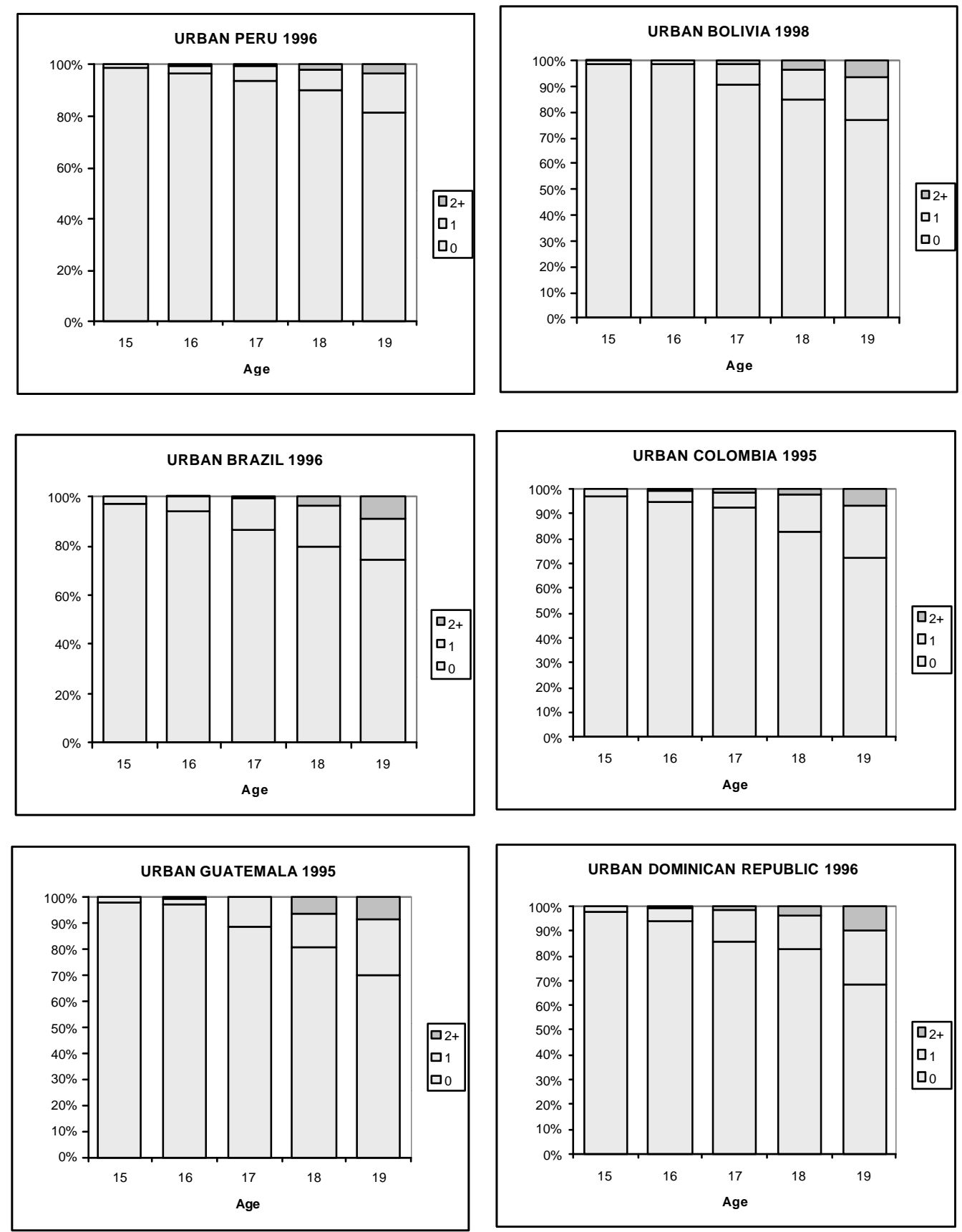
Figure 2b: Distribution of adolescents by number or children ever born at each age.

Selected LAC countries. Rural area
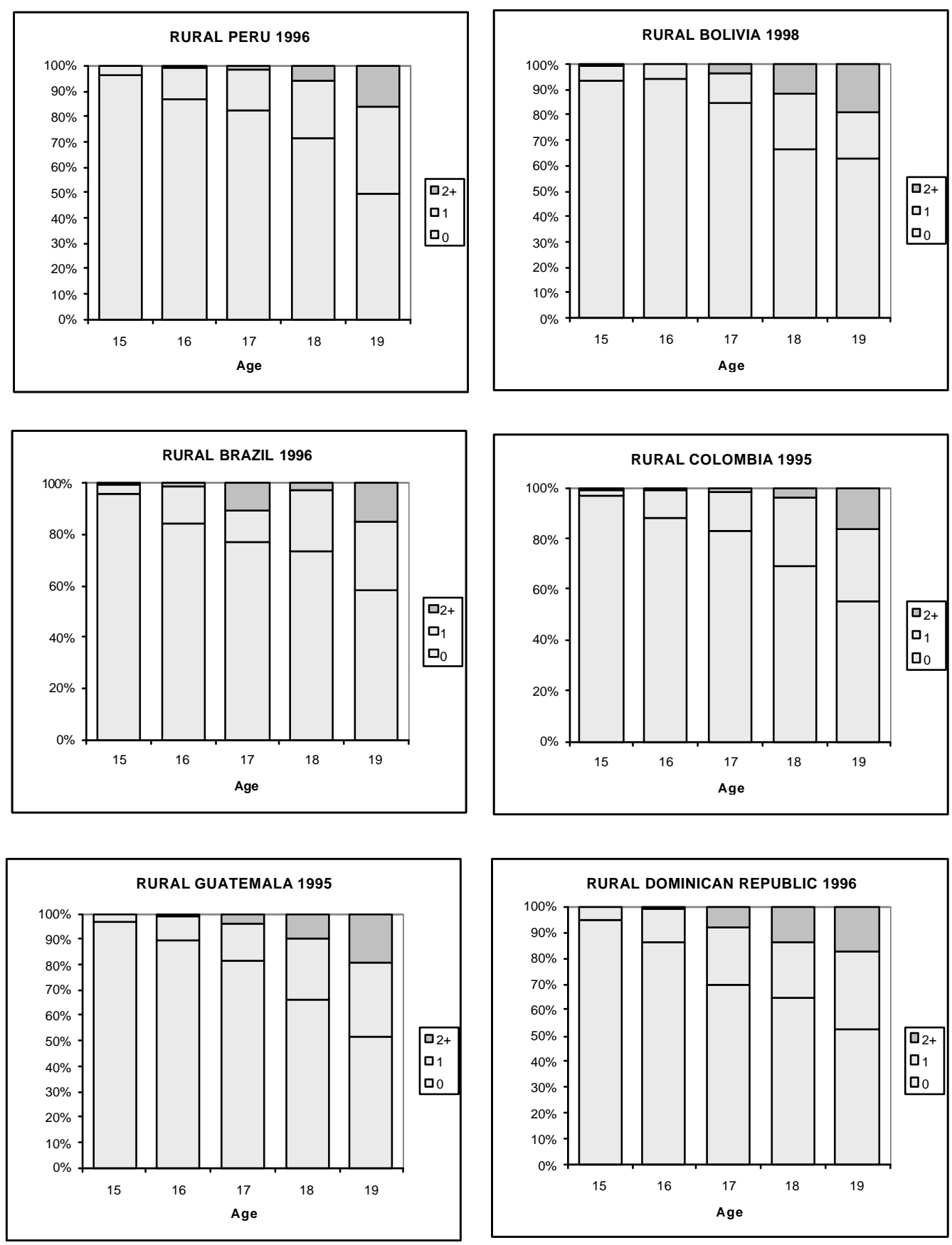


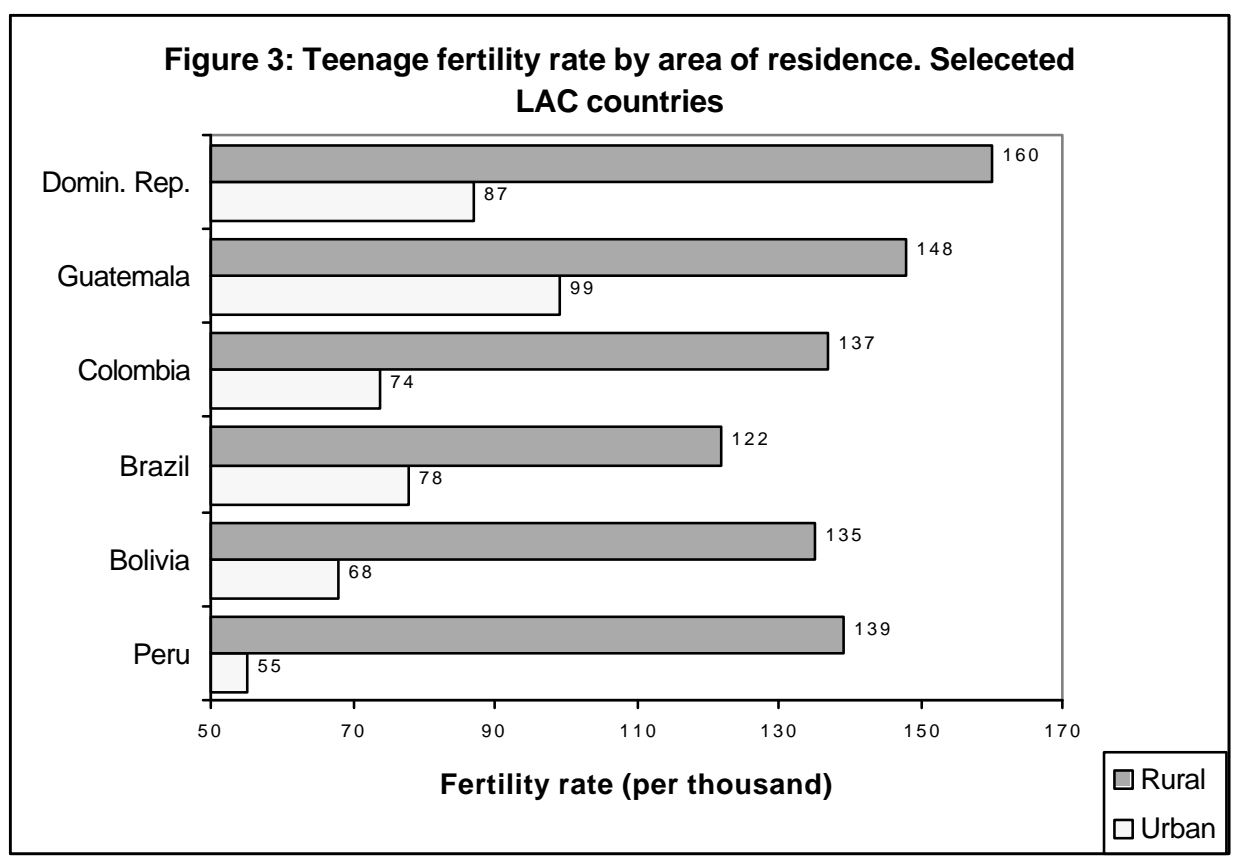


Figure 4: Proportion of adolescent mothers by region. Selected LAC countries
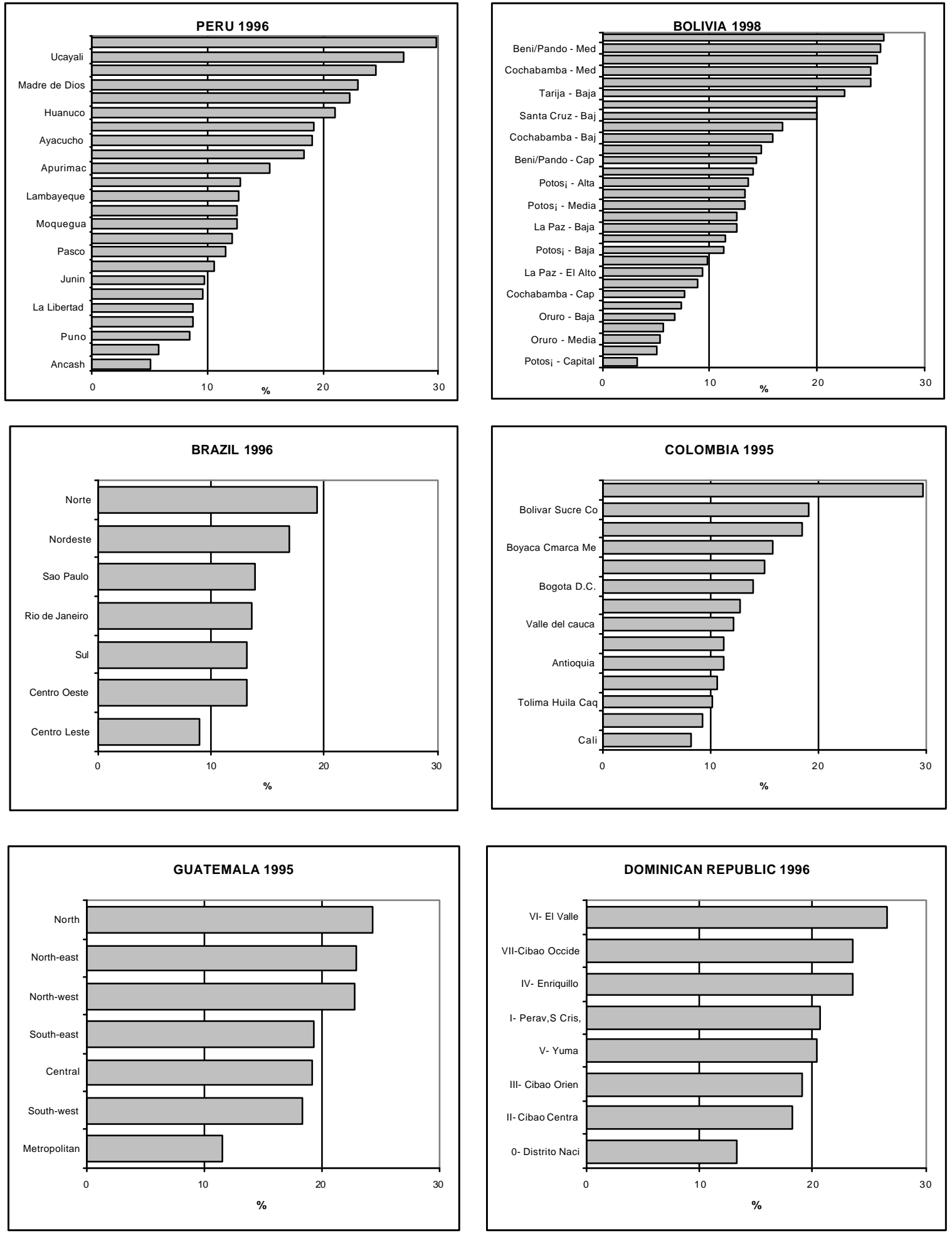
Figure 5: Proportion of adolescent mothers by level of education. Selected LAC countries
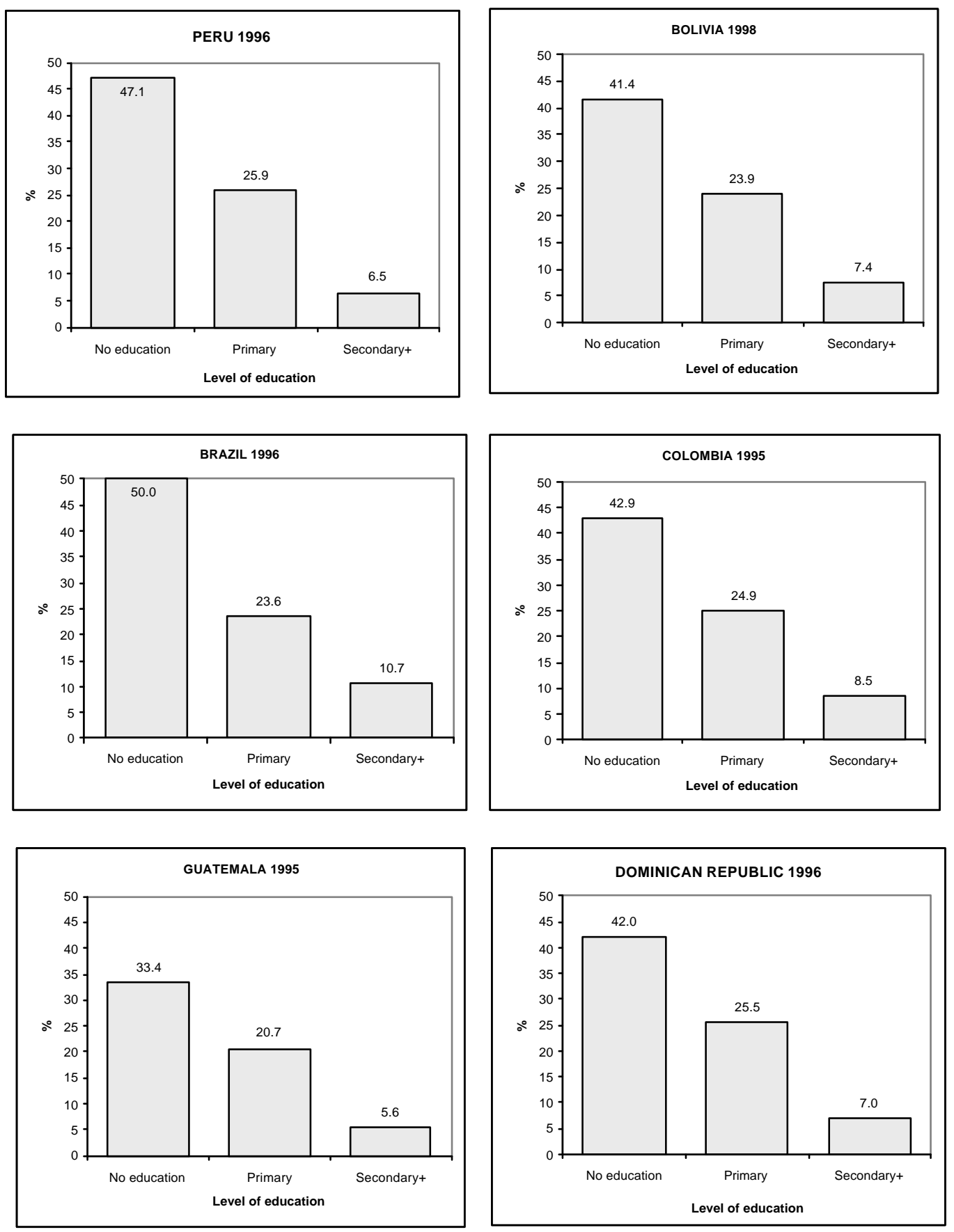
Fiqure 6a: Proportion of women with a child born bv exact aqe $\mathrm{x}$ by aqe group.

Selected LAC countries. Urban areas
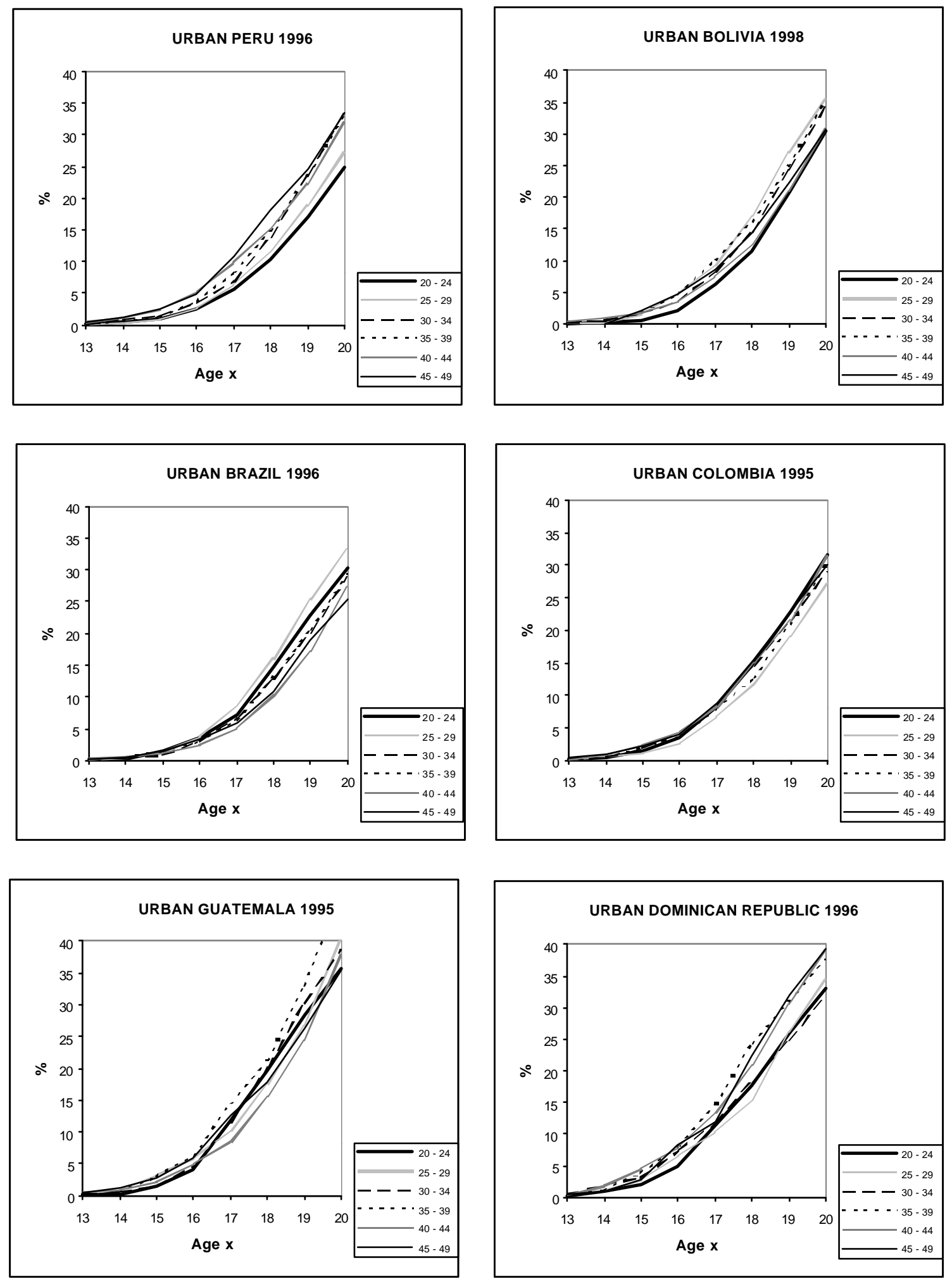
Figure 6b: Proportion of women with a child born by exact age $\mathrm{x}$ by age group. Selected LAC countries. Rural areas
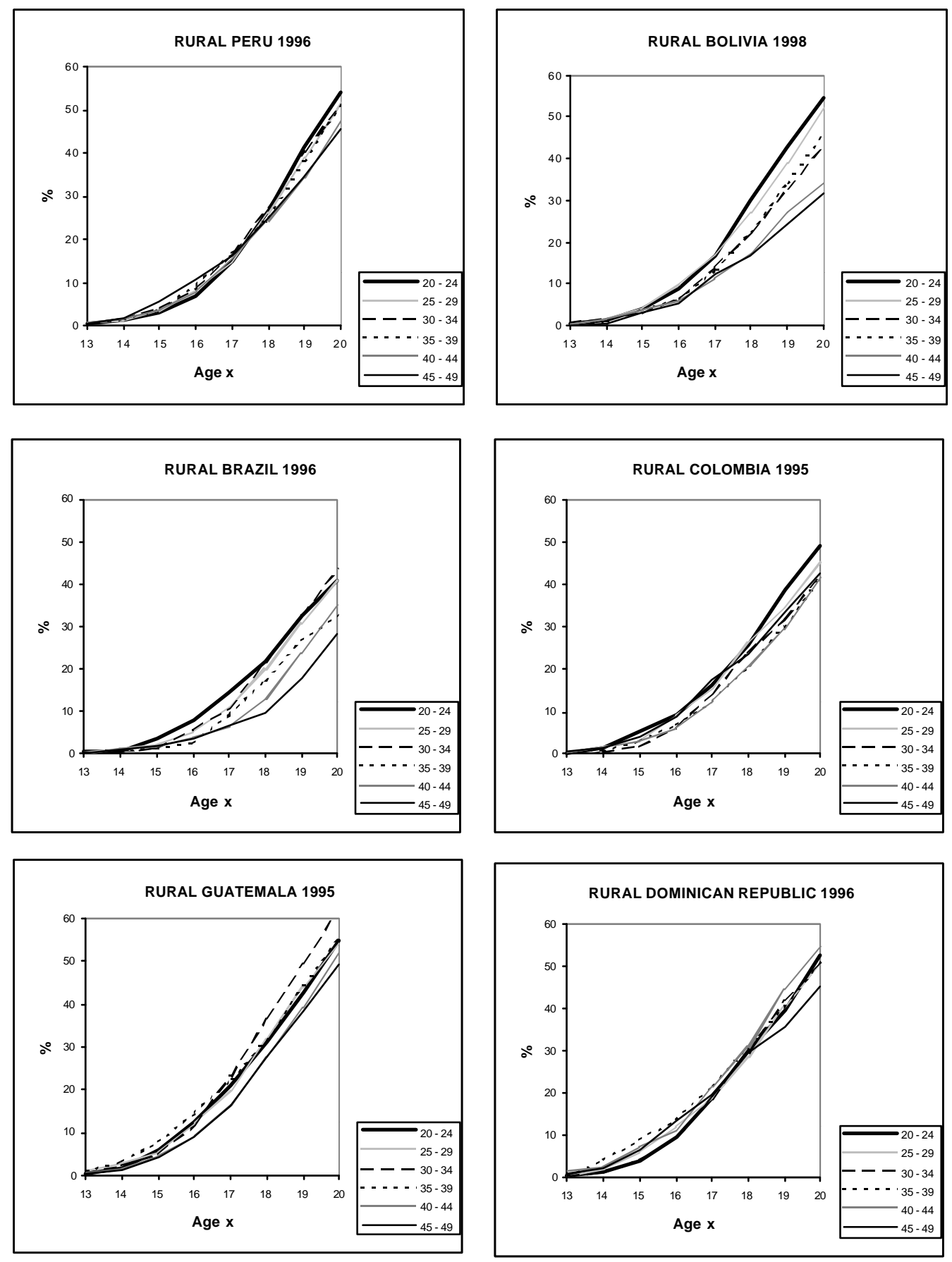
Figure 7a: Proportion of women with a child born bv exact age 16 to 20, bv age group.

Selected LAC countries. Urban areas
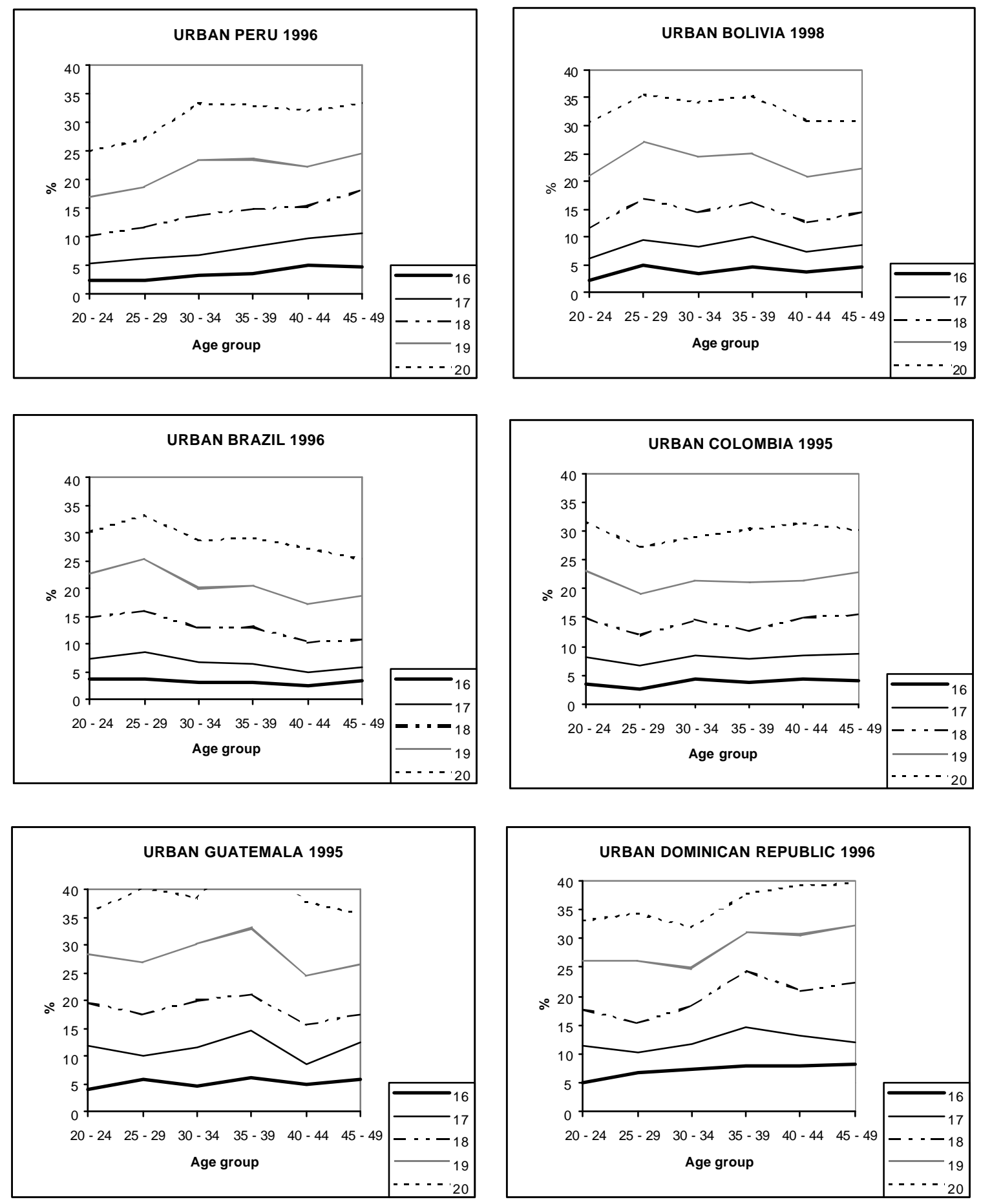
Fiqure 7b: Proportion of women with a child born by exact age 16 to 20, bv age group.

Selected LAC countries. Rural areas
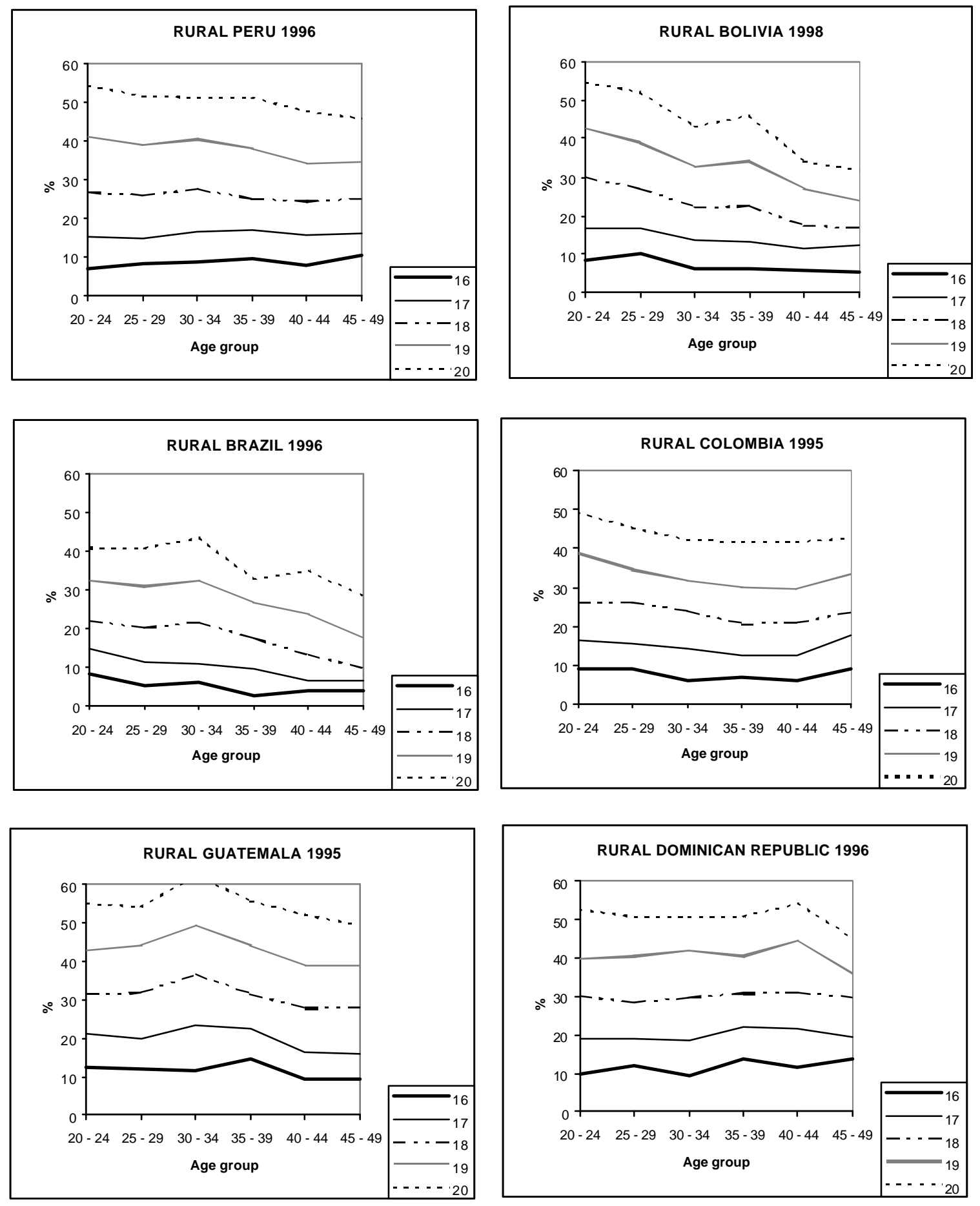
Fiqure 8: Proportion of women with a child born bv exact age 17 bv age group, bv area of residence Selected LAC countries
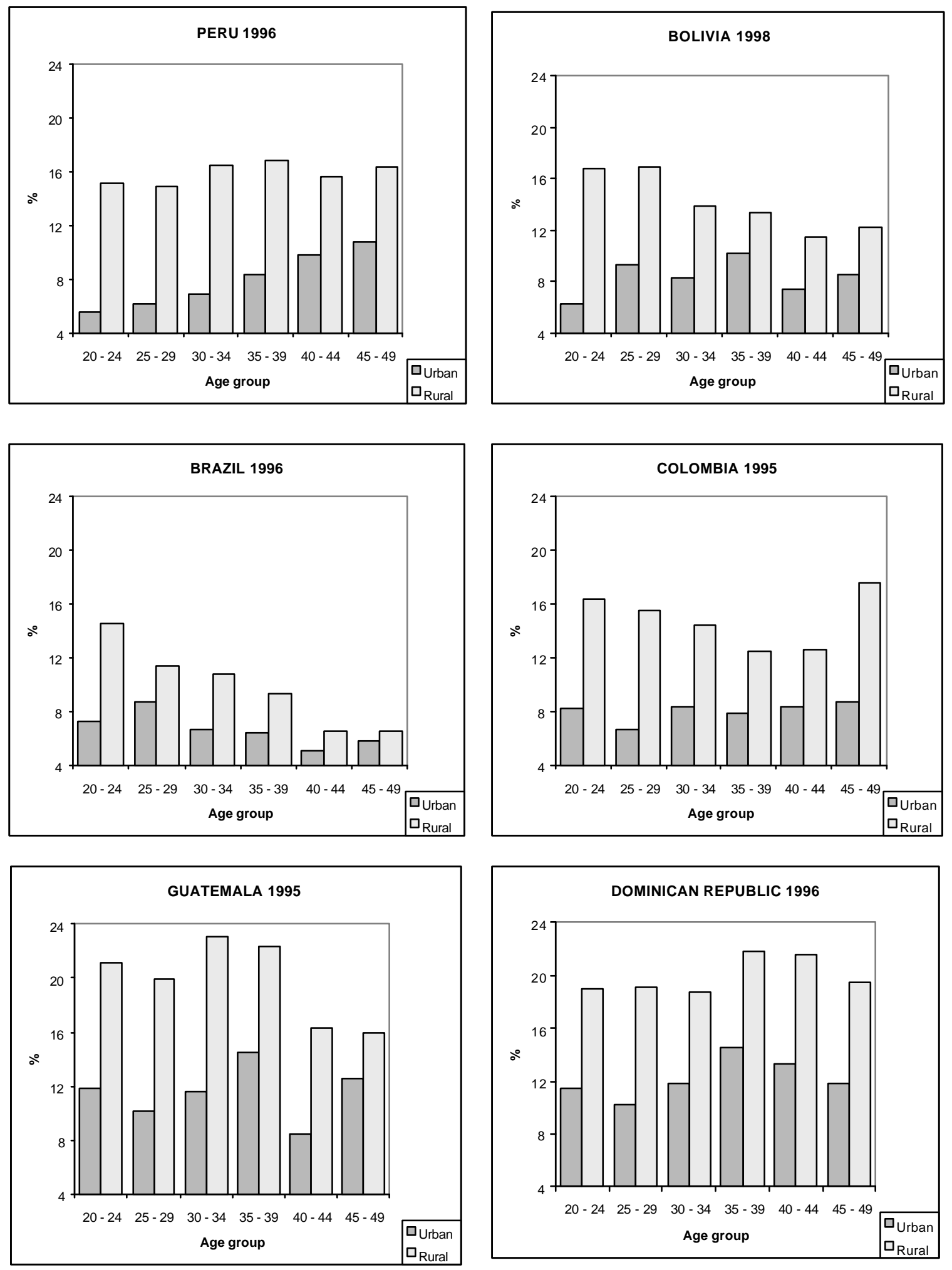
Figure 9: Proportion of women with a child born by exact age 20 by age group, by area of residence Selected LAC countries
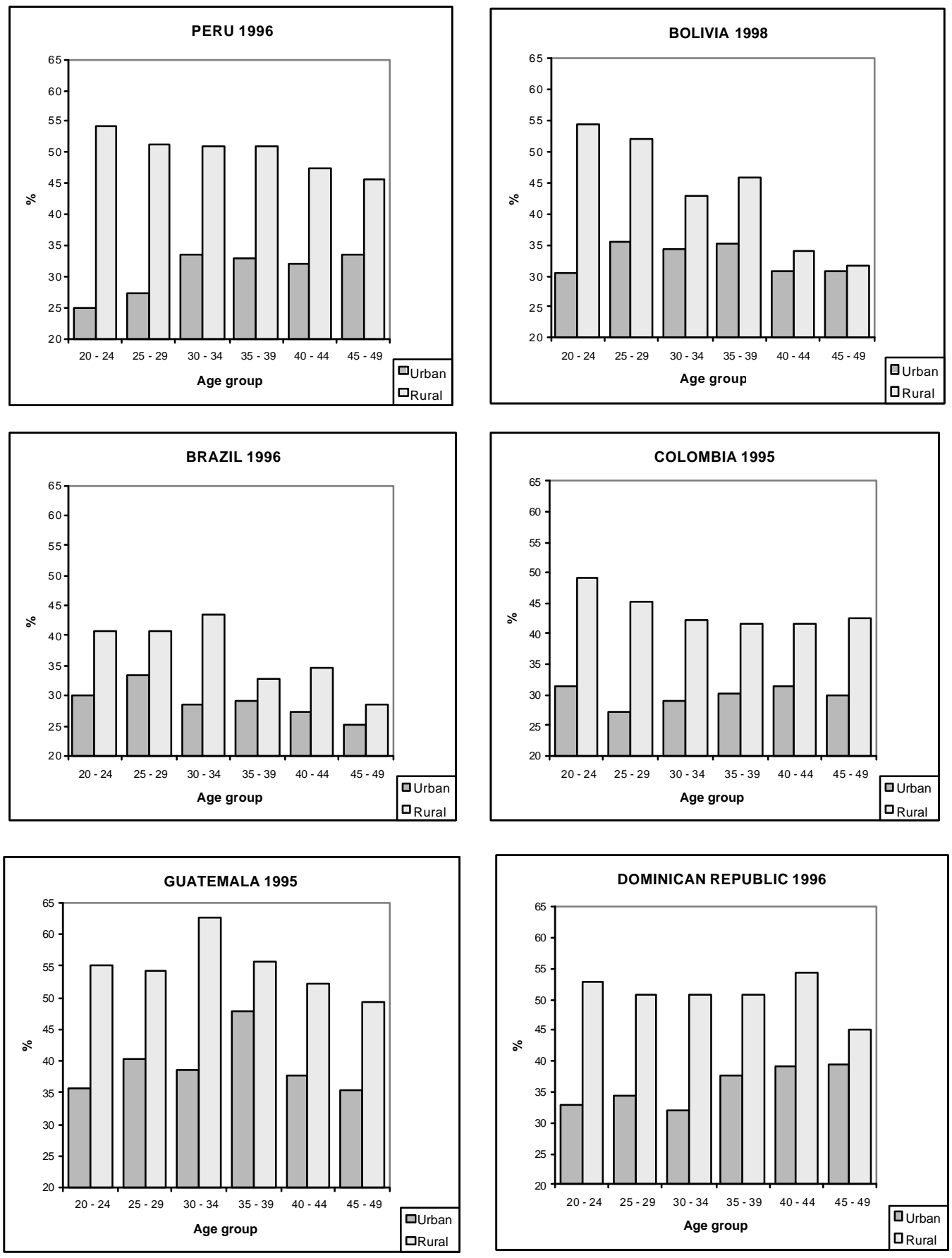


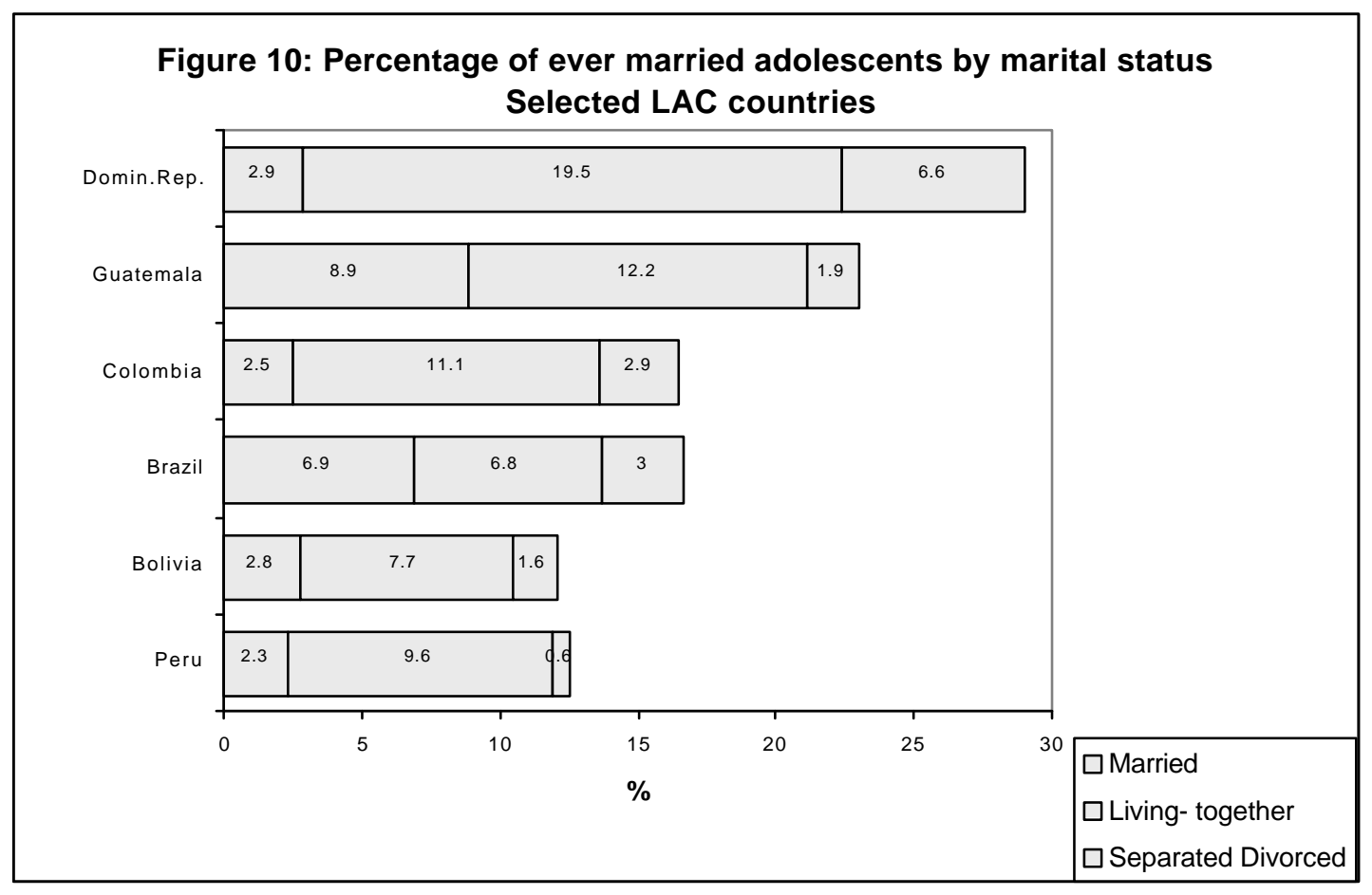


Fiqure 11: Proportion of ever married adolescents by level of education. Selected LAC countries
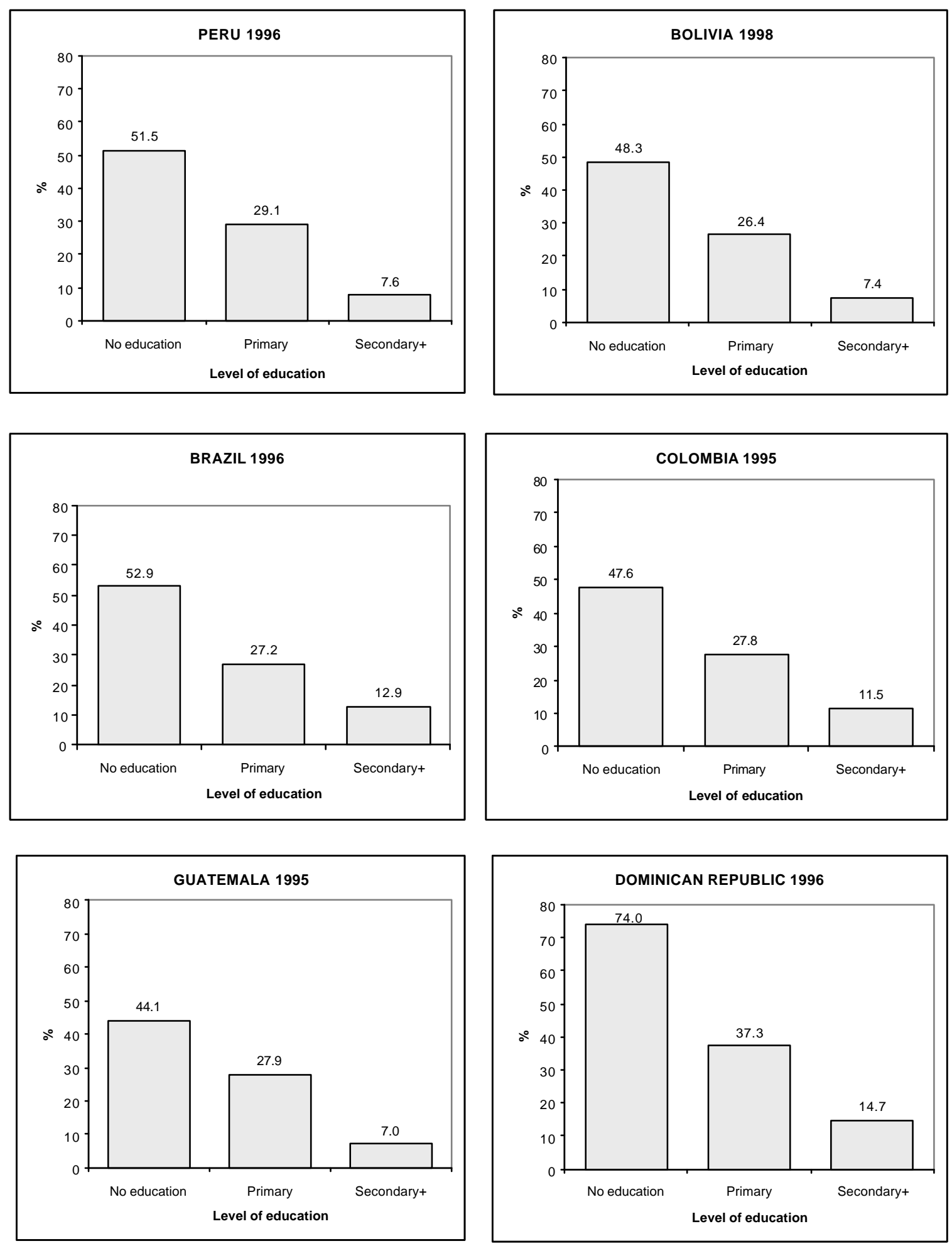
Figure 12a: Distribution of ever married adolescents by marital status by age.

Selected LAC countries. Urban areas
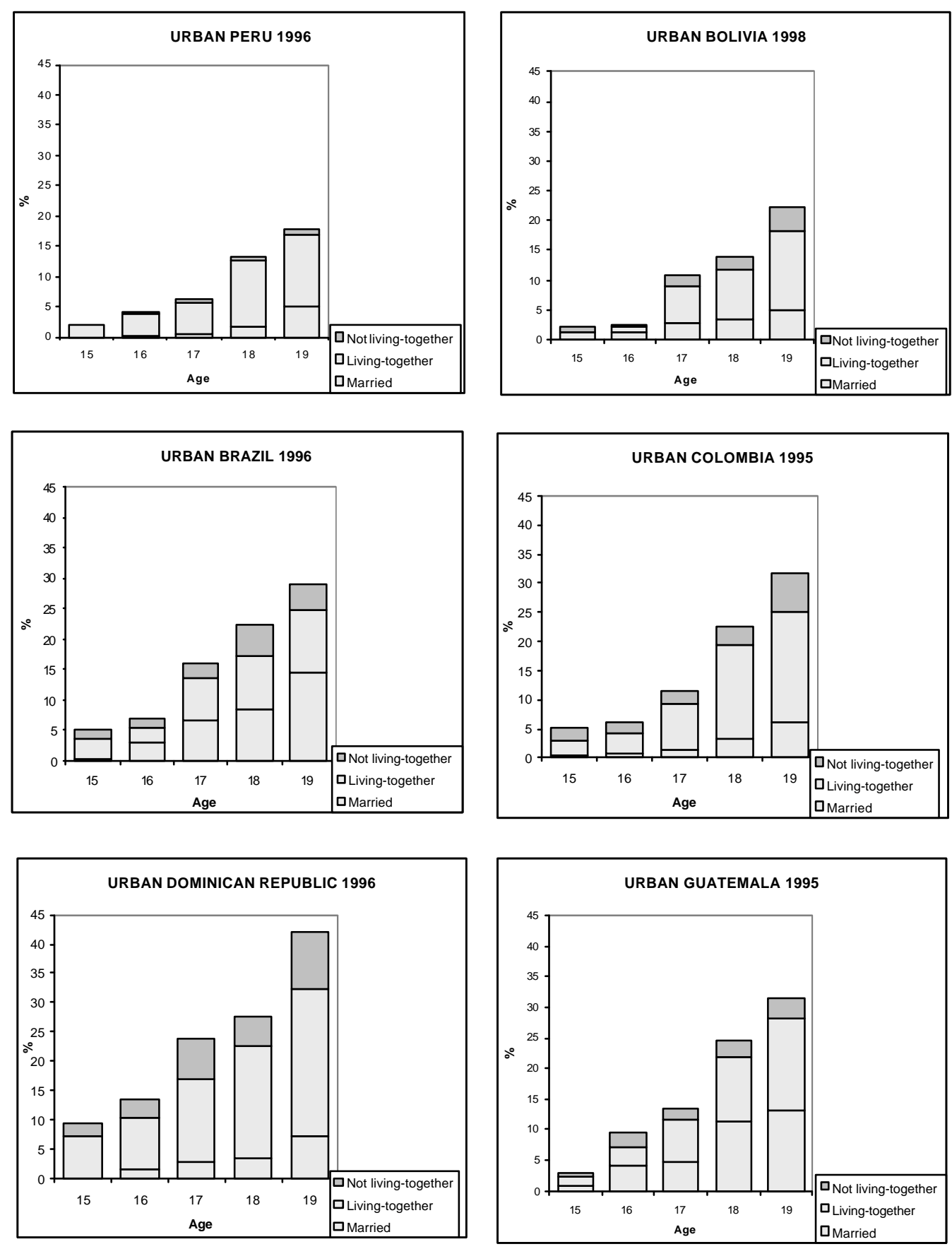
Figure 12b: Distribution of ever married adolescents by marital status by age Selected LAC countries. Rural areas
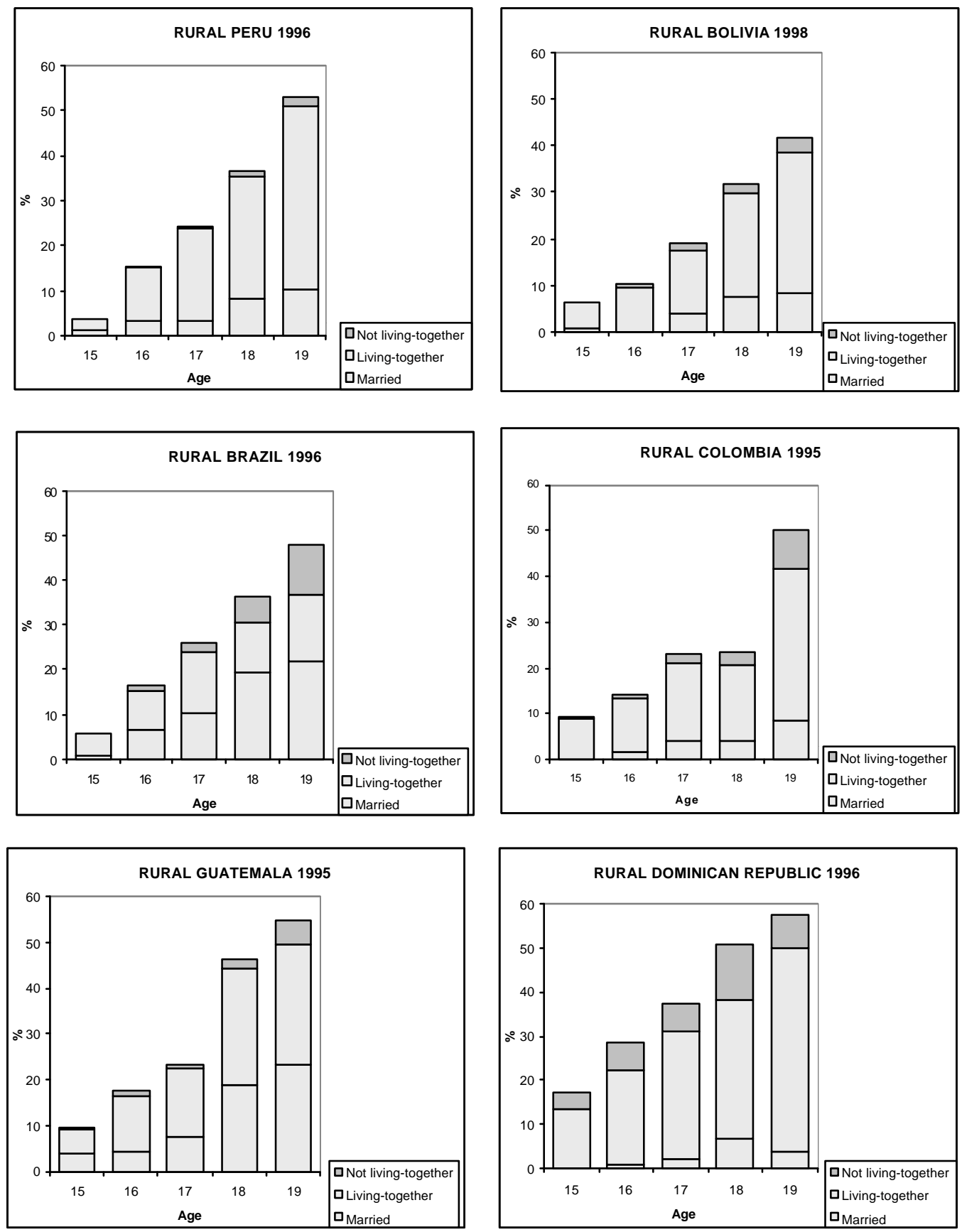
Fiqure 13a: Proportion of ever married women bv exact age $x$ bv aqe qroup Selected LAC countries. Urban areas
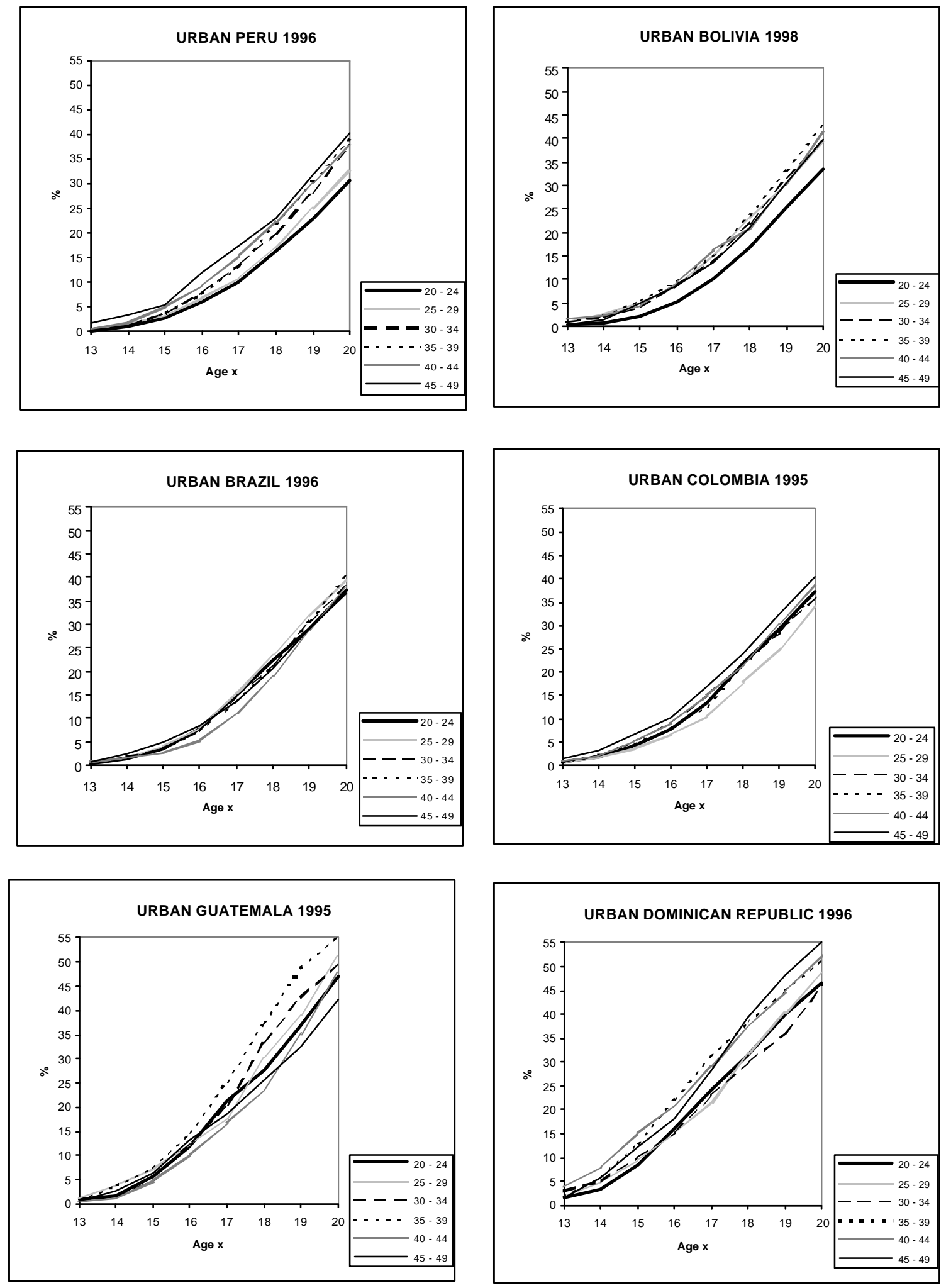
Fiqure 13b: Proportion of ever married women bv exact aqe $x$ bv aqe qroup

Selected LAC countries. Rural areas
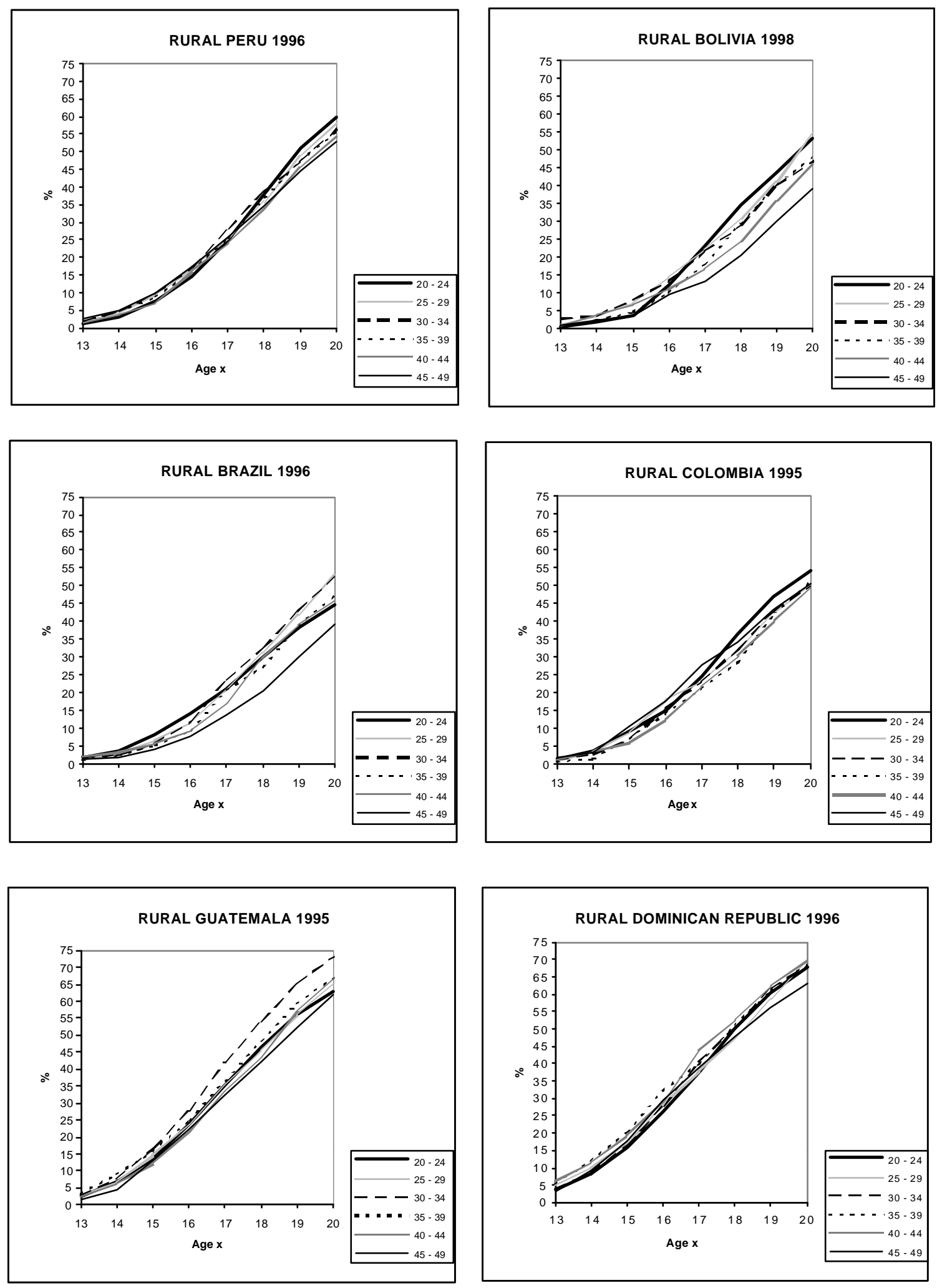
Fiqure 14a: Proportion of ever married women bv exact aqe 16 to 20 bv aqe group.

Selected LAC countries. Urban areas
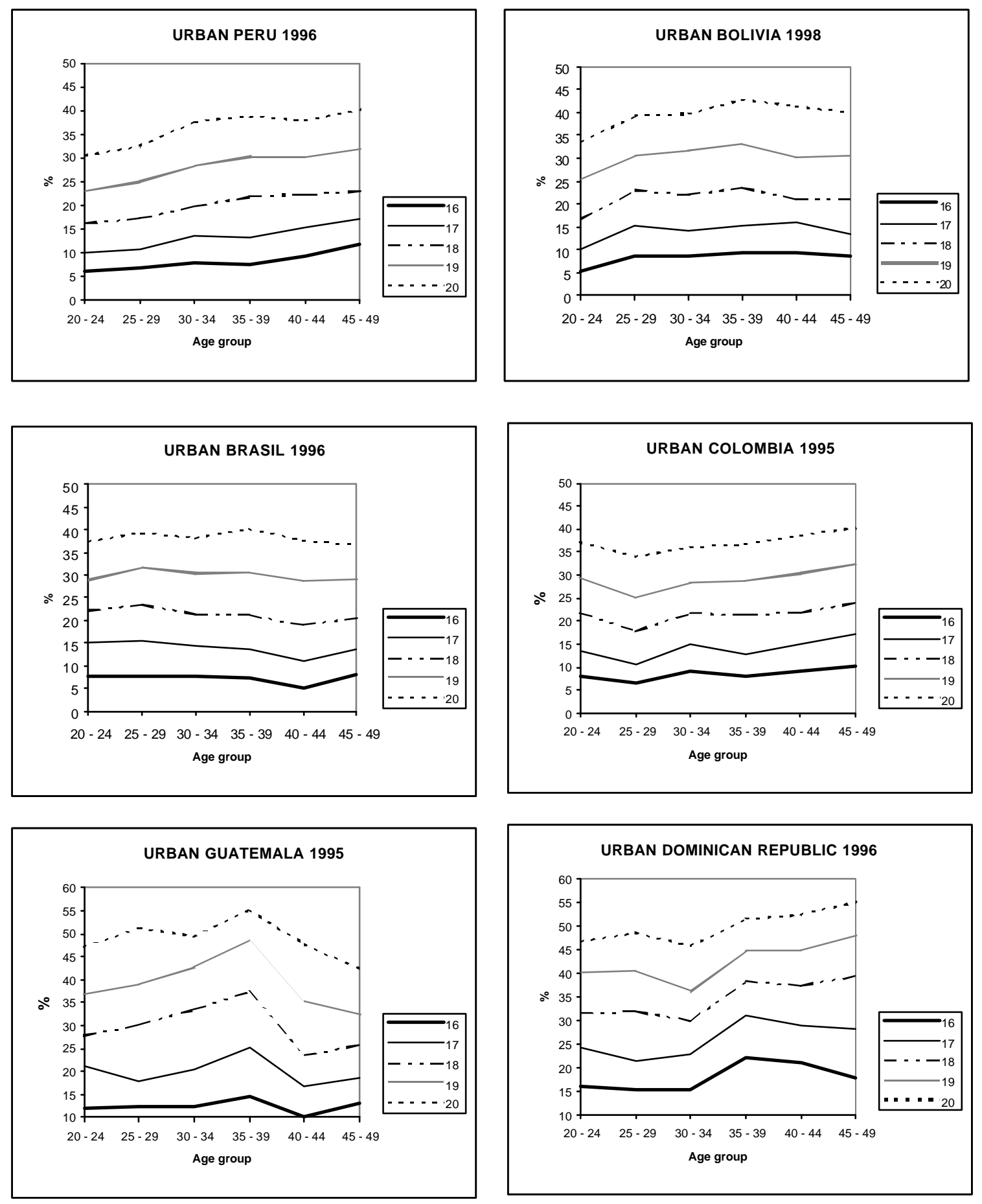
Fiqure 14b: Proportion of ever married women bv exact aqe 16 to 20 by aqe qroup.

Selected LAC countries. Rural areas
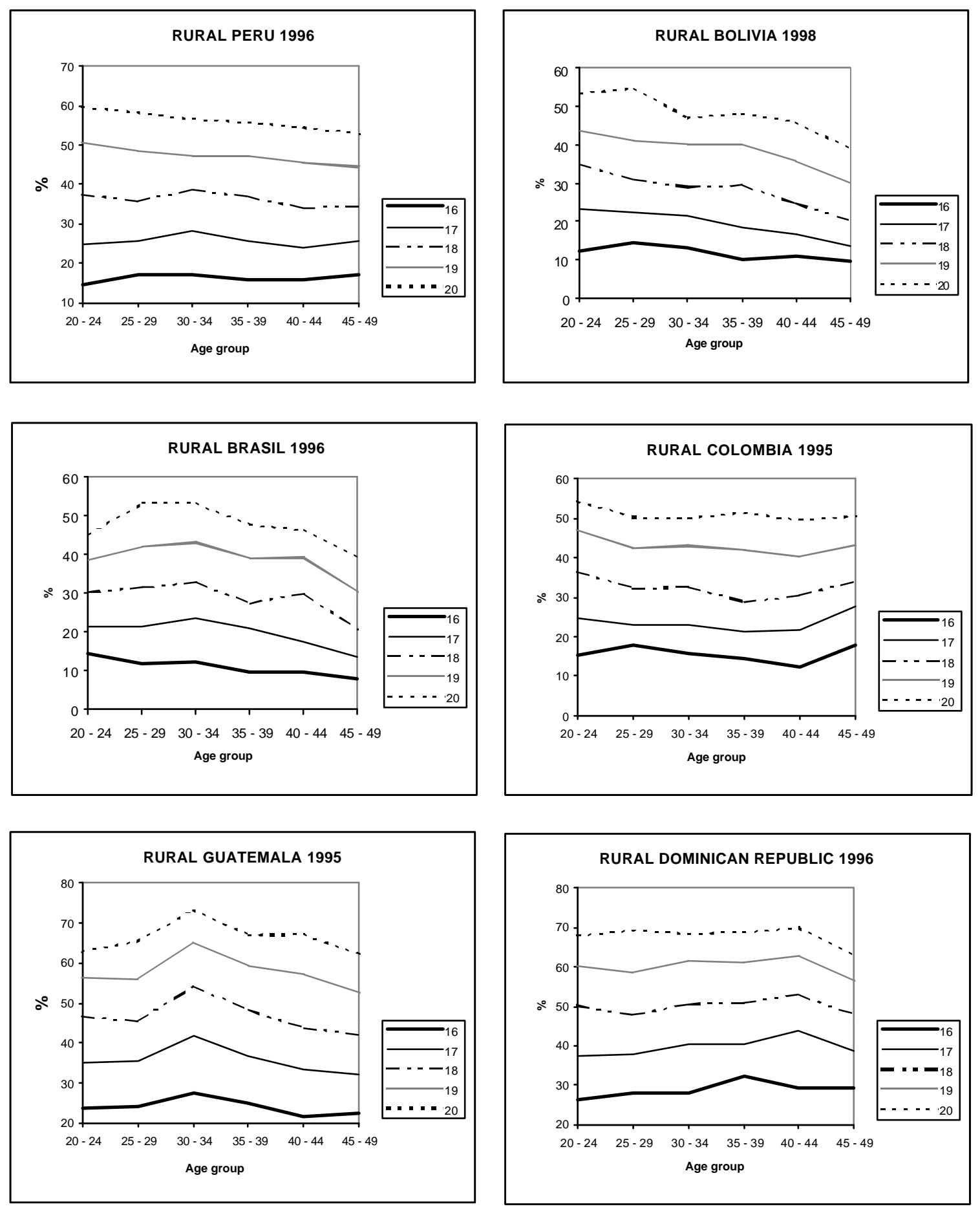
Fiqure 15: Proportion of ever married women by exact age 17 bv aqe group, by area of residence Selected LAC countries
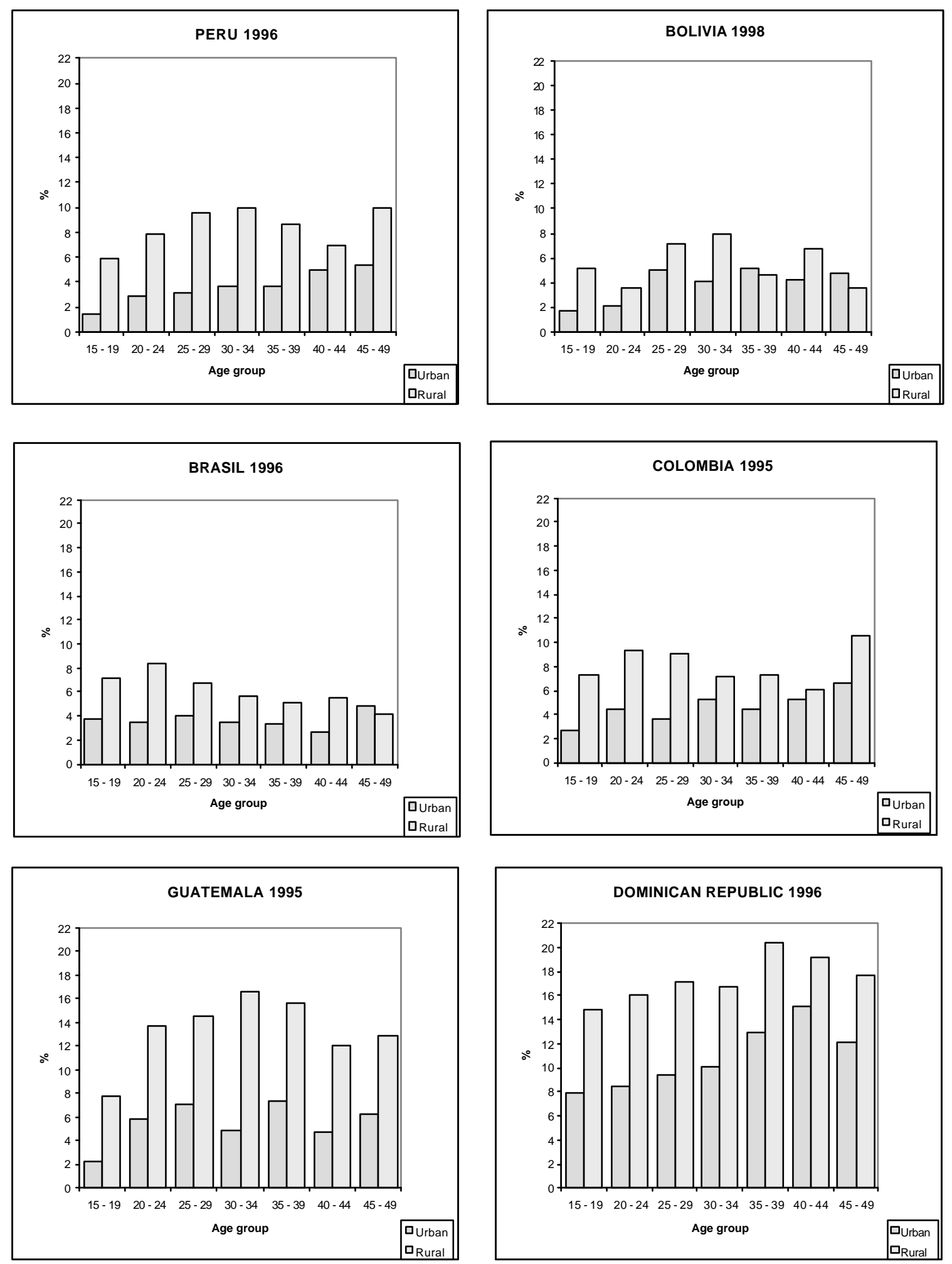
Fiqure 16: Proportion of ever married women by exact age 20 bv aqe group, by area of residence Selected LAC countries
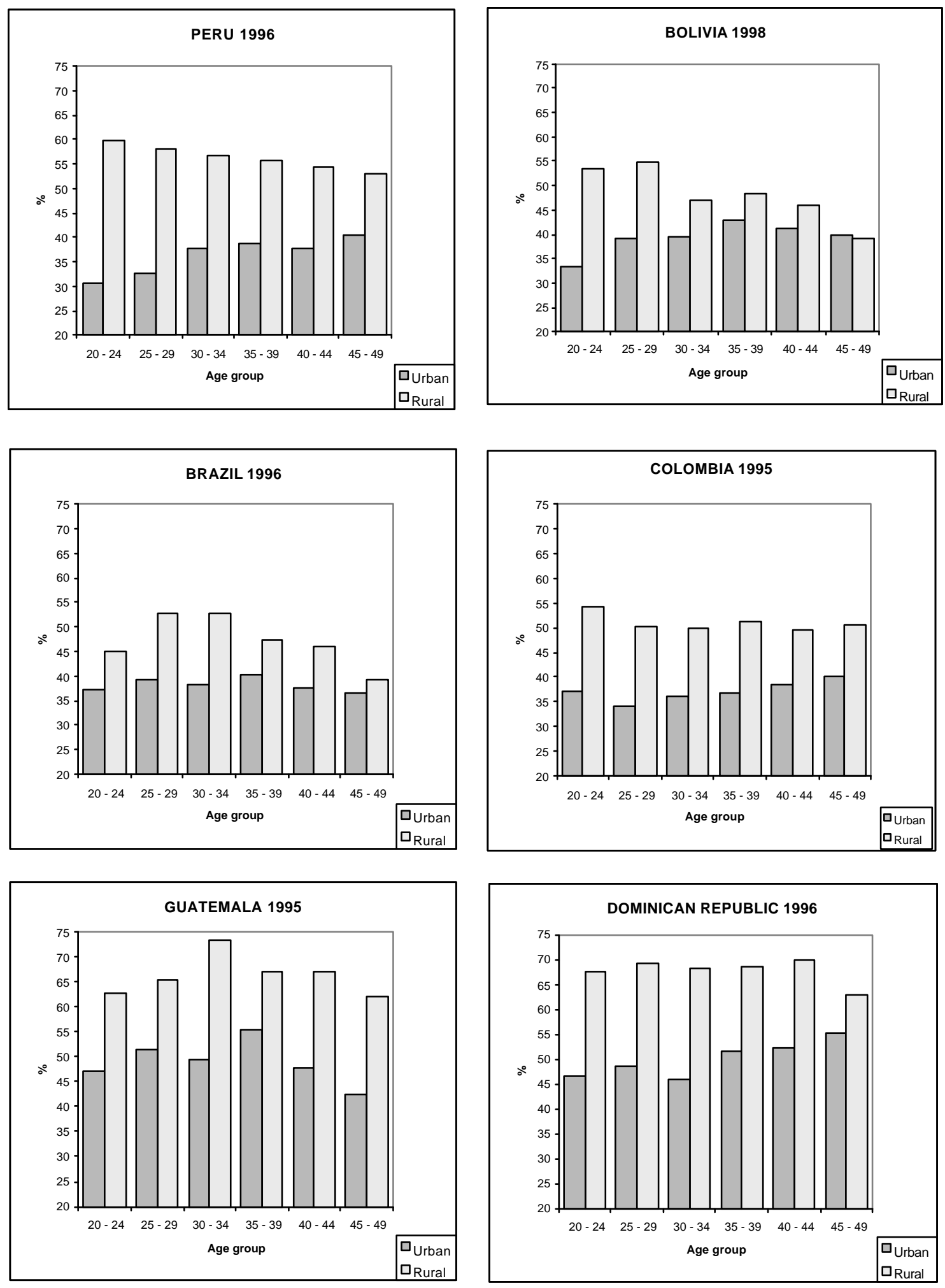
Fiqure 17a: Proportion of never married adolescents with a sex partner bv age.

Selected LAC countries. Urban areas
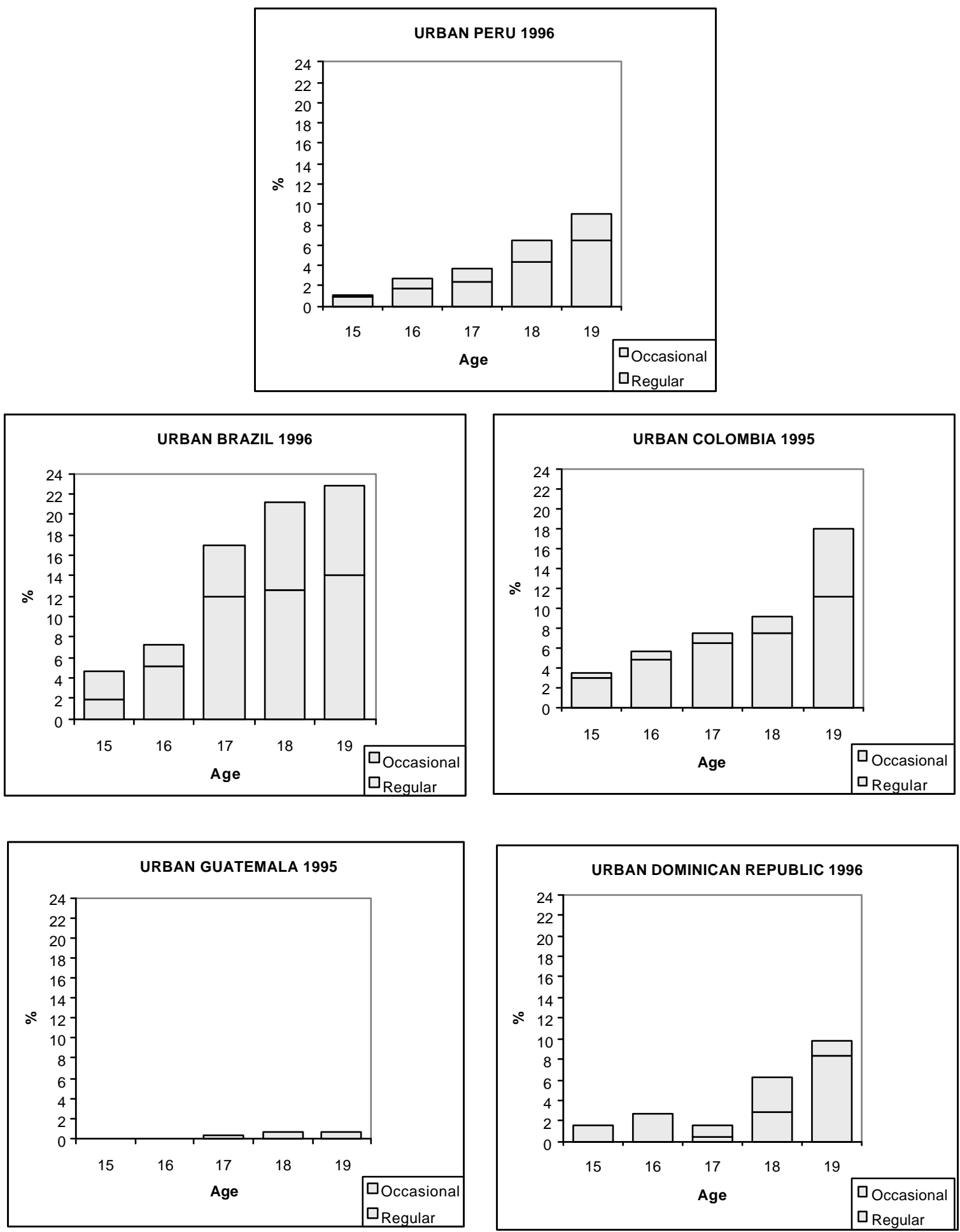
Figure 17b: Proportion of never married adolescents with a sex partner by age. Selected LAC countries. Rural areas
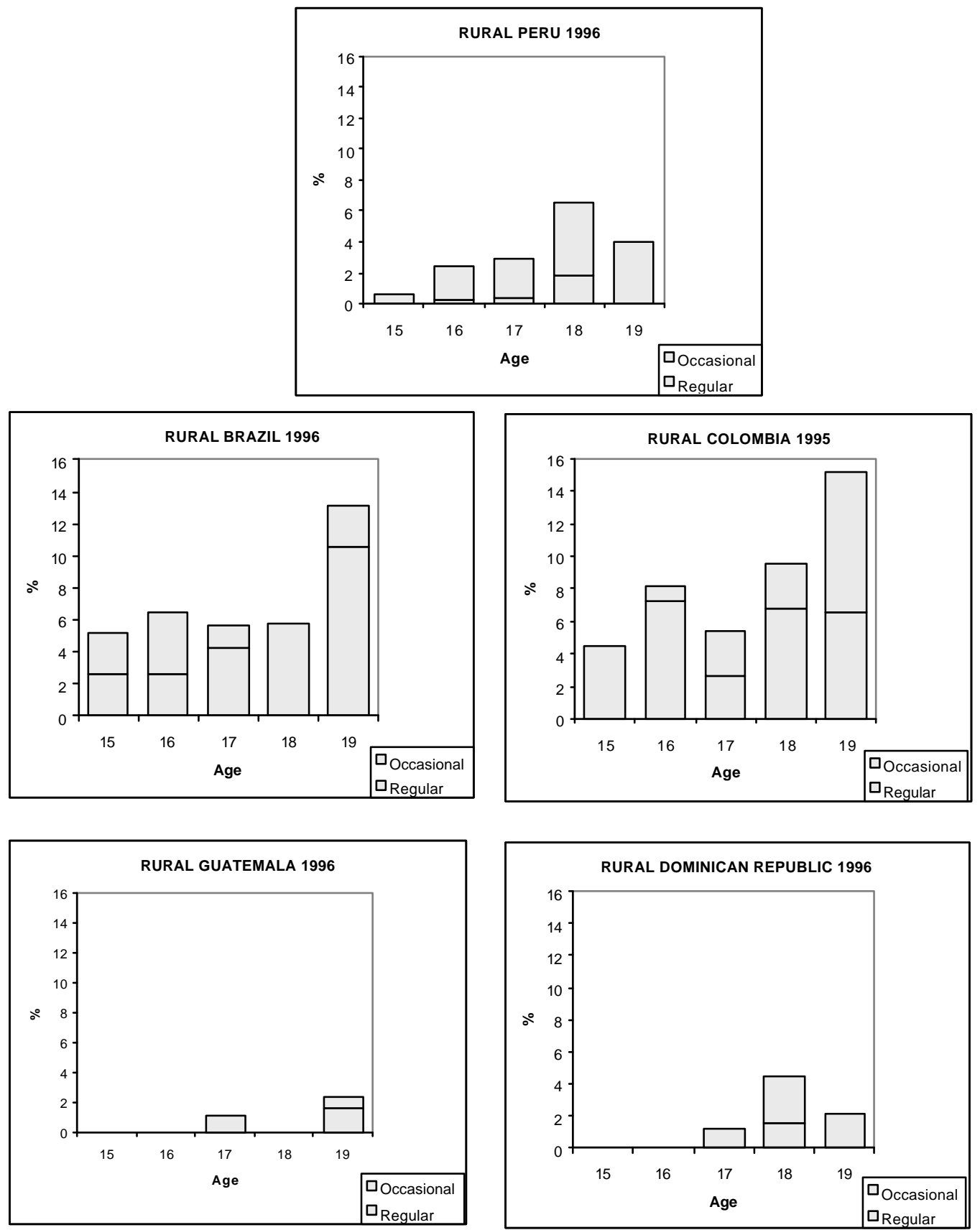


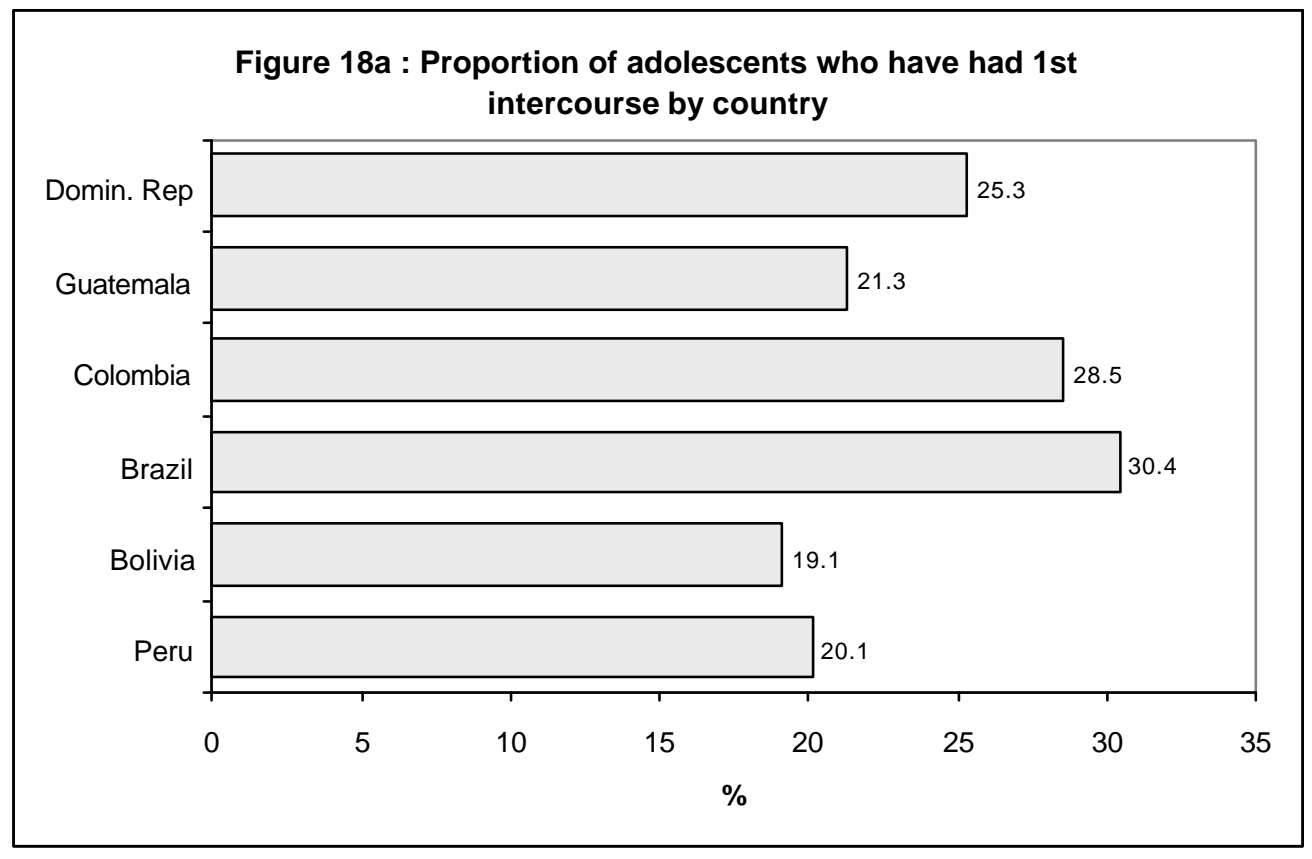

Figure 18b : Proportion of adolescents who have had 1st intercourse by area of residence by country

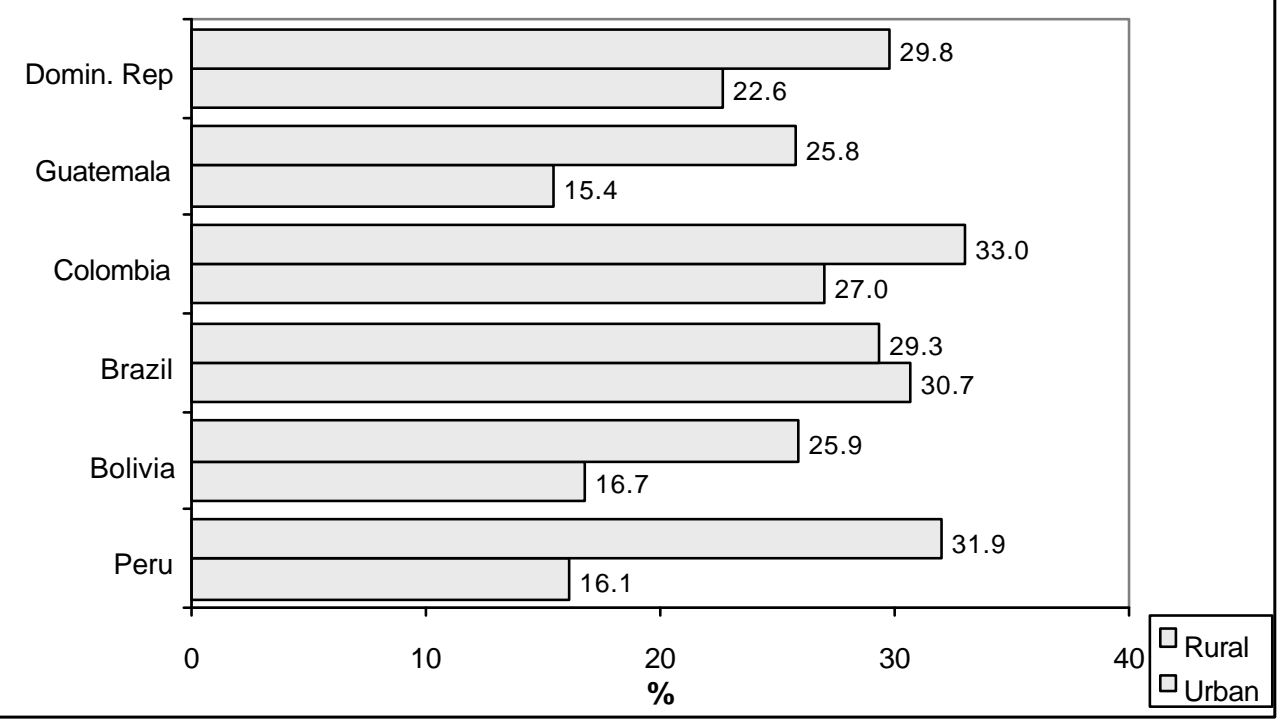


Fiqure 19a: Proportion of women who have had 1st intercourse by exact age $x$ bv age group.

Selected LAC countries. Urban areas
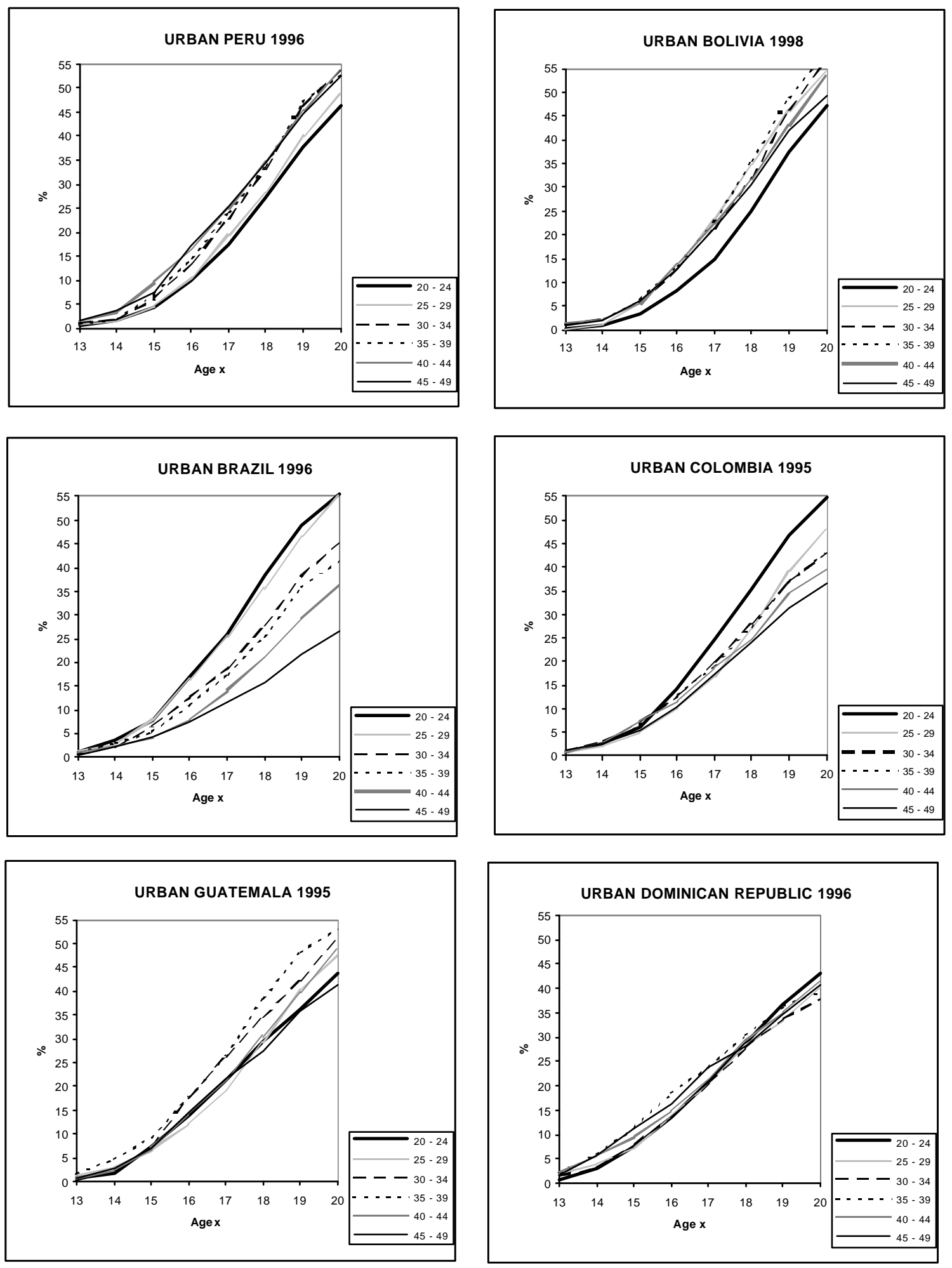
Fiqure 19b: Proportion of women who have had 1st intercourse by exact aqe $\mathrm{x}$ by aqe group.

Selected LAC countries. Rural areas
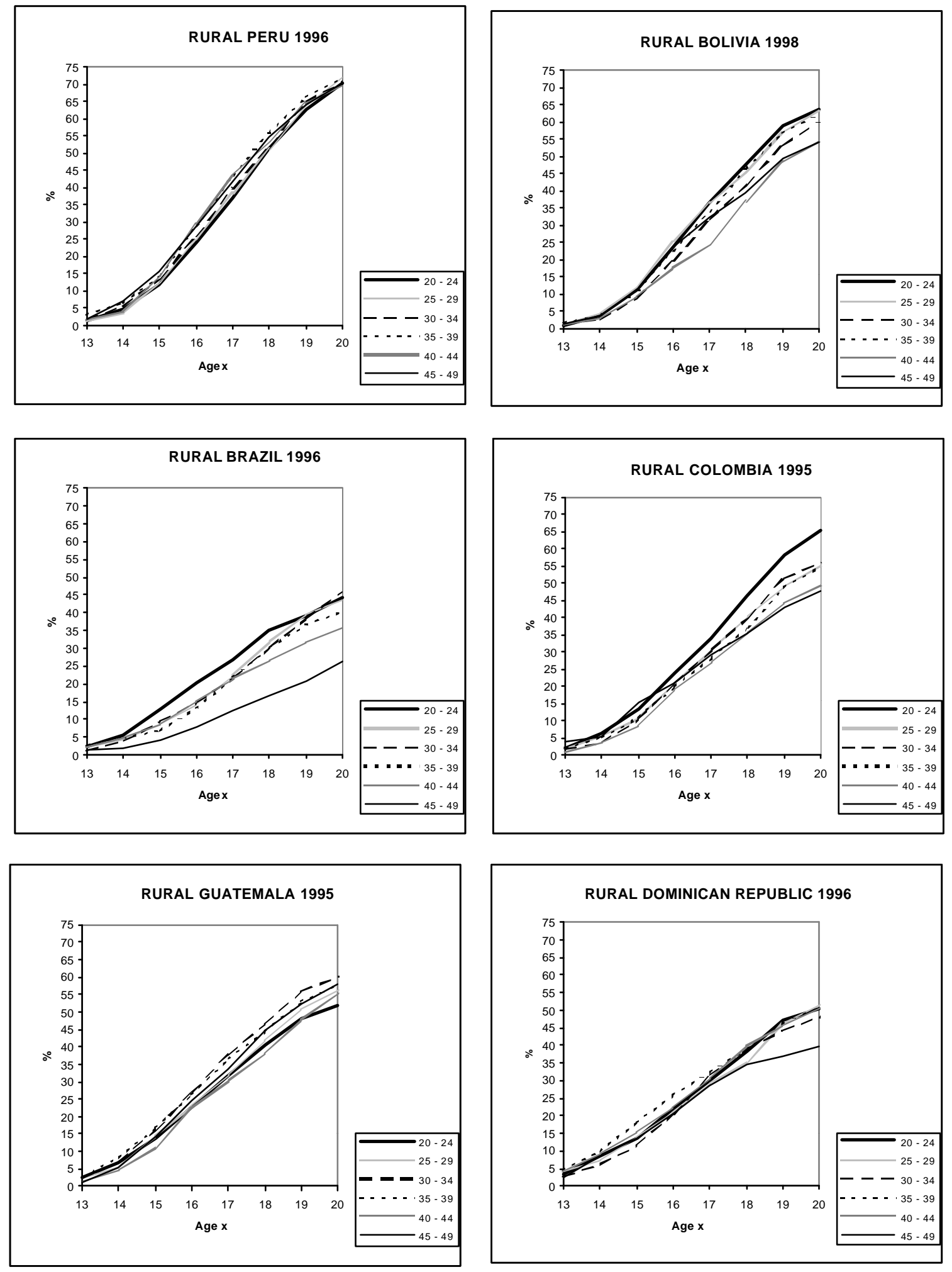
Fiqure 20a: Proportion of women who have had 1st intercourse bv exact age 16 to 20, bv aqe group. Selected LAC countries. Urban areas
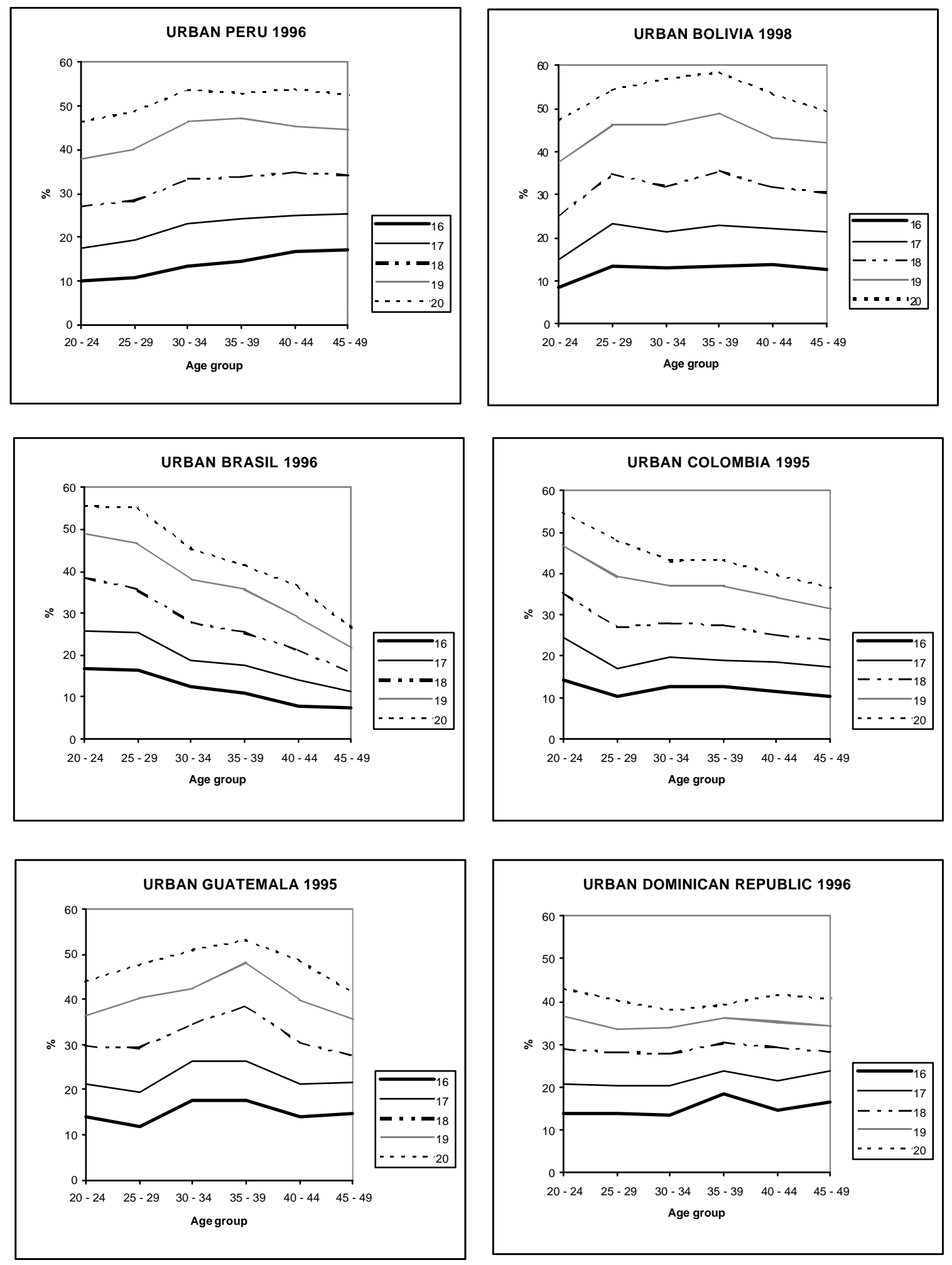
Fiqure 20b: Proportion of women who have had 1st intercourse bv exact aqe 16 to 20, bv age group. Selected LAC countries. Rural areas
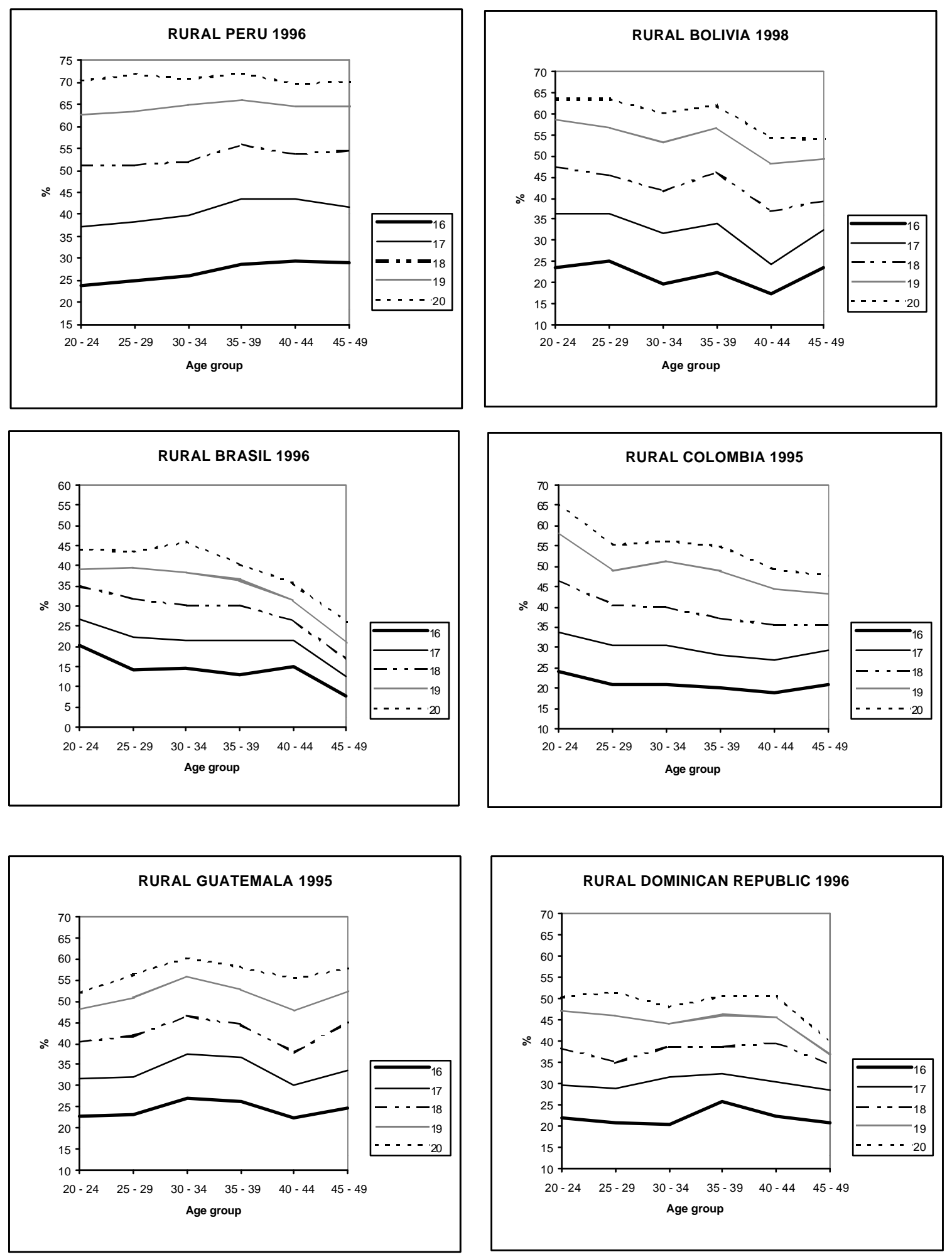
Fiqure 21: Proportion of women who have had 1st intercourse bv exact aqe 17 bv aqe group, by area of residence. Selected LAC countries
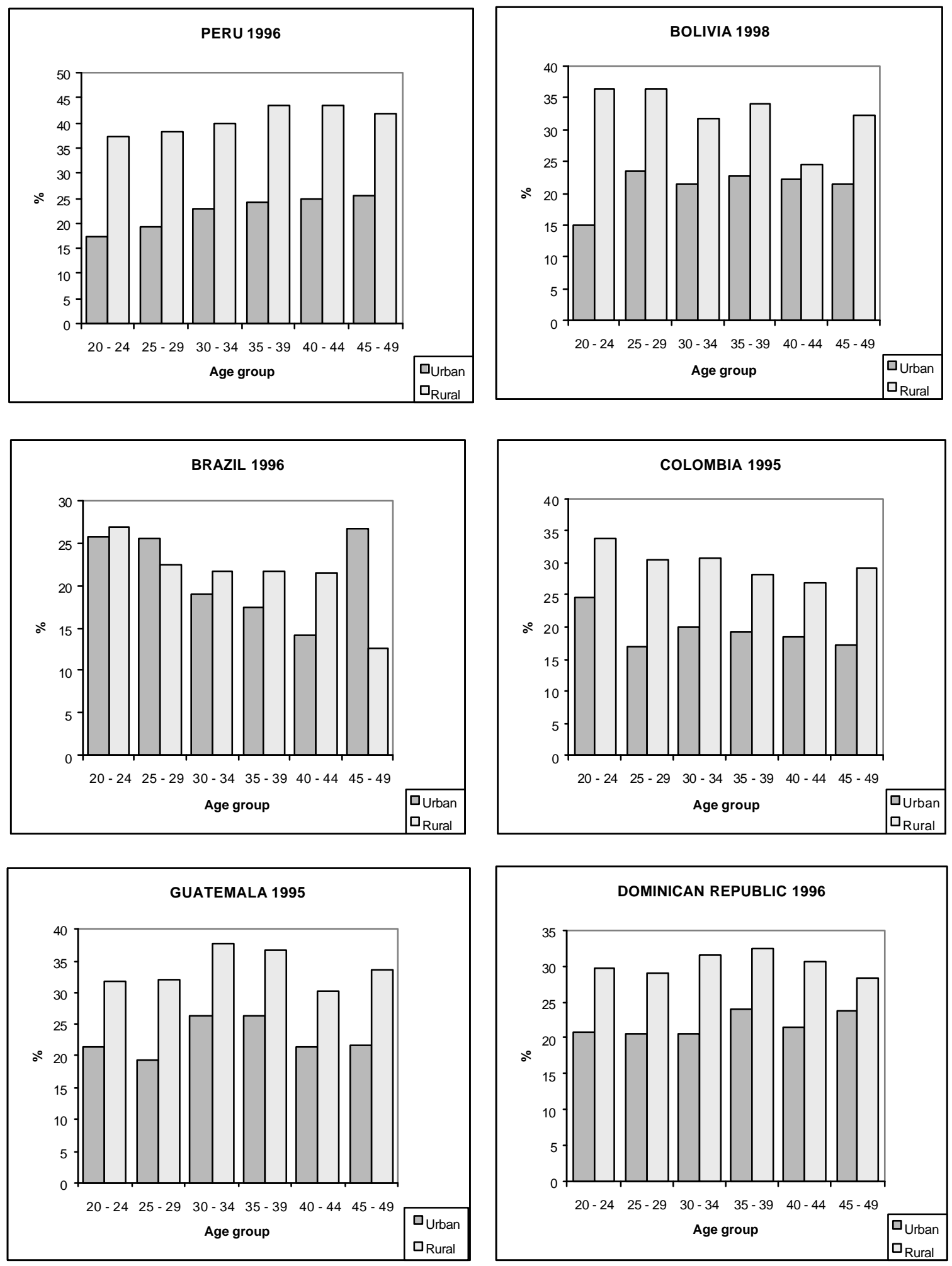
Fiqure 22: Proportion of women who have had 1st intercourse by exact aqe 20 by aqe group, bv area of residence. Selected LAC countries
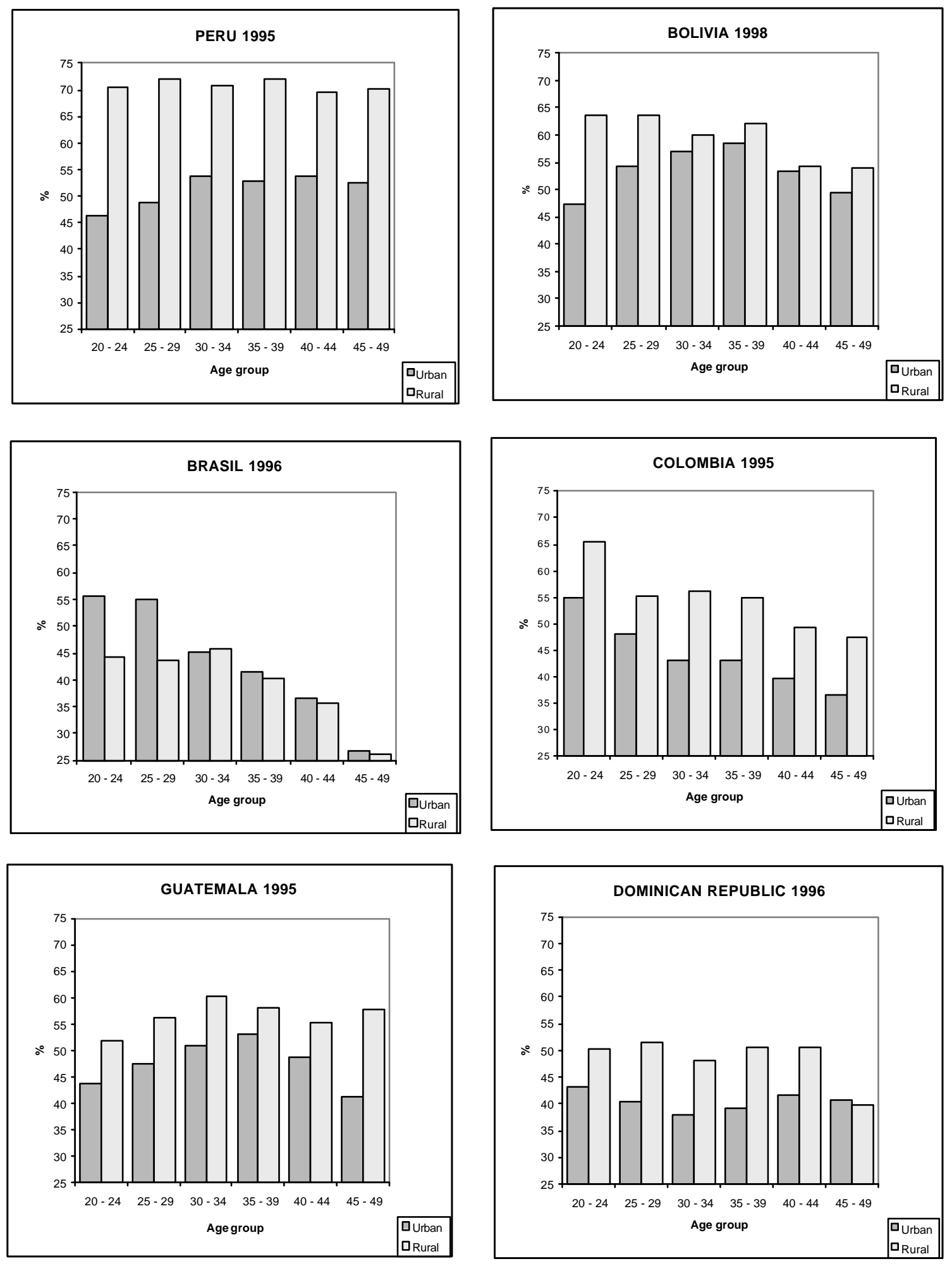

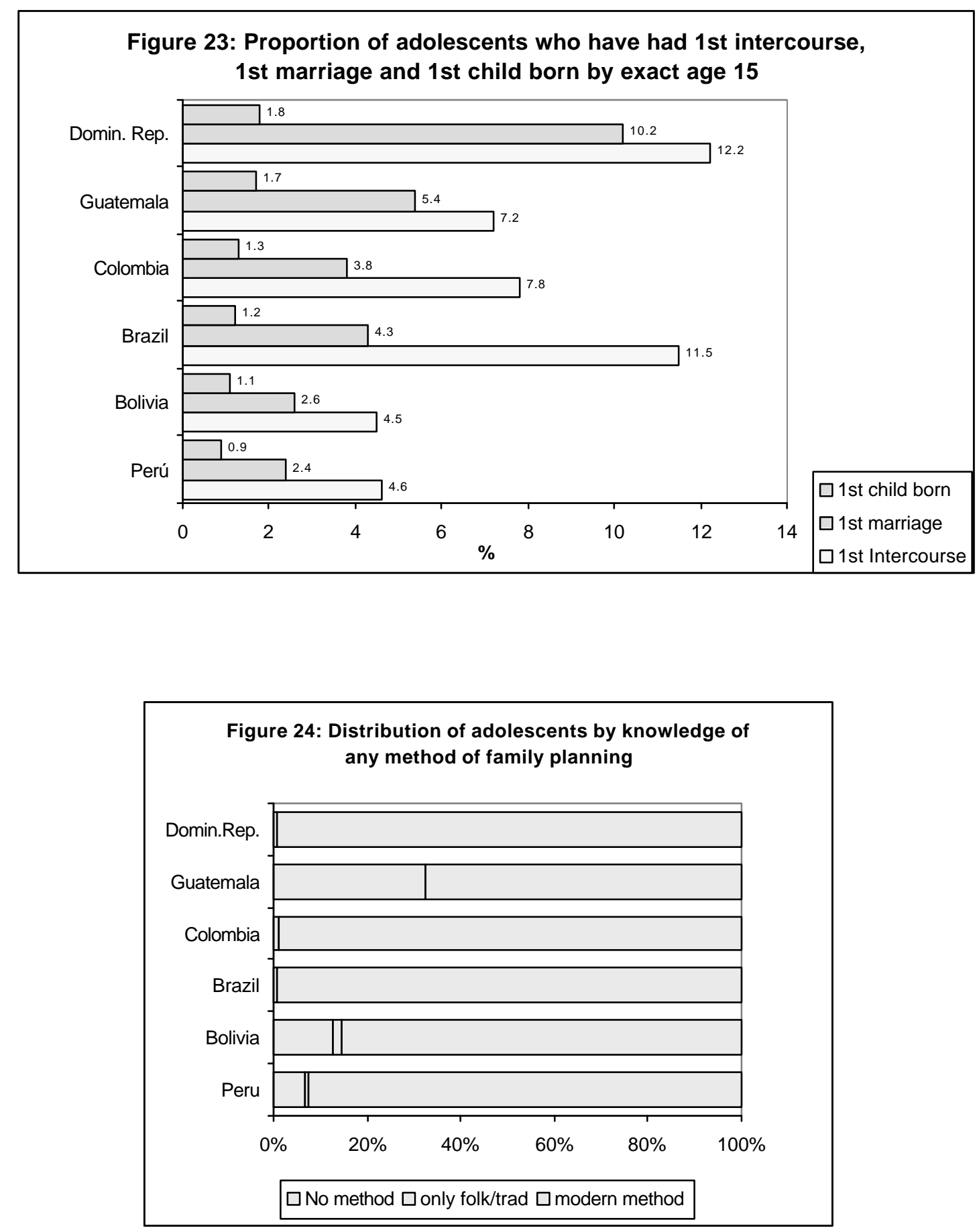
Fiqure 25: Knowledge of family planning methods among adolescents by education. Selected LAC countries
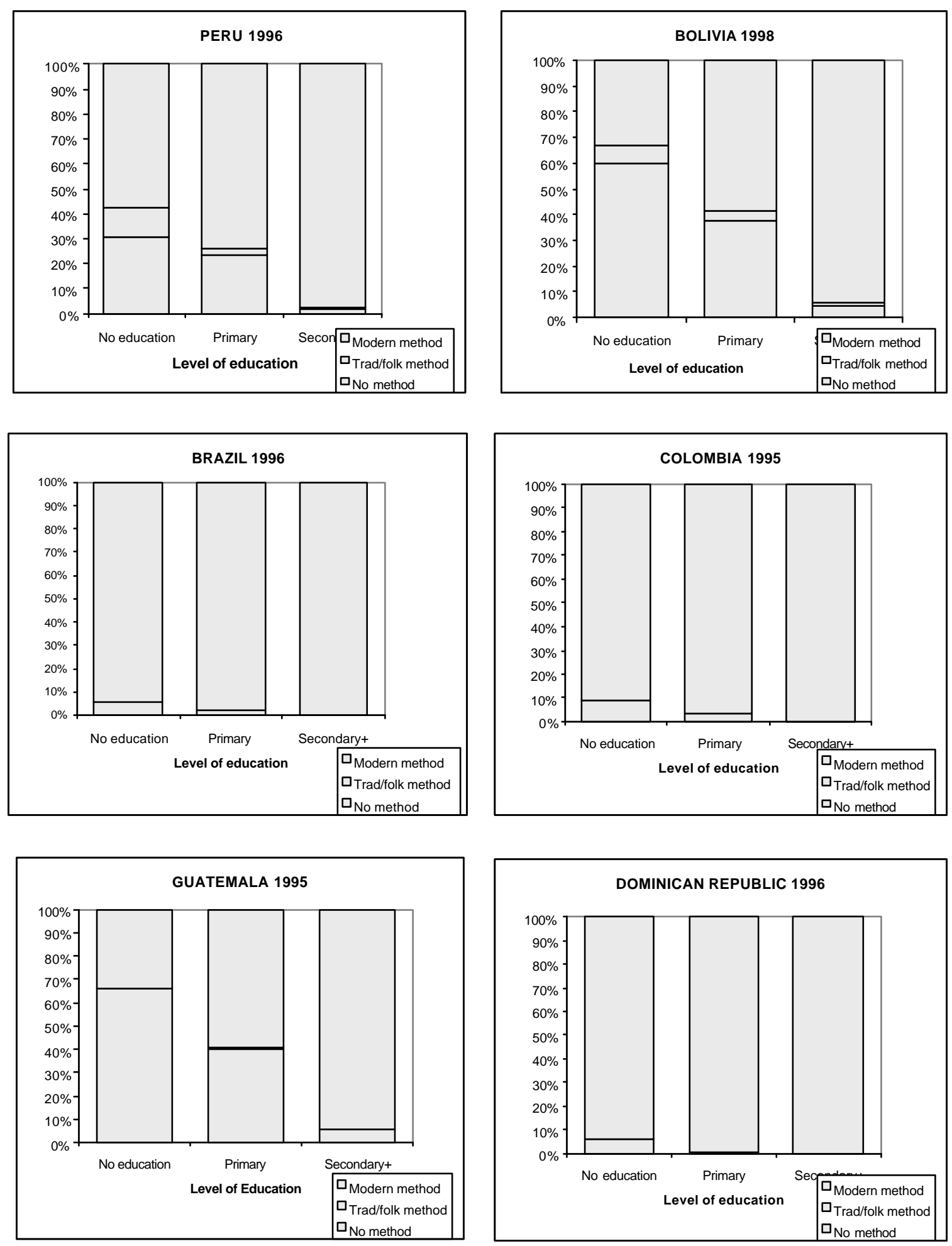
Fiqure 26: Distribution of adolescents by current use of family planning method by marital status Selected LAC countries
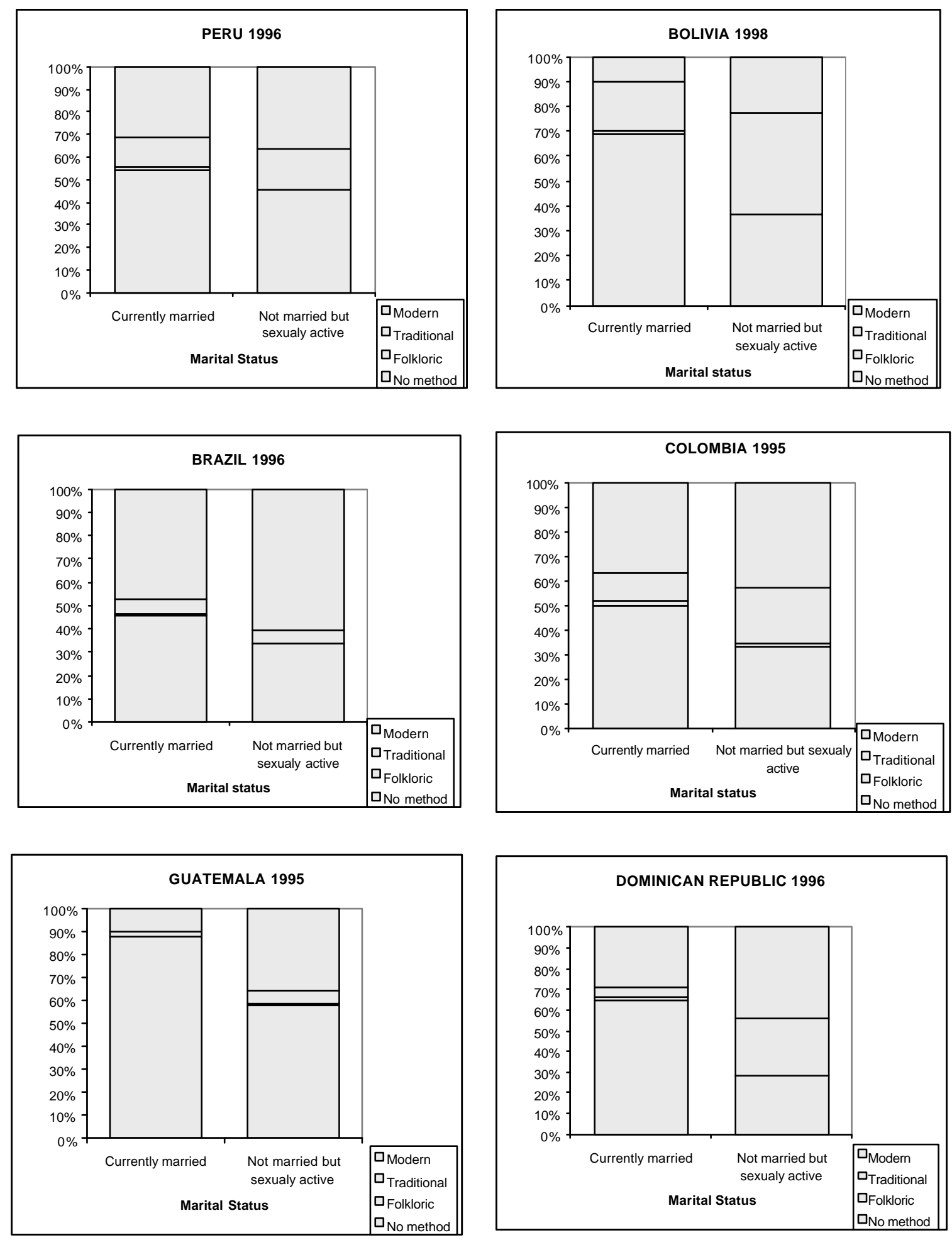

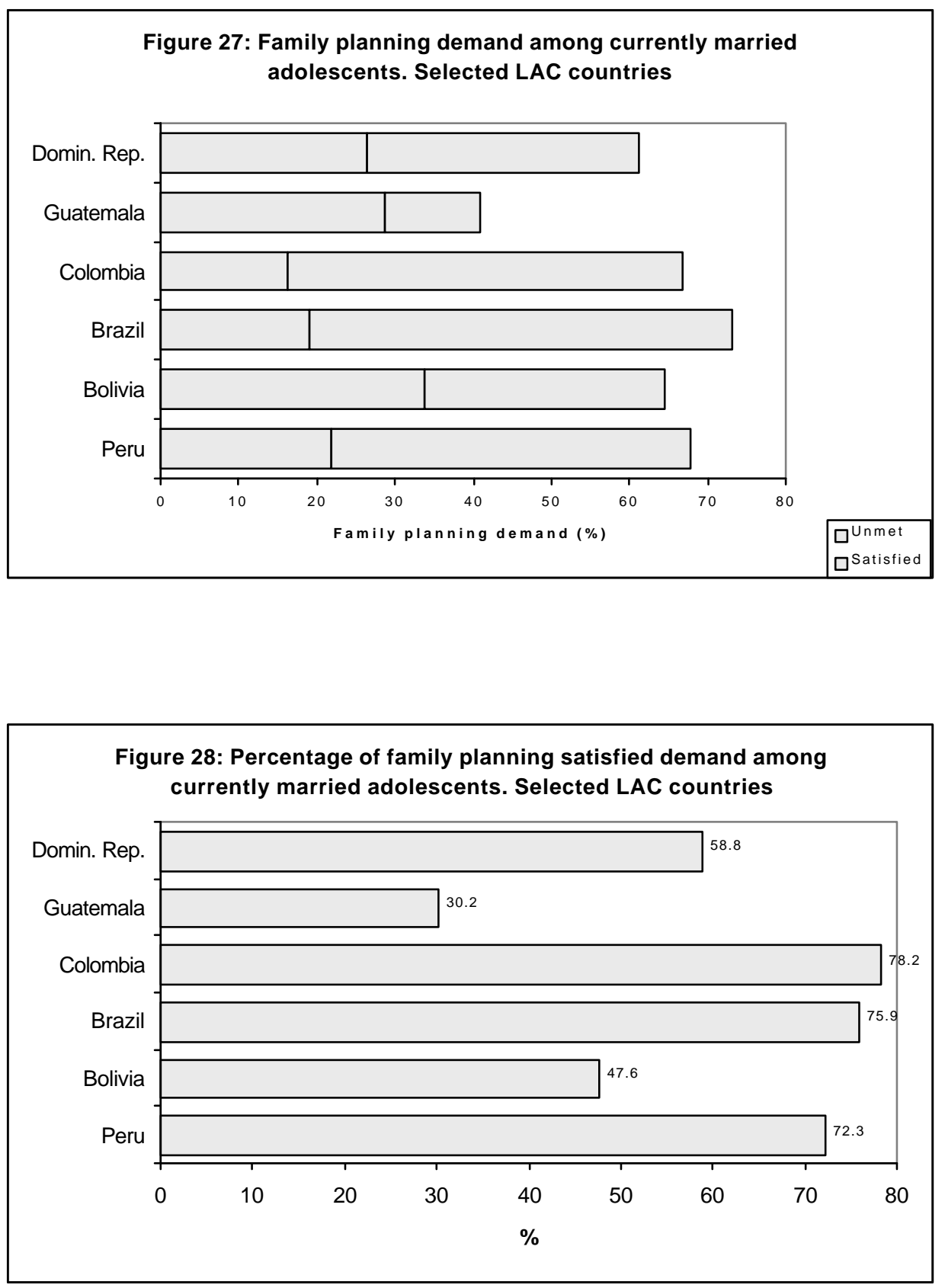
Fiqure 29a: Family planning demand among currently married adolescents by area of residence,

\section{Selected LAC countries}
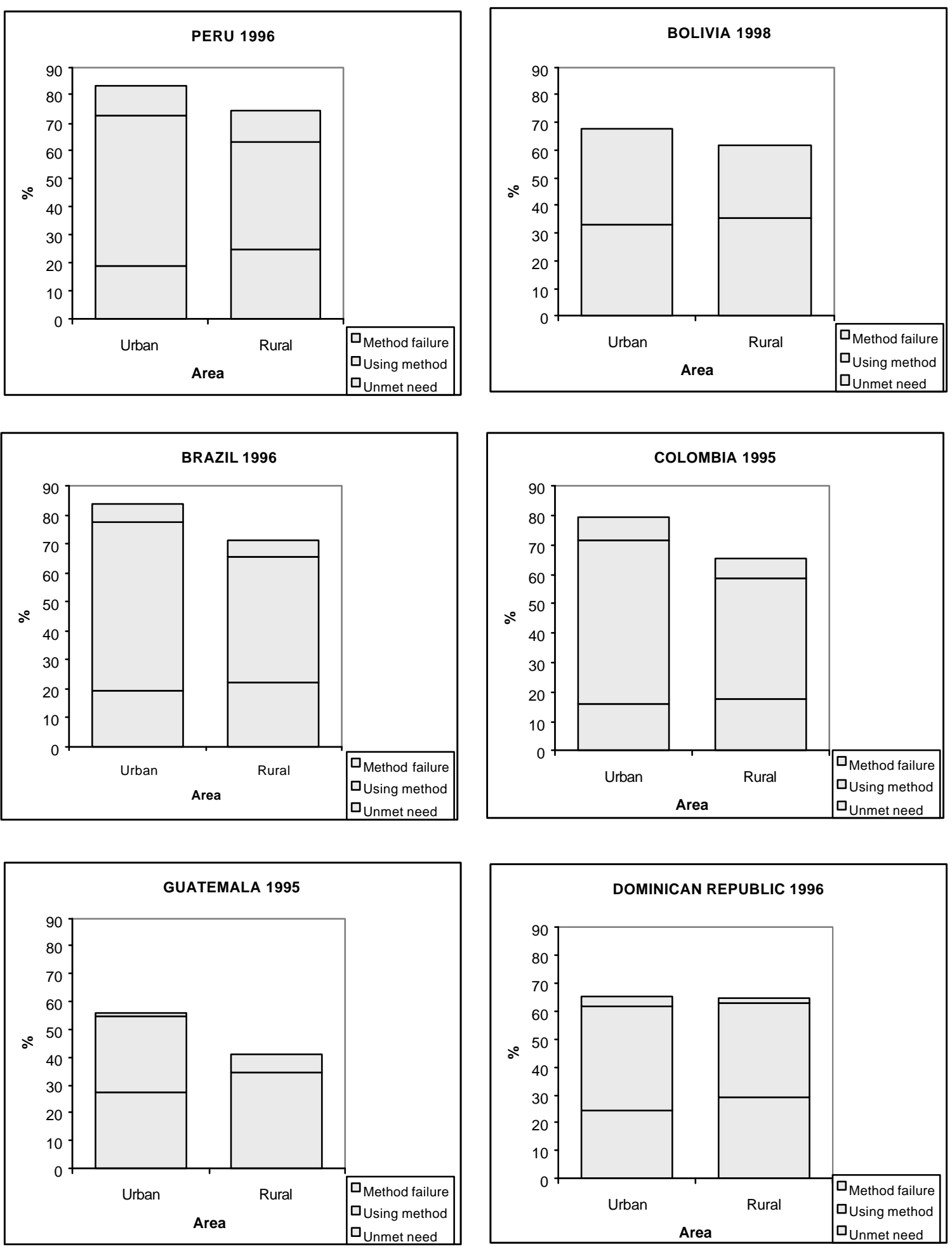
Fiqure 29b: Family planning demand amonq unmarried adolescents by area of residence,

Selected LAC countries
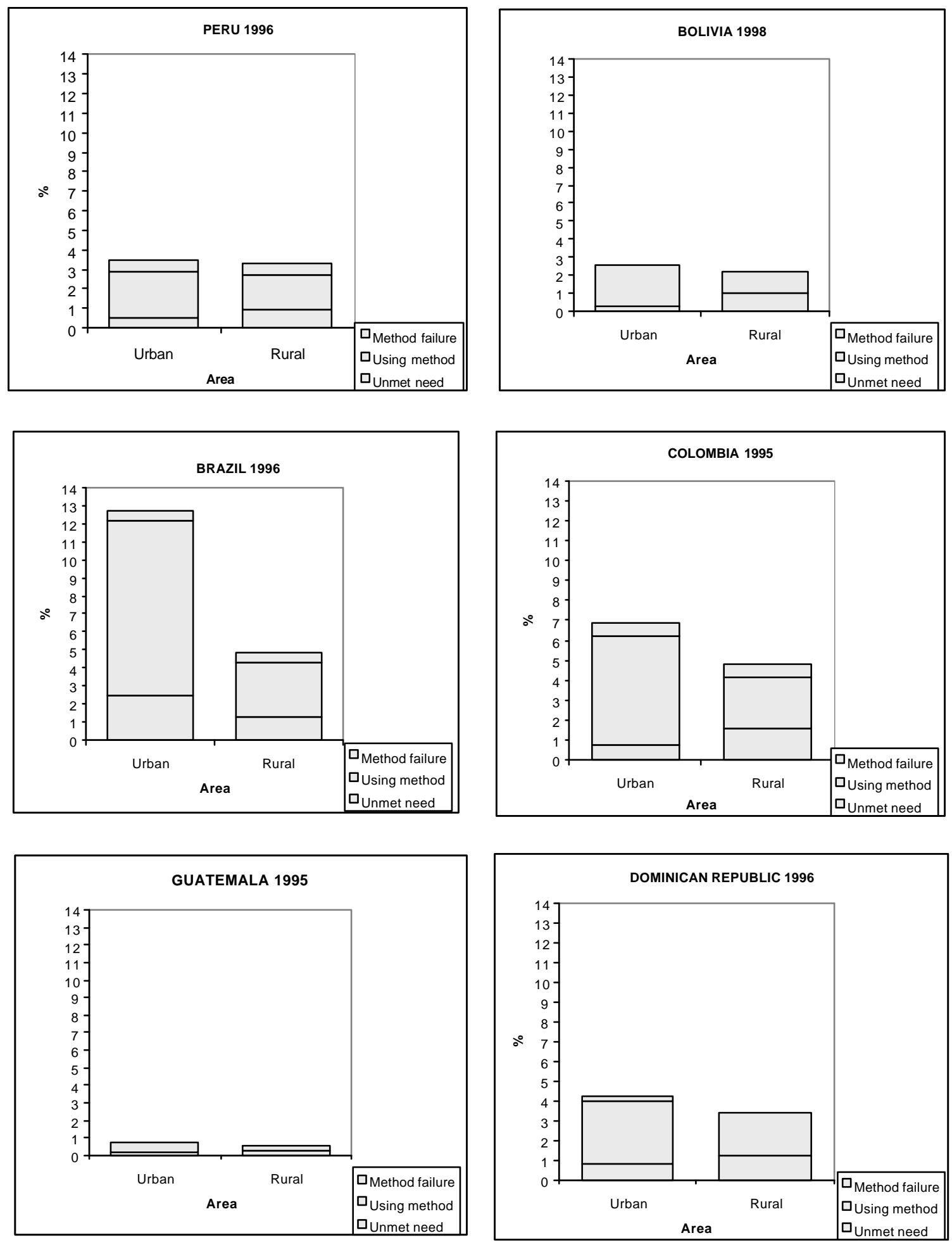
Fiqure 30: Percentage of satisfied family planning demand amonq adolescents by marital status, bv area of residence. Selected LAC countries
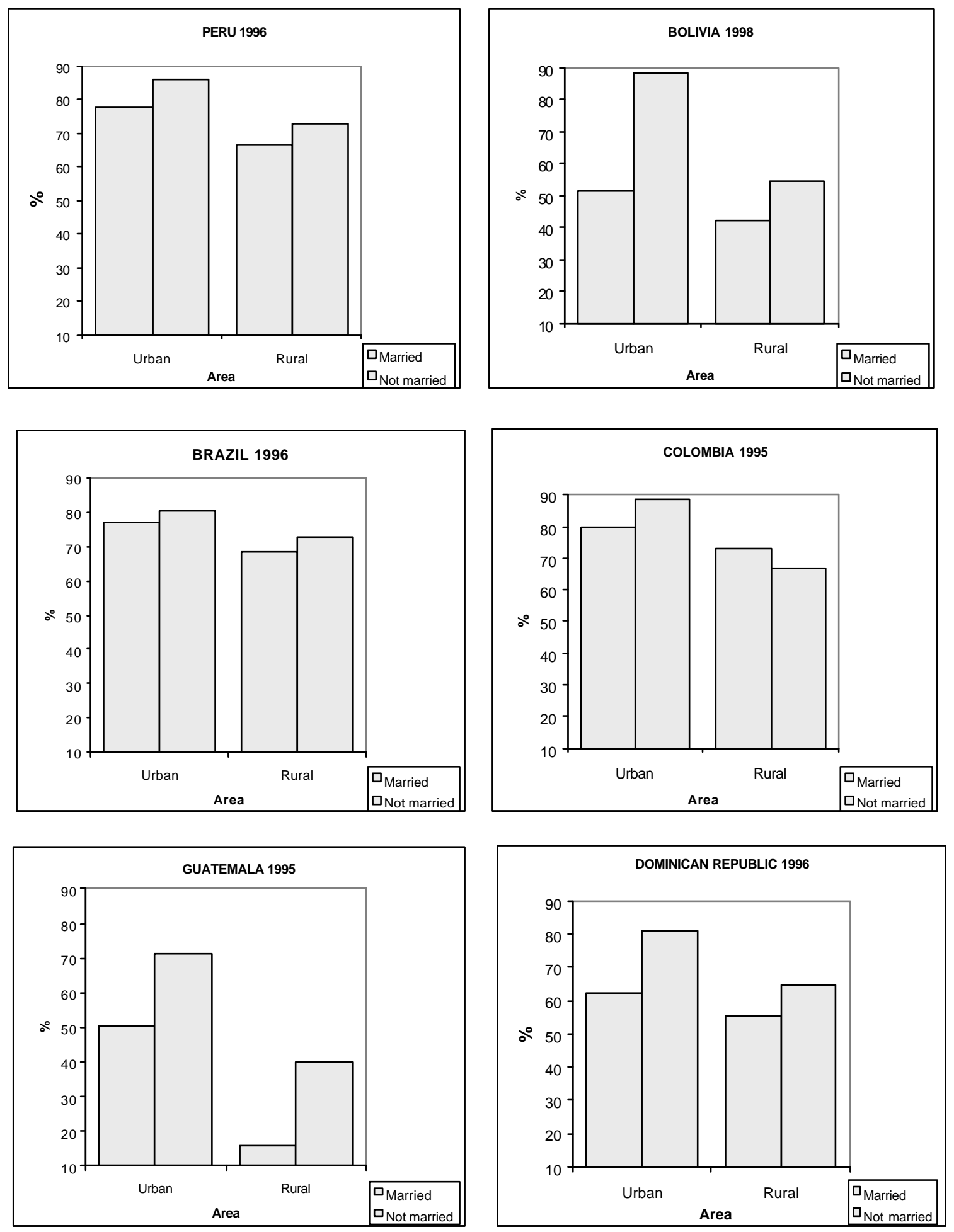
Fiqure 31: Ever use of family planning methods among ever married adolescents bv education. Selected LAC countries
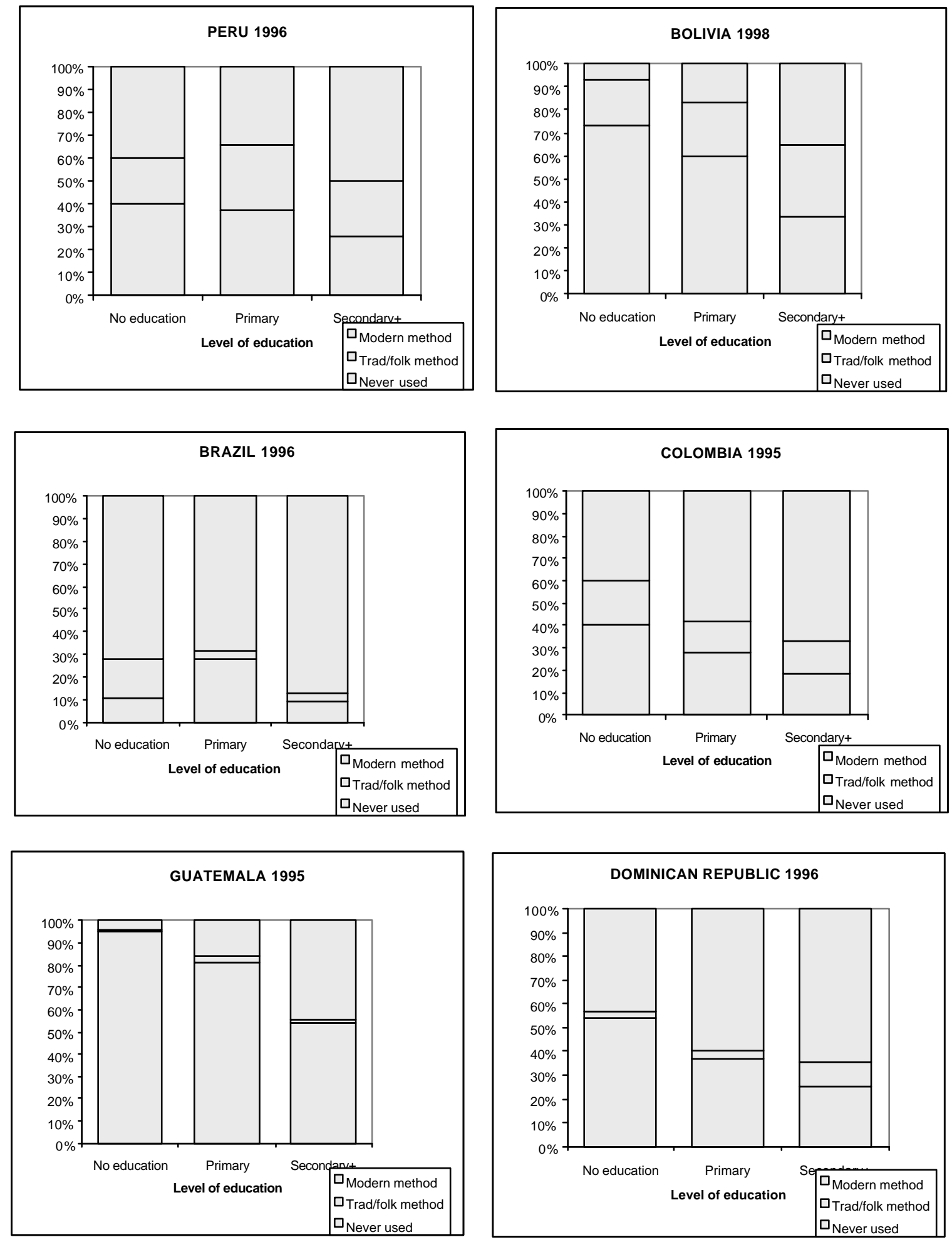
Fiqure 32: Exposure-time and teenaqe fertility levels bv area of residence.

Selected LAC countries
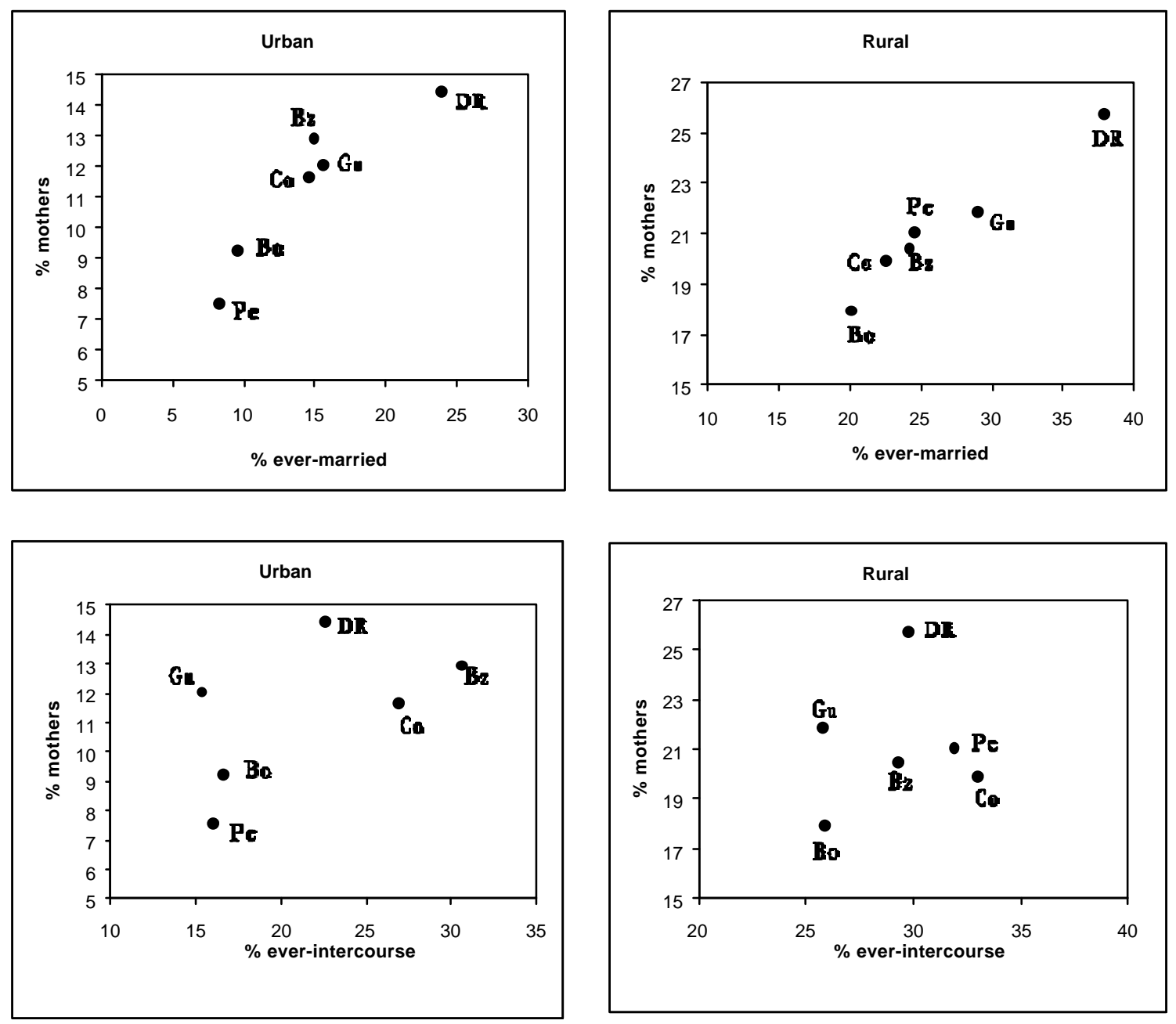
Figure 33a: Distribution of mothers by marriage to 1st birth interval by age group. Selected LAC countries. Urban areas
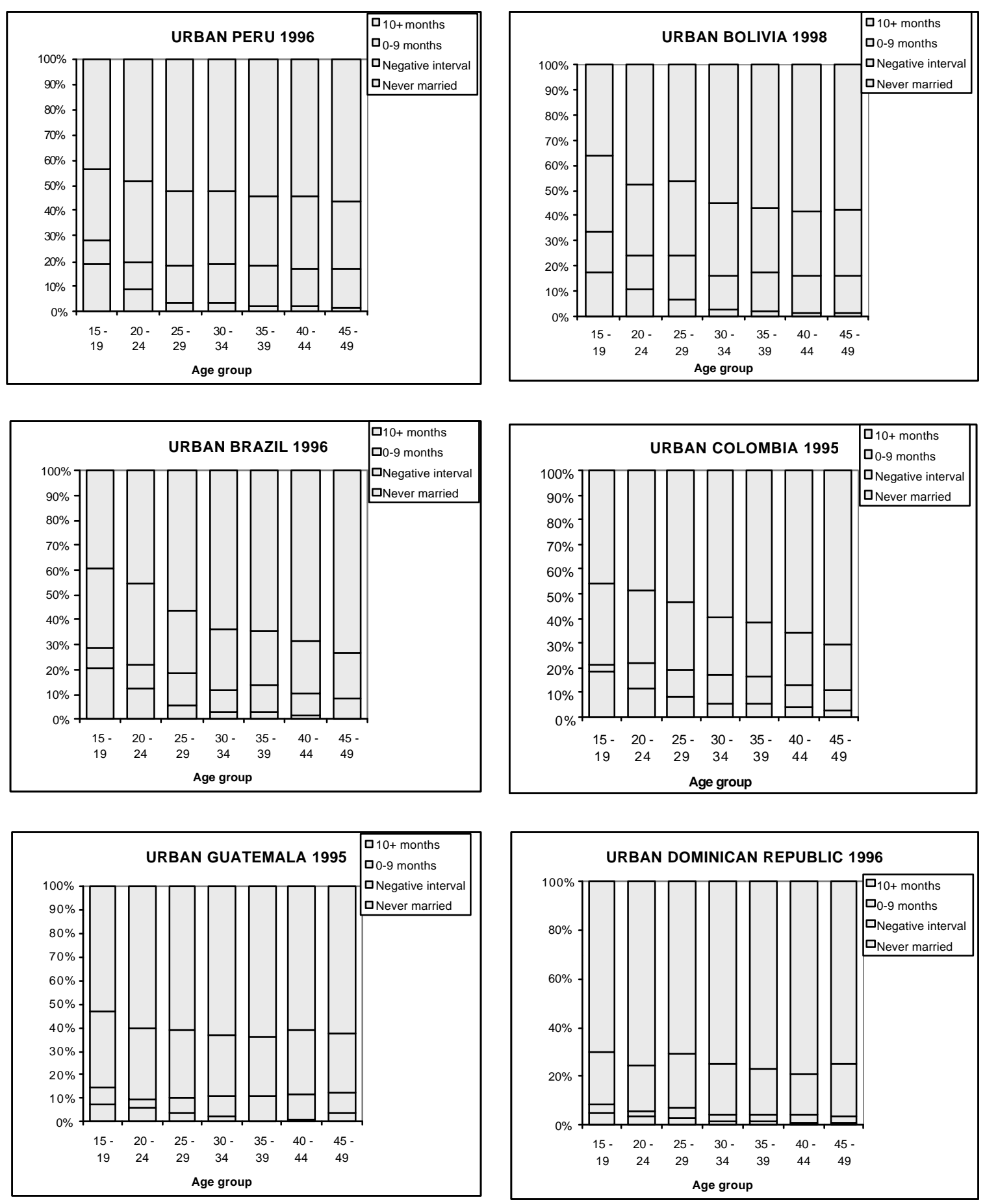
Fiqure 33b: Distribution of mothers bv marriage to 1st birth interval bv aqe group.

Selected LAC countries. Rural areas
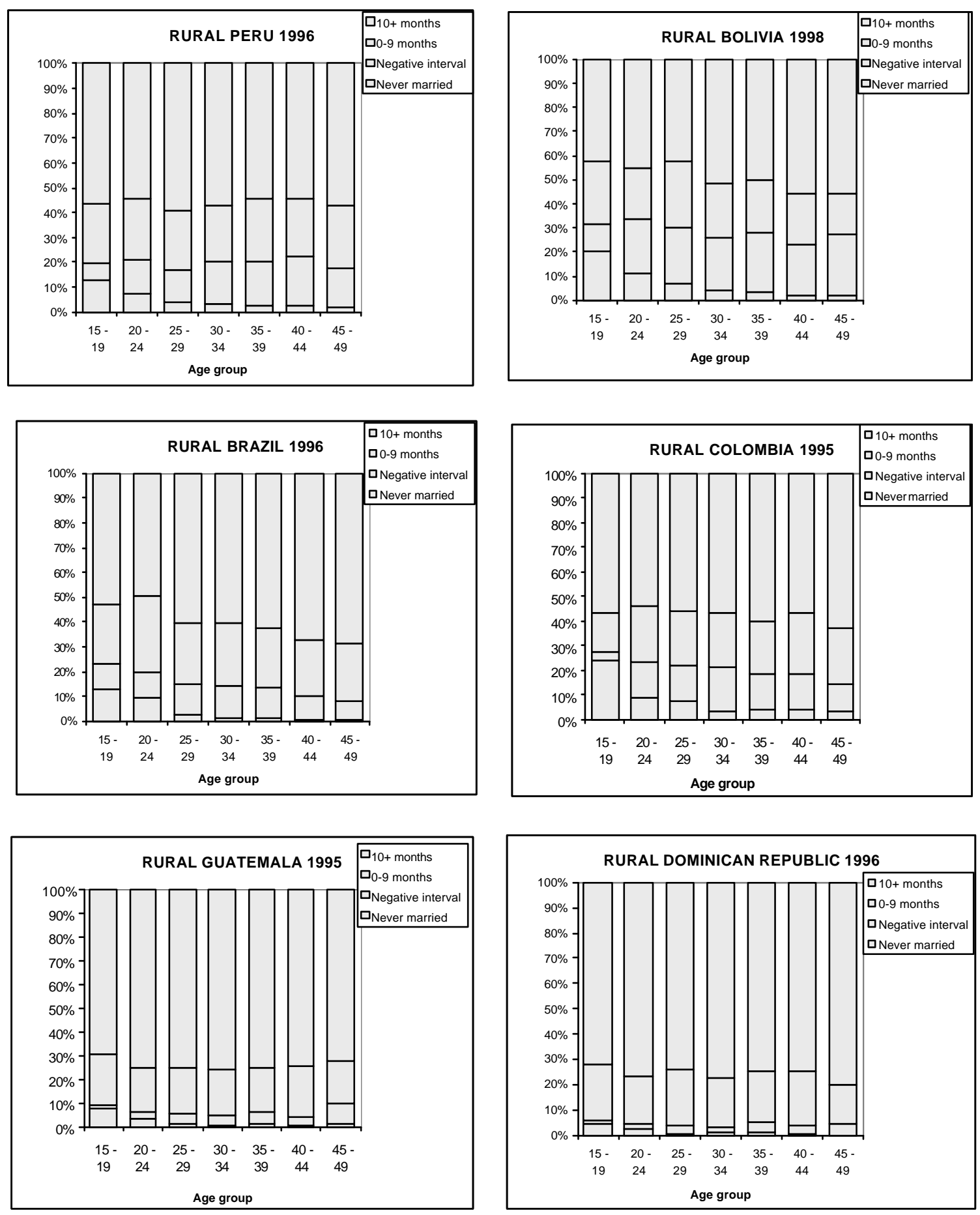
Fiqure 34: Distribution of adolescents mothers by marriage to 1st birth interval by aqe Selected LAC countries
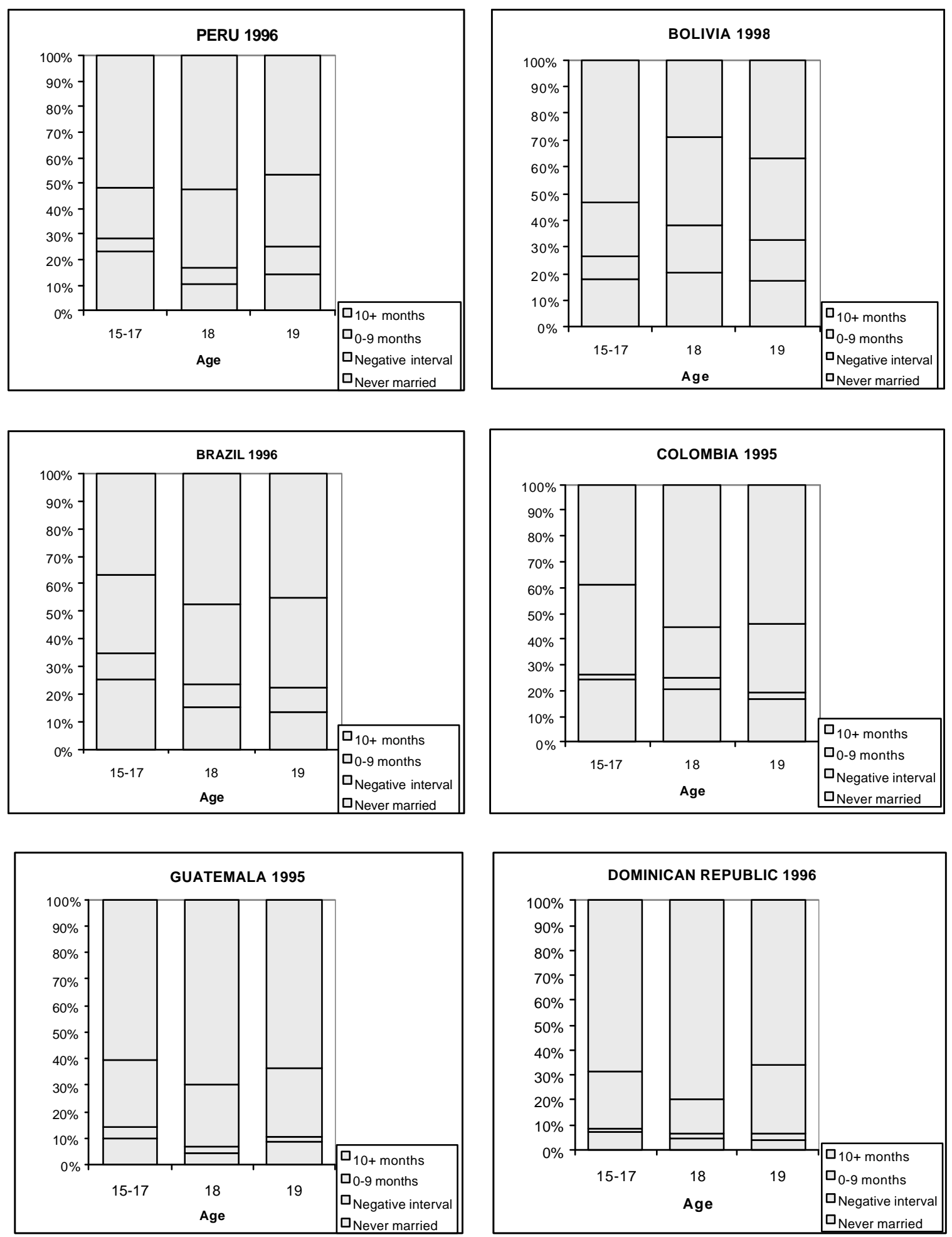
Figure 35: 1st marriage to 1st live birth conception patterns by age. Adolescents aged 18-19 years Selected LAC countries
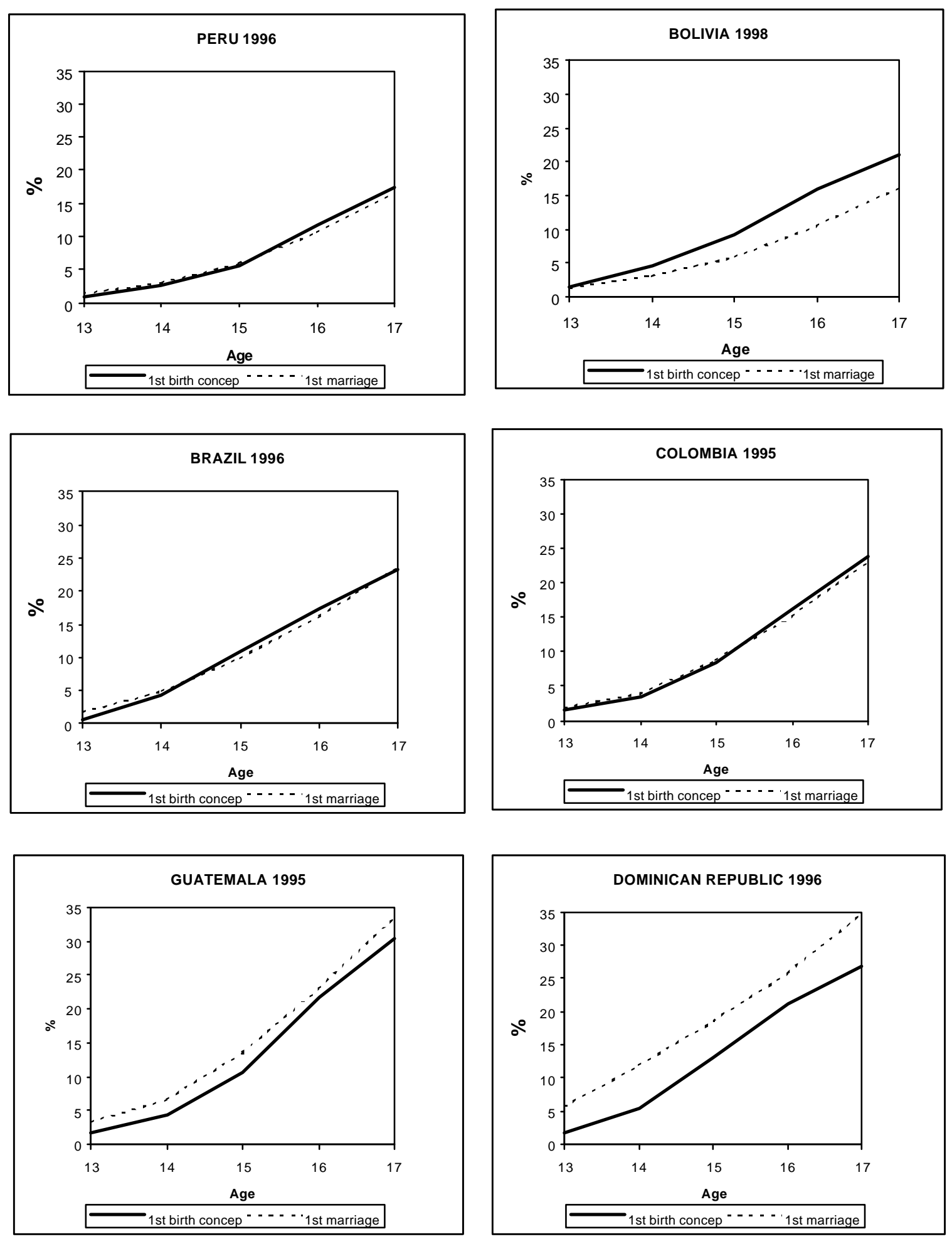
Figure 36: Distribution of adolescents mothers by marital status by area of residence Selected LAC countries
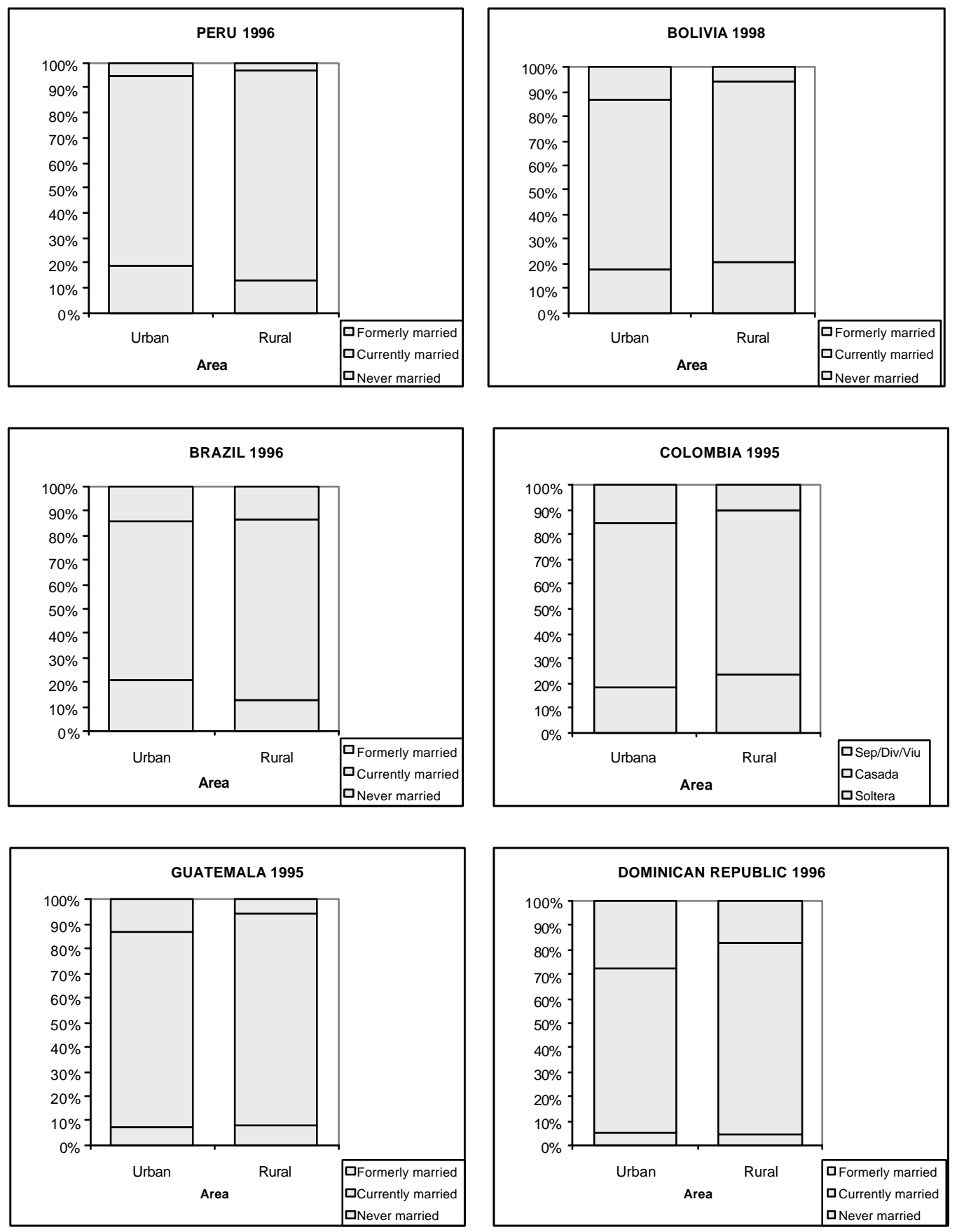


\section{ANNEX 1 \\ MULTILEVEL ANALYSIS (MA)}

\section{What is MA?}

Because individuals interact with the social context to which they belong, and that the individuals, who make up the group, in turn influence the properties of those groups, we need to take in account those effects, in the econometric analysis. If we think that some regional (country, group, etc.) variables affect the fertility rate we have to use MA. For instance, we hope that a woman who lives in a region with a high fertility rate has a higher probability of childbearing than a woman who lives in a region with a low fertility rate. We also have to use MA when we think any variables have different effects on fertility. In MA, the data structure in the population is hierarchical, and the sample data are viewed as a multistage sample from this hierarchical population.

\section{The consequences of ignoring a multilevel structure can be summarized as:}

1. Suppose we have two levels. A sample from the population can be described as a multistage sample: first we take a sample of units from the higher level (women), and next we sample the subunits from the available units (we sample women from the regions). In such samples, the individual observations are generally not completely independent. For instance, women in the same region tend to be similar to each other, because of selection processes and because of the common history they share by live in the same region. As a result, the average correlation between variables measured on women from the same region will be higher than the average correlation between variables measured on women from different regions. Standard statistical tests lean heavily on the assumption of independence of the observations. If this assumption is violated the estimates of the standard errors are much too small and this results going to be significant.

2. By focusing attention on the levels of hierarchy in the population, MA enables the researcher to understand where and how effects are occurring. It provides better estimates in answer to the simple questions for which single-level analysis were once used and in addition allows more complex questions to be addressed.

\subsection{Desciption of Multiled Modding}

(Two level)

The full multilevel regression model assumes that there is a hierarchical data set, with one single dependent variable (fertility) that is measured at the lowest level and explanatory variables at all existing levels. A ssume that we have collected data in J regions, with data from a different number of women $\mathrm{N}_{\mathrm{j}}$ in each region. On the women level we have the dependent variable $\mathrm{Y}$ (fertility) and the explanatory variable $\mathrm{X}$, and on the region level we have the explanatory variable $\mathrm{Z}$. 
We can set up a separate regression equation in each separate region to predict the dependent variable $\mathrm{Y}$ by the explanatory variable $\mathrm{X}$ as follows:

$$
Y_{i j}=\beta_{o j}+\beta_{1 j} X_{i j}+e_{i j}
$$

The difference with the usual regression model is that we assume that each region is characterized by a different intercept coefficient $\beta_{o j}$ and also a different slope coefficient $\beta_{1 j}$.

The next step in the hierarchical regression model is to predict the variation of the regression coefficients $\beta_{j}$ by introducing explanatory variables at the region level, as follows:

$$
\beta_{o j}=\gamma_{00}+\gamma_{01} Z_{j}+\mu_{o j}
$$

and

$$
\beta_{1 j}=\gamma_{10}+\gamma_{11} Z_{j}+\mu_{1 j}
$$

The model can be written as one single complex regression equation by substituting equations (2) y (3) into equation (1). Rearranging terms gives:

$$
\begin{aligned}
Y_{i j} & =\gamma_{00}+\gamma_{10} X_{i j}+\gamma_{01} Z_{j}+\gamma_{11} Z_{j} X_{i j} \\
& +\mu_{1 j} X_{i j}+\mu_{o j}+e_{i j}
\end{aligned}
$$


The first part in equation (4) contains all the fixed (or deterministic) coefficients and the second part contains all the random (or stochastic) error terms of the model. The term $Z{ }_{j} X_{i j}$ is an interaction term that appears in the model as a consequence of modeling the varying regression slope $\beta_{1 j}$ of woman level variable $X_{i j}$ with the region level variable $Z_{j}$. Thus, the moderator effect of $Z$ on the relationship between the dependent $\mathrm{Y}$ and $\mathrm{X}$ is expressed as a cross-lev el interaction.

Multilevel models are needed because with grouped data the observations in the same group are generally more similar than the observations from different groups, which violates the assumption of independence of all observations. This lack of independence can be expressed as a correlation coefficient: the intra class correlation $\rho$ that we can estimate by the equation:

$$
\rho=\sigma_{00} /\left(\sigma_{00}+\sigma^{2}\right)
$$

this is the variance explained by the grouping structure.

The estimators currently used in multilevel regression are Maximum Likelihood.

The model definition is 


$$
\begin{aligned}
& \left.\begin{array}{l}
y_{i j} \sim \operatorname{Binomial}\left(n_{i j}, \pi_{i j}\right) \\
y_{i j}=\pi_{i j}+e_{0 i j} x_{0}^{*}
\end{array}\right\} \\
& \operatorname{logit}\left(\pi_{i j}\right)=\beta_{1 j} x_{1}+\beta_{2 j} x_{2 i j}+\beta_{3} x_{3 i j}+\beta_{4} x_{4 j} \\
& \beta_{1 j}=\beta_{1}+u_{1 j} \\
& \beta_{2 j}=\beta_{2}+u_{2 j} \\
& {\left[\begin{array}{l}
u_{1 j} \\
u_{2 j}
\end{array}\right] \sim \mathrm{N}\left(0, \Omega_{u}\right): \Omega_{u}=\left[\begin{array}{ll}
\sigma_{u 1}^{2} & \\
\sigma_{u 21} & \sigma_{u 2}^{2}
\end{array}\right]} \\
& x_{0}^{*}=x_{0}\left[\pi_{i j}\left(1-\pi_{i j}\right) / n_{i j}\right]^{0.5} \\
& {\left[e_{0 i j}\right] \sim\left(0, \Omega_{e}\right): \Omega_{e}=[1]}
\end{aligned}
$$

